\title{
DETECTION, PROTECTION, REPAIR AND REHABILITATION OF CORRODED PRESTRESSED CONCRETE STRUCTURES
}

by

Md Khorshed Alam Khan

M Eng (Civil), Ryerson University, Canada, 2005

\begin{abstract}
A project
Presented to Ryerson University

In partial fulfillment of the

Requirements for the degree of

Master of Engineering

In the Program of Civil Engineering
\end{abstract}

Toronto, Ontario, Canada, 2005

(C) Md Khorshed Alam Khan, 2005 


\title{
UMI Number: EC53029
}

\author{
All rights reserved \\ INFORMATION TO USERS
}

The quality of this reproduction is dependent upon the quality of the copy submitted. Broken or indistinct print, colored or poor quality illustrations and photographs, print bleed-through, substandard margins, and improper alignment can adversely affect reproduction.

In the unlikely event that the author did not send a complete manuscript and there are missing pages, these will be noted. Also, if unauthorized copyright material had to be removed, a note will indicate the deletion.

\section{$\mathrm{UMI}^{\circ}$}

UMI Microform EC53029

Copyright 2008 by ProQuest LLC

All rights reserved. This microform edition is protected against unauthorized copying under Title 17, United States Code.

ProQuest LLC

789 East Eisenhower Parkway

P.O. Box 1346

Ann Arbor, MI 48106-1346 


\section{Author's Declaration}

I hereby declare that I am the sole author of this project report. I authorize Ryerson University to lend this project report to other institutions or individuals for the purpose of scholarly research.

Md Khorshed Alam Khan

I further authorize Ryerson University to reproduce this project report by photocopying or by other means, in total or in part, at the request of their institutions or individuals for the purpose of scholarly research.

Md Khorshed Alam Khan 


\section{Borrowers Page}

Ryerson University requires the signatures of all persons using or photocopying this project report. Please sign below and give address and date.

\begin{tabular}{|c|c|c|c|}
\hline Name & Address & Signature & Date \\
\hline & & & \\
\hline & & & \\
\hline & & & \\
\hline & & & \\
\hline & & & \\
\hline & & & \\
\hline & & & \\
\hline & & & \\
\hline & & & \\
\hline & & & \\
\hline & & & \\
\hline & & & \\
\hline & & & \\
\hline & & & \\
\hline & & & \\
\hline & & & \\
\hline & & & \\
\hline & & & \\
\hline & & & \\
\hline & & & \\
\hline
\end{tabular}




\title{
DETECTION, PROTECTION, REPAIR AND REHABILITATION OF \\ CORRODED PRESTRESSED CONCRETE STRUCTURES
}

\author{
Md Khorshed Alam Khan \\ M. Eng., Department of Civil Engineering, Ryerson University, 2005
}

\begin{abstract}
Corrosion is a natural and unavoidable process and its control is a global challenge. The civil engineer's of $21^{\text {st }}$ Century are facing a major problem for corrosion of prestressed concrete as they maintain an aging infrastructure. It affects various public and private economic sectors including infrastructure, transportation, production, manufacturing and utilities.
\end{abstract}

Corrosion of prestressing steel is much more severe than corrosion of mild steel reinforcement. This is due to higher strength of the prestressing steels, and the high level of stressing in the steel. Usually prestressing steels are stressed about $70 \%-80 \%$ of their ultimate strength which is much lower in mild steel reinforcement. The loss of crosssectional area of the reinforcing steel due to corrosion is likely'lead to tensile failure. The cross-sectional area of prestressing steel is less than mild steel reinforcement due to its higher strength. As a result, the loss of one prestressing strand or bar will have a tremendous effect on the capacity of the member than the loss of an equivalent size mild steel bar.

The corrosion of prestressing steel in concrete is an electrochemical reaction that is influenced by various factors including chloride-ion content, $\mathrm{pH}$ level, concrete permeability, and availability of moisture to conduct ions within the concrete. Normally 
steels in concrete are protected from corrosion by a passive film of iron oxides resulting from the alkaline environment of the concrete. For the corrosion process to be initiated, the passive oxide film on the prestressing steel must be destroyed. Passivation of the steel may be destroyed by the carbonation or by the presence of the chloride ions. In Canada, one of the reasons of this problem is due to the use of huge amount of deicing chemicals to combat the cold climate. Once corrosion occurs, the corrosion products occupy upto six times as much volume as steel, leading to cracking and disruption of the concrete. The $\mathrm{ACI}$ limit on chloride in prestressed concrete members is half of that for conventionally reinforced concrete.

Prestressing steel is also more inclined to other forms of corrosion related deterioration that do not occur in mild steel reinforcement. These forms are stress corrosion cracking, hydrogen embrittlement, fretting fetigue and corrosion fatigue. These types of deterioration are very difficult to detect, and can lead to brittle failure with little or no sign of warning.

This report presents the mechanisms, causes and effects of corrosion in North American design and construction and the proper detection technique and protection systems. 


\section{Acknowledgements}

I would like to express my gratitude and appreciation to my supervisor Dr. Lamya Amleh for her main and first advise to research on a key and hot issue of $21^{\text {st }}$ Century's encountering problem of civil engineer's which is the topic of this report. I also grateful for her valuable advise, guidance, suggestion, discussion about the topic, even her patience and encouragement throughout my study period at Ryerson University. During her busy period, her continuous encouragement made me busy to search the latest research information and to overcome the difficulties in completing this report.

Grateful acknowledge is also given to NACE International Corrosion Society for sending me the Material Performance Journals to get the valuable information about corrosion and also to FHWA for their informative online publications.

Finally, I would like to express my heartful gratitude to my parents and family, their love, affection and support encouraged me to the completion of this report.

A special gratitude is owed to my wife Nimmy for her infinite and unconditional love, support, patience and encouragement made me possible to complete this report. 


\section{Table of Contents}

Author's Declaration i

Borrowers Page ii

Abstract

Acknowledgements $\quad$ v

Table of Contents 1

List of Figures $\quad$ vi

List of Tables viii

List of Symbols $\quad$ ix

\begin{tabular}{lr} 
CHAPTER 1 & 4 \\
\hline
\end{tabular}

INTRODUCTION $\quad 4$

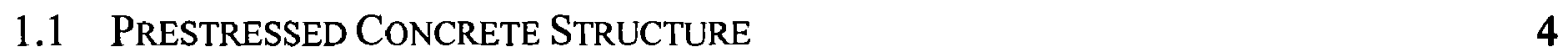

1.2 Corrosion of Prestressing SteEl $\quad 5$

$\begin{array}{lll}1.3 \text { COST OF CORROSION } & 6\end{array}$

$\begin{array}{lll}1.4 & \text { OBJECTIVES } & 7\end{array}$

\begin{tabular}{lr} 
CHAPTER 2 & 8 \\
\hline
\end{tabular}

CAUSES, MECHANISMS AND EFFECTS OF CORROSION 8

2.1 CORROSION FUNDAMENTALS

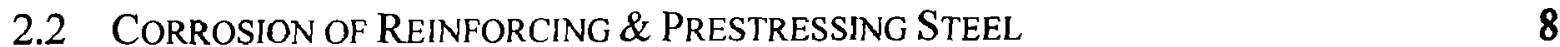

2.3 Causes of Corrosion in Prestressed ConCrete 12

2.3.1 Corrosion Due to Carbonation 12

2.3.2 Corrosion Due to Chloride Ion Penetration 12

2.4 FORMS OF CORROSION

2.5 CORROSION PROCESS 16

2.6 CONCRETE DETERIORATION DUE TO CORROSION 21

2.7 FACTORS INFLUENCING THE CHLORIDE DIFFUSION RATE $\quad 23$

2.8 FACTORS INFLUENCING CORROSION RATE $\quad 24$

2.9 EFFECT OF CONCRETE CRACKING ON CORROSION 26

$\begin{array}{lll}2.10 & \text { CONSEQUENCES OF CORROSION } & 28\end{array}$ 
CORROSION DETECTION

3.1 INTRODUCTION 30

3.2 NON-DESTRUCTIVE TECHNIQUES FOR CORROSION DETECTION 31

3.3 INSPECTION METHODS $\quad 32$

3.3.1 Radiography 33

3.3.2 Computed Tomography 33

$\begin{array}{lll}\text { 3.3.3 Surface Penetrating Radar } & 34\end{array}$

$\begin{array}{lll}\text { 3.3.4 Impact Echo } & 36\end{array}$

3.3.5 Acoustic Emission Monitoring 36

3.3.6 Magnetic Field Disturbance $\quad 37$

$\begin{array}{lll}\text { 3.3.7 } & \text { Remnant Magnetism Method } & 39\end{array}$

3.3.8 Linear Polarization Method $\quad 40$

3.3.9 Electrical Resistance $\quad 42$

3.3.10 Surface Potential Survey 42

CHAPTER $4 \quad 44$

CORROSION PROTECTION

4.1 INTRODUCTION

4.2 SELECTION OF PROTECTION SYSTEMS 46

4.2.1 Design Provisions for Protection 47

4.2.2 Construction as Protection Provisions 48

4.2.3 Concrete as Protection Provisions $\quad 49$

4.2.4 Reinforcement as Protection $\quad 50$

4.3 Corrosion Protection for Post-Tensioned Concrete Structures 51

4.3.1 Structural Form $\quad 53$

4.3.2 Drainage 53

$\begin{array}{lll}4.3 .3 & \text { Joints } & 54\end{array}$

4.3.4 Splashing $\quad 54$

4.3.5 Geometry 55

4.4 Structural Design Details $\quad 56$

4.4.1 Cracking $\quad 56$

4.4.2 Reinforcement Detailing $\quad 57$

4.5 Post-Tensioning DetaILS $\quad 57$

4.5.1 Bonded Post-Tensioning System Details 58

4.6 Post-Tensioning Tendon Materials Selection 58

4.6.1 Epoxy Coatings for Prestressing Steel 59

4.6.2 Epoxy-Coated Strand $\quad 59$

4.6.3 Epoxy-Coated Prestressing Bars 61

4.6.4 Galvanized Prestressing Steel $\quad 62$

4.6.5 Galvanized Prestressing Strand 63

4.6.6 Galvanized Prestressing Bars 63

4.6.7 Non-Metallic Prestressing Materials $\quad 64$

4.7 DUCTS FOR POST-TENSIONING 64 
4.7.1 Galvanized Steel Duct $\quad 65$

4.7.2 Epoxy-Coated Duct $\quad 65$

4.7.3 Plastic Duct 66

4.8 TEMPorary Corrosion Protection 66

4.9 Cement Grout For Post-Tensioning 67

4.10 ANCHORAGE PROTECTION 69

4.11 ENCAPSULATED AND ELECTRICALLY ISOLATED SYSTEMS

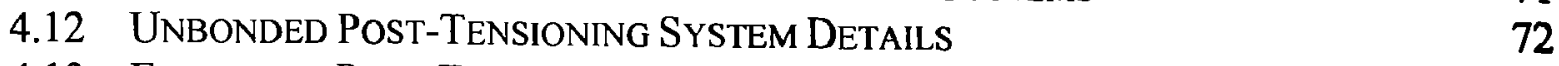

4.13 EMBEDDED POST-TENSIONING

4.14 EXTERNAL POST-TENSIONING

4.15 CORROSION INHIBITORS AS CORROSION PROTECTION

4.15.1 DCI (Darex Corrosion Inhibitor) and DCI-S 76

$\begin{array}{lll}\text { 4.15.2 Rheocrete } 222 \text { and Rheocrete } 222^{+} & 78\end{array}$

4.15.3 Armatec 2000, Ferrogard 901, and MCI $2000 \quad 78$

$\begin{array}{lll}4.15 .4 \text { Catexol } 1000 \mathrm{Cl} & 79\end{array}$

\begin{tabular}{lr} 
CHAPTER 5 & 80 \\
\hline
\end{tabular}

CORROSION PREVENTION AND REPAIR $\quad 80$

5.1 COMMON METHODS FOR CORROSION PREVENTION AND REPAIR $\quad \mathbf{8 0}$

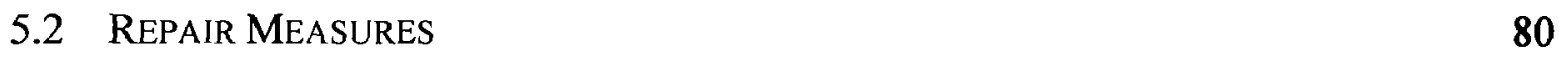

5.3 Preventive Measures $\quad 81$

5.4 Galvanic Protection $\quad 82$

5.5 CATHODiC ProteCtion Fundamentals $\quad 82$

5.6 FRP WRAPS FOR CORROSION PROTECTION

\begin{tabular}{lr} 
CHAPTER 6 & 86 \\
\hline
\end{tabular}

CONCLUSION AND FUTURE RECOMMENDATIONS 86

REFERENCES $\quad 89$ 


\section{List of Figures}

Figure 1.1: Surface Area of Bars and Strands $\quad 6$

Figure 2.1: Chloride ion induced corrosion cell in concrete 9

Figure 2.2: Deterioration Mechanism for Corrosion of Steel in Concrete $\quad 10$

Figure 2.3: Failure instances of corrosion: (a) corrosion in the length of tendon; (b) failed strands; (c) bridge corrosion; and (d) cracking and spalling of piers in marine environment. 11

Figure 2.4: Termination of the passive layer by chloride ions 13

Figure 2.5: Electrochemical corrosion cell. 16

Figure 2.6: Corrosion cell in reinforced concrete $\quad 17$

$\begin{array}{ll}\text { Figure 2.7: Microcell vs. Macrocell corrosion } & 17\end{array}$

Figure 2.8: Electrolytic corrosion of reinforcement in concrete exposed to chloride and moisture $\quad 18$

Figure 2.9: Simple deterioration model, corrosion of steel in concrete 22

Figure 2.10: Increased Penetration of Moisture and Chlorides at 27

Crack Location Accelerates the Onset and Severity of Corrosion

Figure 2.11: Cracking Accelerates Onset of Corrosion, But Over

Time Corrosion is Similar in Cracked and Uncracked Concrete 28

Figure 3.1: 3D-neutron CT-image of slice 6 to 14 of the concrete cube 34

Figure 3.2: Ground Penetrating Rader (GPR) Test to Locate Steel

Reinforcement 35

Figure 3.3: Local Area Monitoring (LAM) System with 8 sensors and holding magnets $\quad 37$

Figure 3.4: AE Monitoring of NYSDOT boxbeam test 37

Figure 3.5: Schematic of the measurements conducted on the valley

bridge Michelsrombach. (1) the tendons were localized using Ground 
Penetrating Radar. (2) the prestressed steel rebars were inspected by scanning the yoke with the SQUID system along the member

Figure 3.6: Magnetizing techniques used for residual field experiments.

In each case the magnetization procedure started by drawing the cable on to the yoke (Stage 1). The cable was then pulled along the yoke (Stage 2) until the end was reached (Stage 3). Two different procedures were then followed. The cable was either pulled directly away from the yoke (Stage 4a) or the cable was pulled off the magnet by continuing the movement in the same direction as the previous stages (Stage $4 \mathrm{~b}$ )

Figure 3.7: Three Electrode Linear Polarization (3LP) device

Figure 4.1: Avoiding Horizontal Surfaces for drainage

Figure 4.2: Severe Substructure Corrosion Damage Due to

Defective Expansion Joint

Figure 4.3: Sloped Bent Cap to Promote Run-Off

Figure 4.4: Column Corrosion Resulting for Splashing Adjacent to Roadway

Figure 4.5: Geometry Effects on Durability for Alternate

Substructure Designs $\quad 56$

Figure 4.6: Epoxy-Coated Strand for Pre and Post Tensioning System 60

Figure 4.7: Multi-Layer Corrosion Protection for Buried

Post-Tensioning Anchorages

Figure 4.8: Member End Details for Anchorage Corrosion

Protection

Figure 4.9: External Post-Tensioning Tendon Corrosion

Protection

Figure 5.1: Precast/prestressed beam repair. Delaminated

concrete cover removed but strands remain partially embedded in chloride contaminated concrete

Figure 5.2: Endcap delamination 


\section{List of Tables}

\section{Page}

Table 3.1: Data interpretation for the 3LP Device

41

Table 3.2: Summary of Non-Destructive Techniques

43

Table 4.1: Corrosion Protection Mechanisms and Methods

51

Table 4.2: Calcium nitrite dosage rates

78

Table 5.1: FRP Wrap Manufacturers

84 


\section{List of Symbols \& Abbreviations}

ACI $=$ American Concrete Institute

AASHTO = American Association of State Highway and transportation Officials

ASTM = American Society for Testing and Materials

AMA $=$ Amino-Alcohol

$\mathrm{ACM}=$ Advanced Composite Materials

CSE $\quad=$ Copper-Copper Sulfate Electrode

$\mathrm{Cl}^{-} \quad$ Chloride ion

$\mathrm{CO}_{2} \quad=$ Carbon-di-oxide

$\mathrm{Ca}(\mathrm{OH})_{2}=$ Calcium Hydroxide

$\mathrm{CaCl}_{2}=$ Calcium Chloride

$\mathrm{C}_{3} \mathrm{~A} \quad=$ Tri-calcium Aluminate

$\mathrm{CP} \quad=$ Cathodic Protection

$\mathrm{CuSO}_{4}=$ Copper Sulfate

$\mathrm{cm} \quad=$ Centimeter

DCI = Darex Corrosion Inhibitor

DMEA = Dimethylethanolamine

DOT = Department of Transportation

EMF = Electromotive Force

EIC = Environmentally Induced Cracking

$\mathrm{EG} \quad=$ Epoxy Grout

$\mathrm{Fe}(\mathrm{OH})_{2}=$ Ferrous Hydroxide

$\mathrm{Fe}_{2} \mathrm{O}_{3}=$ Ferrous Oxide

FHWA $\quad=$ Federal Highway Administration

$\mathrm{Fe}^{+} \quad=$ Ferrous ion

FRP $\quad=$ Fiber Reinforced Polymer

FRPC = Fiber Reinforced Polymer Composite

$\mathrm{ft} \quad=$ Feet

G $\quad$ Grade 


\begin{tabular}{|c|c|}
\hline $\mathrm{HCl}$ & = Hydrochloric Acid \\
\hline $\mathrm{HIC}$ & $=$ Hydrogen Induced Cracking \\
\hline $\mathrm{KOH}$ & $=$ Potassium Hydroxide \\
\hline $\mathrm{K} \Omega$ & $=$ Kilo Ohm \\
\hline $\mathrm{Kg}$ & $=$ Kilogram \\
\hline LMC & $=$ Latex Modified Concrete \\
\hline LP & $=$ Linear Polarization \\
\hline $\mathrm{L}$ & $=$ Leter \\
\hline $\mathrm{lb}$ & $=$ Pound \\
\hline MFD & $=$ Magnetic Field Disturbance \\
\hline MEKP & $=$ Methyl Ethyl Ketone Peroxide \\
\hline $\mathrm{m}$ & $=$ Meter \\
\hline Mpa & $=$ Mega Pascal \\
\hline $\mathrm{mV}$ & $=$ Mili-volt \\
\hline $\mathrm{NaOH}$ & $=$ Sodium Hydroxide \\
\hline NDT & $=$ Non-Destructive Techniques \\
\hline $\mathrm{NO}_{2}^{-}$ & $=$Nitrous Oxide ion \\
\hline NY & $=$ New York \\
\hline $\mathrm{OH}^{-}$ & $=$Hydroxil ion \\
\hline PCI & $=$ Precast Concrete Institute \\
\hline PTI & $=$ Post-Tensioning Institute \\
\hline PVC & $=$ Polyvenyle Chloride \\
\hline SCC & $=$ Stress Corrosion Cracking \\
\hline SCRIMP & $=$ Seeman Composite Resin Infusion Modeling Process \\
\hline SCE & $=$ Saturated Calomel Electrode \\
\hline TxDOT & $=$ Texas Department of Transportation \\
\hline US & $=$ United States \\
\hline UK & $=$ United Kingdom \\
\hline UV & $=$ Ultra Violate \\
\hline$\mu \mathrm{m}$ & $=$ Micron \\
\hline$\mu \mathrm{A}$ & $=$ Micro Ampere \\
\hline
\end{tabular}




\section{CHAPTER 1}

\section{INTRODUCTION}

\subsection{Prestressed Concrete Structure}

In prestressed concrete structures, high-strength prestressing steel is used to increase load capacity, improve crack control and allow the construction of more slender components. There are two main types of prestressed concrete:

- Pre-tensioned and

- Post-tensioned.

In pre-tensioned concrete, the tendons (wires or strands) are tensioned before the concrete is placed and cured. After a predetermined required strength is achieved, the tendons are released. Prestressed concrete members are normally produced in a controlled environment. As a result, a higher quality concrete can be achieved. A factory made standardized sections such as I-beams, box beams, built- $\mathrm{T}$, and modified built-t can be achieved. In post-tensioned concrete, the tendons are tensioned after the concrete is placed and cured, and has achieved a predetermined required strength. After the tendons are stressed, they are anchored through the use of mechanical anchorages at each end of the member. There are two categories of post-tensioning tendons:

- Bonded and

- Unbonded.

Bonded tendons are placed within ducts that were previously cast into the concrete. After the tendons are stressed and anchored, the ducts are filled with grout. Unbonded tendons are greased and then sheathed in plastic. Unbonded tendons are not used very much since it is difficult to ensure adequate corrosion protection. However, they have been used as external tendons to increase structural strength and integrity. In general, external tendons can be more easily inspected than internal tendons. Segmental bridges are a type of posttensioned concrete structure where precast segments are joined together by posttensioning tendons or bars [Fogarasi, 1986]. 


\subsection{Corrosion of Prestressing Steel}

Corrosion of prestressing steel is much more severe than corrosion of mild steel reinforcement. This is due to the higher strength of the prestressing steels, and the high level of stressing in the steel. Usually prestressing steels are stressed about $70 \%$ to $80 \%$ of their ultimate strength which is much lower in mild steel reinforcement. For example, in working stress design method, the tensile strenght of G60 (400 MPa) reinforcement is $40 \%$ of the yield strength. In ultimate strength design method, the stress levels will be higher but lower than prestressing steels. The loss of cross-sectional area due to corrosion will likely lead to tensile failure of mild steel reinforcing bars. The cross-sectional area of prestressing steel is less than that of mild steel reinforcement due to its higher strength. As a result, the loss of one prestressing strand or bar will have a tremendous effect on the capacity of the member than the loss of an equivalent sized mild steel bar.

Prestressing steels are more susceptible to corrosion than mild steel reinforcement for several reasons. The surface area to volume ratio of 7-wire prestressing strand is larger than for the equivalent diameter bar as shown in Figure 1.1. This larger ratio means that more surface area is available for corrosion, and the cross-sectional area of the strand may be reduced at a faster rate. The configuration of the 7-wire prestressing strand also makes the strand more susceptible to crevice corrosion. Crevice corrosion is a type of severe corrosion occurring in small spaces or crevices, such as the interstices between wires. The geometric constraints of the crevice enhance the formation of chloride ion concentration cells. Once corrosion has initiated, it progresses similar to pitting corrosion. Due to the geometry of the crevice, $\mathrm{Fe}^{2+}$ ions cannot disperse easily, and $\mathrm{Cl}^{-}$ions are drawn into the crevice by the positive charge accumulation. The process becomes autocatalytic as the presence of chloride ions leads to formation of hydrochloric acid $(\mathrm{HCl})$ which accelerate the corrosion rate. 


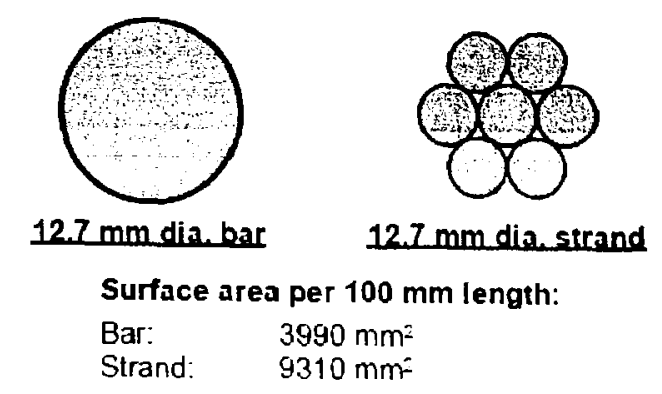

Figure1.1: Surface Area of Bars and Strands

Prestressing steel is also more inclined to other forms of corrosion related deterioration that do not occur in mild steel reinforcement. These forms are stress corrosion cracking, hydrogen embrittlement, fretting fatigue and corrosion fatigue. These types of deterioration are very difficult to detect, and can lead to brittle failure with little or on sign of warning [West et al, 1999].

\subsection{Cost of Corrosion}

Corrosion is a natural and unavoidable process and its control is a global challenge. It affects various public and private economic sectors including infrastructure, transportation, production, manufacturing and utilities. Various government agencies estimated the cost of corrosion for different economic sectors. In developed countries, several studies have estimated the cost of corrosion to be about $3-4 \%$ of the gross national product. In Canada, one of the reasons of this problem is due to the use of huge amount of deicing chemicals to combat the cold climate. In the United States, the replacement value for concrete structures nearing the end of their service life is estimated over US $\$ 500$ billion. Also one of the well-known studies was carried out in 1996 by "Batelle and Specialty Steel Industry of North America" and the report estimates that the annual cost of metallic corrosion in the United States during that year was approximately US\$ 300 billion. The study also estimates that at least one-third of the cost of corrosion (US\$ 100 billion) is avoidable and could be saved by wider applications of corrosion resistant materials and application of proper anti-corrosive practice from design through maintenance. 
Corrosion has serious socioeconomic impact, for example, corrosion of steel in urban infrastructure can proceed unnoticed and can result in the partial or complete failure of a highway bridges, collapse of steel structures such as electrical towers, and damage to buildings, parking structures, and other structures, resulting in significant repair costs and/or more endangering public safety. In the United States, currently there are about 583,000 bridges, out of these, 200,000 are steel bridges, 235,000 are in conventional

reinforced concrete, 108,000 are prestressed concrete. A joint study of the CC Technologies Laboratories (a firm specializing in corrosion control) and the Federal Highway Administration (FHWA) reported that there are approximately 15\% of these bridges are structurally deficient due to corrosion. It was also estimated that the annual direct cost of corrosion for highway bridges is US\$ 8.3 billion. It should be noted that the life-cycle cost analysis estimates the indirect costs to the user due to traffic delays and lost productivity at more than 10 times the direct cost of corrosion maintenance, repair and rehabilitation [Hussam, 2004].

\section{$1.4 \quad$ Objectives}

The main objectives of this report are:

- To study the mechanisms and causes of corrosion of prestressing steel in prestressed concrete structures.

- To study the detection techniques and protection systems for prestressed concrete. 


\section{CHAPTER 2}

\section{CAUSES, MECHANISMS AND EFFECTS OF CORROSION}

\subsection{Corrosion Fundamentals}

Prestressing steel corrosion fundamentals are similar to non-prestressed reinforcement corrosion. Normally steels in concrete are protected from corrosion by a passive film of iron oxides resulting from the alkaline environment of the concrete. Passivation of the steel may be destroyed by the carbonation $\left(\mathrm{CO}_{2}\right)$ or by the presence of the chloride ions. The electrochemical process of corrosion requires several key elements, all of which must be present for corrosion to occur. The rate of corrosion is affected by many complex factors [West et al, 1999].

\subsection{Corrosion of Reinforcing \& Prestressing Steel}

The corrosion of reinforcing/prestressing steel in concrete is an electrochemical reaction that is influenced by various factors including chloride-ion content, $\mathrm{pH}$ level, concrete permeability, and availability of moisture to conduct ions within the concrete. Five elements are required to complete the corrosion cell:

- An anode,

- A cathode,

- An ionic path,

- A metallic path between the anode and cathode and

- The availability of oxygen.

The anodic site becomes the site of oxidation (corrosion) and the cathodic site is the location of the reduction reaction which is driven by the activity at the anode. In precast/prestressed concrete, the metallic path can be provided by the embedded prestressing strands and/or the mild steel reinforcement. The ionic path is provided by the concrete with sufficient moisture for conductivity and oxygen is generally available from the atmosphere due to the permeability of concrete. Due to the high alkalinity of the 
concrete pore water solution, a thin passivating oxide layer is formed and maintained on the surface of the embedded steel thus protecting it from corrosion activity. Until this passive film is destroyed by the intrusion of aggressive elements or a reduction in the alkalinity of the concrete, the reinforcement will remain in a passive non-corroding state. The process is shown in Figure 2.1

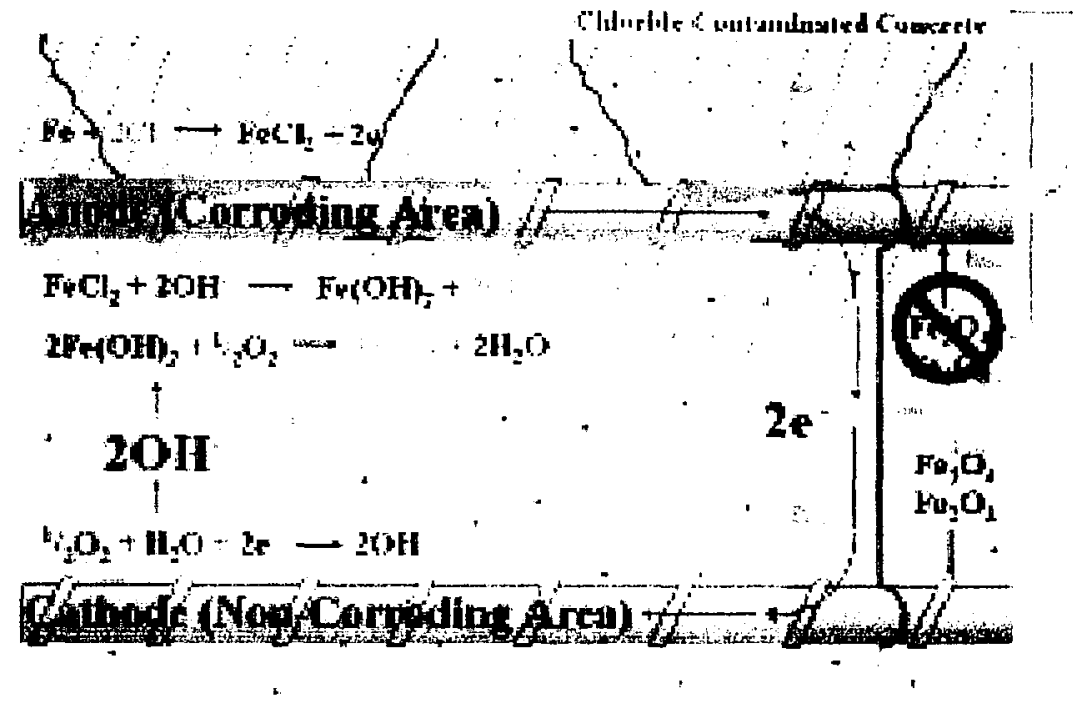

Figure 2.1: Chloride ion induced corrosion cell in concrete [Whitmore et al, 2003]

Chloride-induced corrosion is most commonly observed in structures exposed to roadway de-icing salts or a marine environment exposure to salt water or windborne sea spray. Chlorides can also be introduced during the original construction by the use of contaminated aggregates or chloride-containing admixtures.

The passive condition of the reinforcing steel can also be disrupted by the loss of alkalinity in the concrete surrounding the reinforcing steel. It is generally accepted that a $\mathrm{pH}$ greater than 10 is sufficient to provide corrosion protection in chloride ion free concrete[Whitmore et al, 2003]. The reduction in alkalinity is generally caused by carbonation, a reaction between atmospheric carbon dioxide and calcium hydroxide in the cement paste in the presence of water. The result is a reversion of the calcium hydroxide to calcium carbonate which has insufficient alkalinity to maintain the passive oxide layer. The amount of time for the zone of carbonated concrete to reach the level of the 
reinforcing steel is a function of the amount of concrete covers, presence and extent of cracks, concrete porosity, humidity levels, and the level of exposure to carbon dioxide gas. Carbonation-induced corrosion can be observed in industrial environments where $\mathrm{CO}_{2}$ is present in air or structures with a high degree of concrete porosity or low concrete cover. Over time, concrete spalling and delaminations result from the expansive pressures of the steel corrosion by-products which can create high tensile stresses in the concrete. If corrosion activity is left unchecked, significant section loss of the reinforcing/prestressing steel can occur and structural repair or replacement may be required [Whitmore et al, 2003]. The deleterious effects of corrosion are illustrated in Figure 2.2.

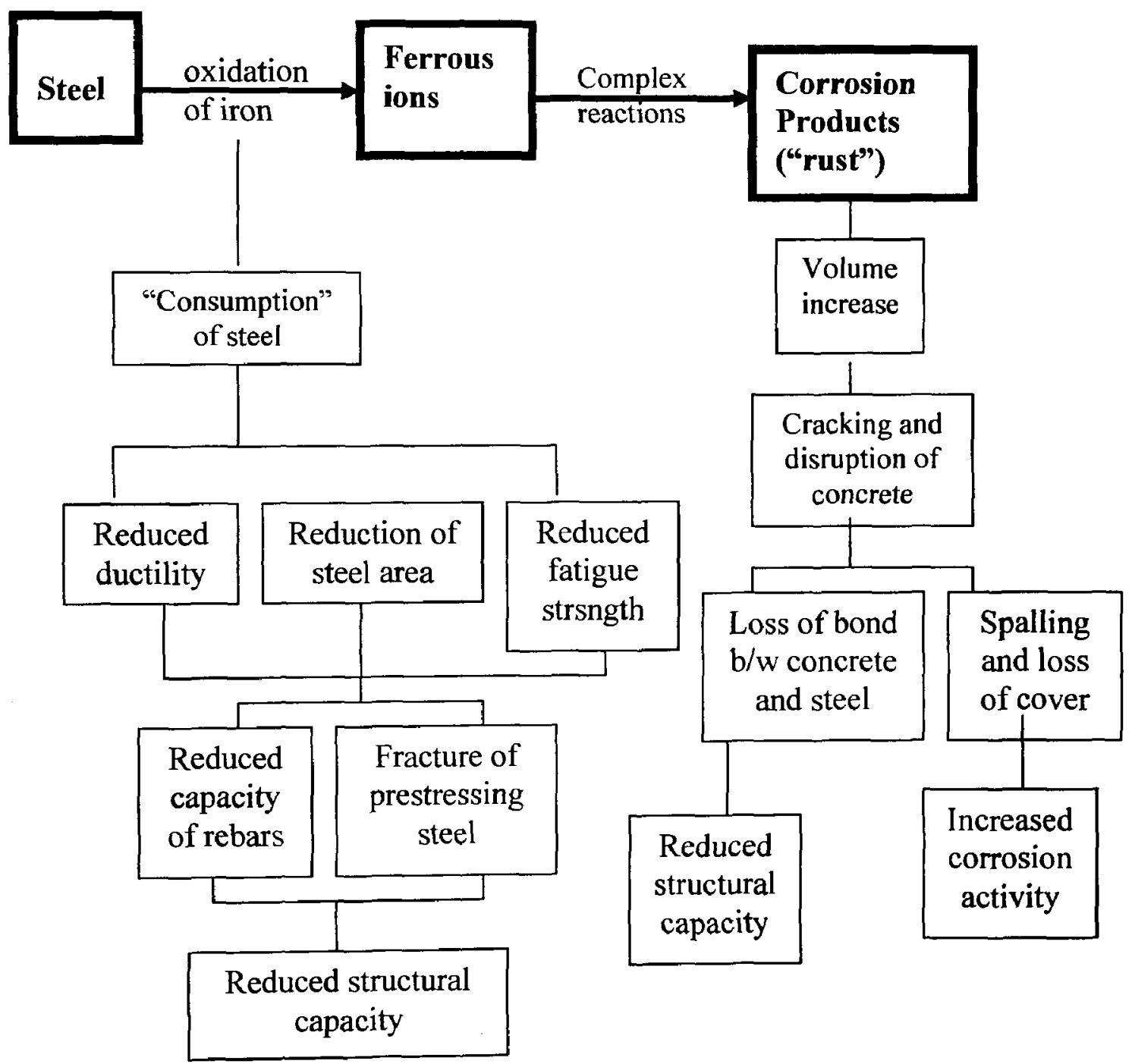

Figure 2.2: Deterioration Mechanism for Corrosion of Steel in Concrete [West et al, 1999] 
The corrosion products can occupy up to six times as much volume as steel, leading to cracking and disruption of the concrete. Corrosion of steel reinforcement in concrete may significantly affect structural integrity through reduced capacity or fracture of the steel reinforcement due to loss of bond between the steel and concrete or through cracking and spalling of the concrete. Because of high level of stress in prestressed concrete members, corrosion is more of a concern for prestressed structures than for conventionally reinforced concrete structures. Any reduction in cross-sectional area due to pitting may lead to fracture of individual wires, as a result, the ACI limit for chlorides in prestressed concrete members is half of that for conventionally reinforced concrete. Some failure instances of corrosion are as shown in Figure 2.3 [West et al, 1999].

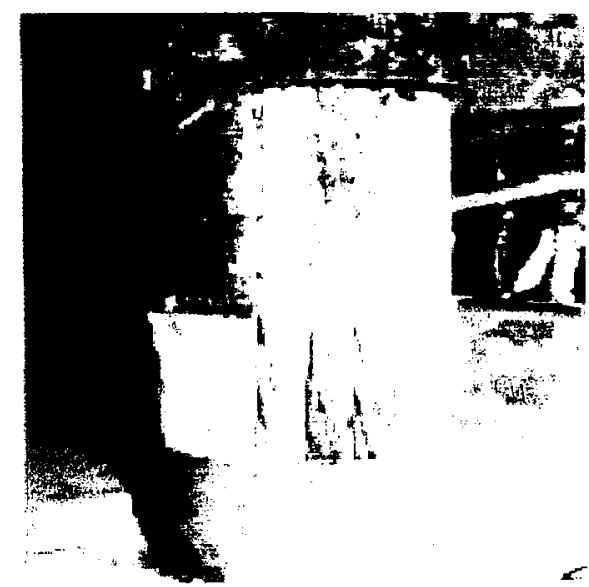

(a)

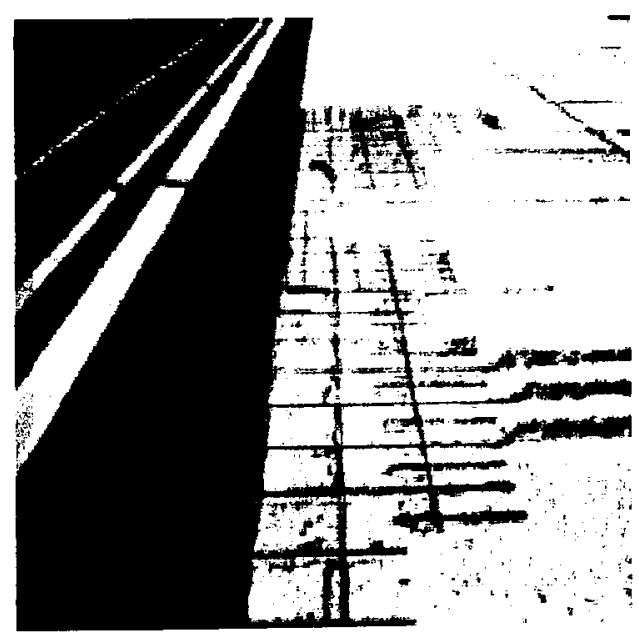

(c)

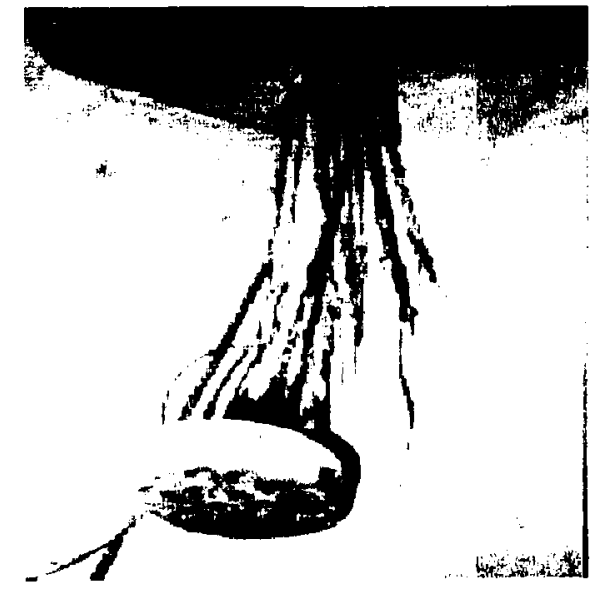

(b)

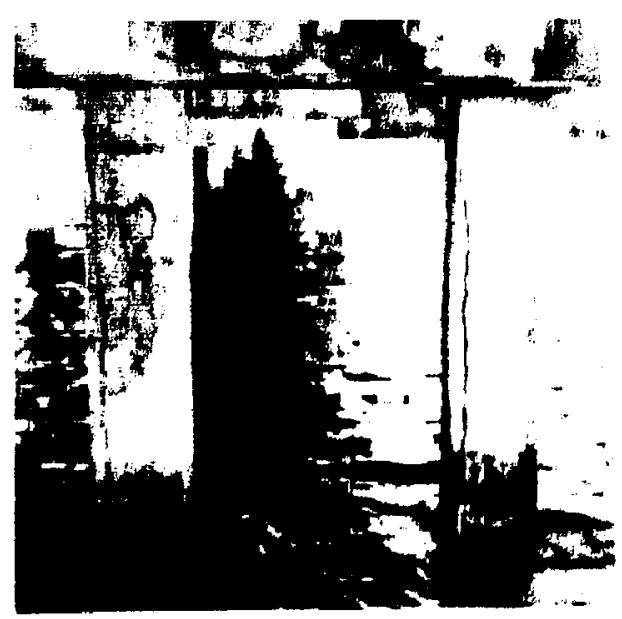

(d)

Figure 2.3: Failure instances of corrosion: (a) corrosion in the length of tendon; (b) failed strands; (c) bridge corrosion; and (d) cracking and spalling of piers in marine environment. 


\subsection{Causes of Corrosion in Prestressed Concrete}

Corrosion, or oxidation of the prestressing steel in concrete occurs when the local environment of steel destroy its passivity. There are two major causes of corrosion damage in reinforced/prestressed concrete structures: carbonation and chloride ion penetration.

\subsubsection{Corrosion Due to Carbonation}

The process by which carbon dioxide in the atmosphere reacts with water in the concrete pores to form a carbonic acid and then reacts with the alkalis in the pores, neutralizing them is known as carbonation. Carbonation migrates to the reinforcing steel, causing $\mathrm{pH}$ reduction and breakdown of the passive layer. Alkalinity may drop as low as a pH of 8 in carbonated regions, much lower than the value required for depassivation. The mechanism of carbonation is basically diffusion of the carbonated pore water into the concrete. Therefore, the parameters are the amount of concrete cover and the concrete permeability which influence corrosion by carbonation. Permeability is a function of water-cement ratio and fine aggregate content. The correlation between permeability and carbonation is evident in cracked specimens. Carbonation will proceed quickly along the crack with little penetration into the concrete perpendicular to the crack surface [Verhulst et al, 2001].

\subsubsection{Corrosion Due to Chloride Ion Penetration}

Most of the corrosion evident in reinforced/Prestressed concrete structures is due to chloride ion penetration. Chloride ion migrates through the concrete matrix, reaching the steel reinforcement and break down the passive layer. The destruction of the passive film in the presence of chlorides is due to localized concentrations of free chloride ions, as shown in Figure 2.4, than to the reduction in $\mathrm{pH}$ at the bar surface. 


\section{Concrete}

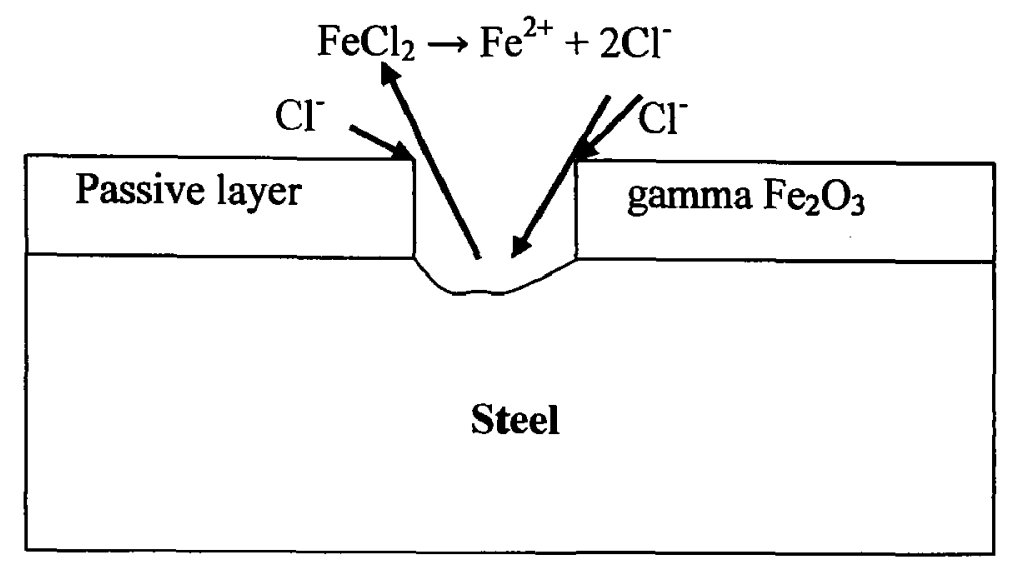

Figure 2.4: Termination of the passive layer by chloride ions [Verhulst et al, 2001]

Many sources of chlorides for corrosion of steel in concrete. Chlorides may be cast into the mix or may diffuse into the concrete during service life. Some sources of chlorides cast into the mix are [Verhulst et al, 2001]:

- Chloride set accelerators

- Use of sea water during mixing

- Contamination of aggregates

Chloride diffusion sources are:

- Marine environment splash and spray

- Use of deicing salts on transportation structures

- Chemical application or storage

It is very difficult to measure the amount of chlorides required to induce corrosion, but is usually expressed as a percentage of concrete weight. Critical chloride percentages are $0.4 \%$ by weight if they are cast into the mix and $0.2 \%$ if they enter the concrete by diffusion. Once corrosion has begun, free chlorides can react with corrosion products to reduce the alkalinity of the immediate area and further promote the corrosion process. 
Since chloride ion penetration is a diffusion process, many of the influencing parameters are the same as for carbonation [Verhulst et al, 2001].

Corrosion of pretensioning tendons may be due to one or more of the following:

1. Voids under or next to the tendons.

2. Lack of passivation of the tendons due to a decrease in alkalinity.

3. A corrosive environment at the tendons due to the presence of chlorides, water, and oxygen.

4. Joints that are not sealed or not watertight.

5. Chlorides from the mix water or aggregates.

6. Inadequate concrete cover due to poor construction practices.

7. Concrete with a high permeability due to a high water-cement ratio and/or poor consolidation.

Corrosion of post-tensioning tendons may be due to one or more of the following:

1. No protection between the time when the tendon is placed in the ducts and is stressed and grouted.

2. Poor-quality concrete and improper construction practices.

3. A corrosive environment at the tendons due to the presence of chlorides, water, and oxygen (for bonded or unbonded tendons).

4. Chlorides in the grout mix.

5. Contact between dissimilar metals, such as the aluminium casings at the anchorages and the steel strands.

6. Voids in the ducts, due to poor grouting procedures, leading to inadequate bonding between the tendon and the grout.

7. Inadequate sheathing (damaged during transportation and placement within the structure) leading to possible exposure of the steel tendons to a corrosive environment.

8. Excessive bleed water. 
9. Chlorides from external sources penetrating the concrete and accumulating at the tendons through perforated ducts or sheathings and at anchorages [Smith et al, 2000].

\subsection{Forms of Corrosion}

The two main forms of corrosive attack of prestressing strands and tendons are:

- Pitting corrosion and

- Stress corrosion (environmentally induced) cracking.

Pitting corrosion is a localized galvanic corrosion cell at weak points or ruptures in the passivation film. The resulting pits reduce the cross-sectional area of the tendons and are stress risers (i.e., they increase the magnitude of applied tensile stresses). This can lead to brittle fracture of individual wires in a strand or tendon and ultimately the failure of the tendon and prestressed concrete member. Pitting corrosion is also a source of atomic hydrogen that can contribute to possible hydrogen embrittlement of the high-strength steel strands.

Environmentally induced cracking (EIC) is when combination of a corrosive environment and tensile stresses induces a brittle fracture in a normally ductile alloy. The cracks can be either transgranular or intergranular and propagate normally to the direction of applied tensile stress. There are two main categories of EIC:

- Stress corrosion cracking (SCC) and

- Hydrogen-induced cracking (HIC).

The cracking in SCC is intergranular, usually breached and propagates at a slower rate. Stress corrosion cracking is when corrosion of the prestressing steel in combination with high tensile stresses lead to cracking perpendicular to the direction of the applied stress. HIC cracking is transgranular, usually unbreached and very brittle and fast growing. Hydrogen-induced cracking is commonly as a form of stress corrosion and is due to hydrogen embrittlement. This is when atomic hydrogen diffuses into the steel and 
combines to form hydrogen gas. The hydrogen molecule exerts an internal pressure that when added to the applied tensile stress can lead to fracture of the steel wires in a strand or tendon [Broomfield, 1997].

\subsection{Corrosion Process}

The corrosion of reinforcing/prestressing steel bars is an electrochemical process that requires a flow of electric current and several chemical reactions. Three essential components of a galvanic corrosion cell are: Anode, Cathode and Electrolyte. The relationship between the components of a corrosion cell is illustrated in Figure 2.5.

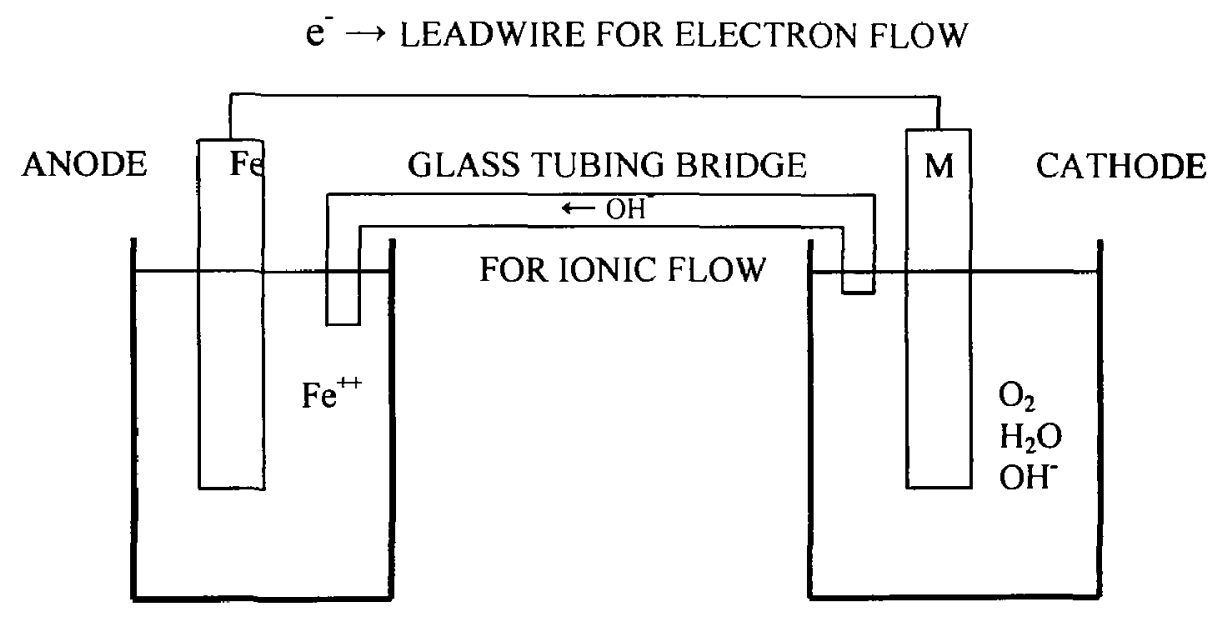

Figure 2.5: Electrochemical corrosion cell [Smith et al, 2000].

The anode and cathode can be on the same steel reinforcing bar. Figure 2.6 shows a corrosion cell for a steel reinforcing bar embedded in concrete. The anode is the location on a reinforcing steel bar where corrosion is taking place and metal is being lost. At the anode, iron atoms lose electrons to become iron ions $\left(\mathrm{Fe}^{+2}\right)$. This oxidation reaction is referred to as the anodic reaction. The cathode is the location on a steel reinforcing bar where metal is not consumed. At the cathode, oxygen, in the presence of water, accepts electrons to form hydroxyl ions $\left(\mathrm{OH}^{-}\right)$. This reduction reaction is referred to as the cathodic reaction. The electrolyte is the medium that facilitates the flow of electron 
(electric current) between the anode and the cathode. Concrete, when exposed to wet-dry cycle, has sufficient conductivity to severe as an electrolyte.

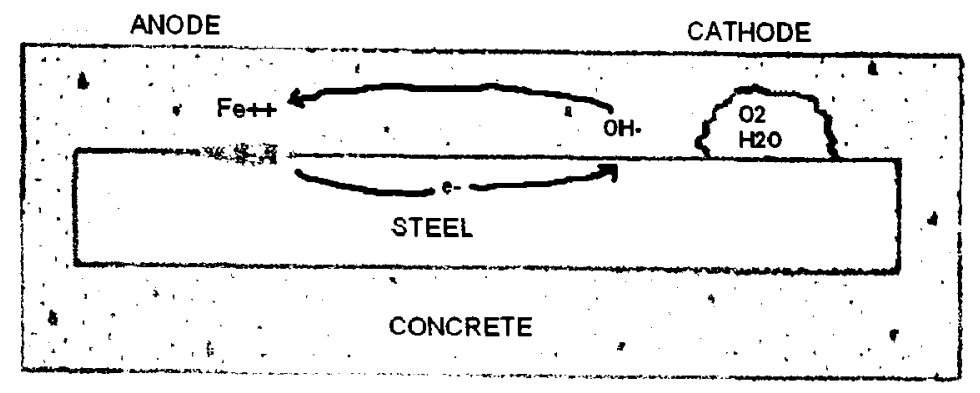

Figure2.6: Corrosion cell in reinforced concrete [Smith et al, 2000]

Both the anodic and cathodic reactions are necessary for the corrosion process and they need to take place concurrently. The anode and cathode can be located next to each other or can be separated. When they are located immediately next to each other, i.e., on a microscopic scale, the resulting corrosion cell is referred to as a microcell. When they are separated by some finite distance, the resulting corrosion cell is referred to as a macrocell. Figure 2.7 shows examples of a microcell and a macrocell. The corrosion of reinforcing/prestressing steel bars embedded in concrete may be due to a combination of microcells and macrocells.

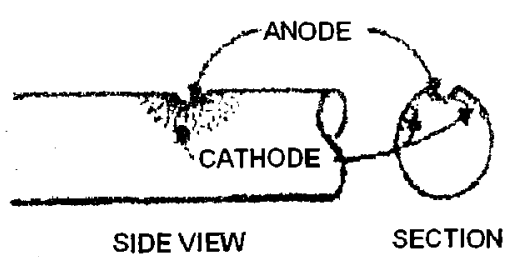

MICROCELL

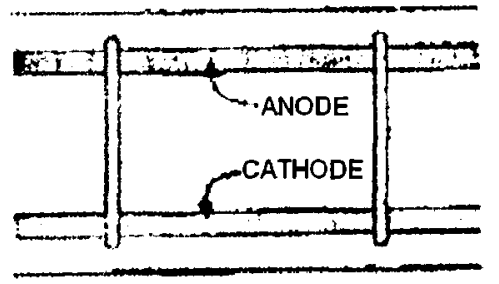

MACROCELL

Figure 2.7: Microcell vs. Macrocell corrosion [Smith et al, 2000]

Corrosion process are controlled by the environment in the concrete surrounding the steel reinforcing bars. Usually chlorides enter to the concrete from the top surface which is 
from deicing chemicals. The top mat of reinforcing steel is then exposed to higher concentrations of chlorides. The chloride shifts the potential of the top mat to a more negative (anodic) value. Since the potential of the bottom mat has a more positive (cathodic) value, the resulting difference in potentials sets up a galvanic type of corrosion cell called a macrocell. An electric circuit is established. The concrete serves as the electrolyte, and wire ties, metal chair support, and steel bars serve as metallic conductors as shown in Figure 2.8. The concentration of chlorides at the top mat is not uniform along the length of the steel bars due to the heterogeneity of the concrete and uneven deicer application. These differences in concentrations establish anodes and cathodes on individual steel bars in the top mat results the formation of microcells.

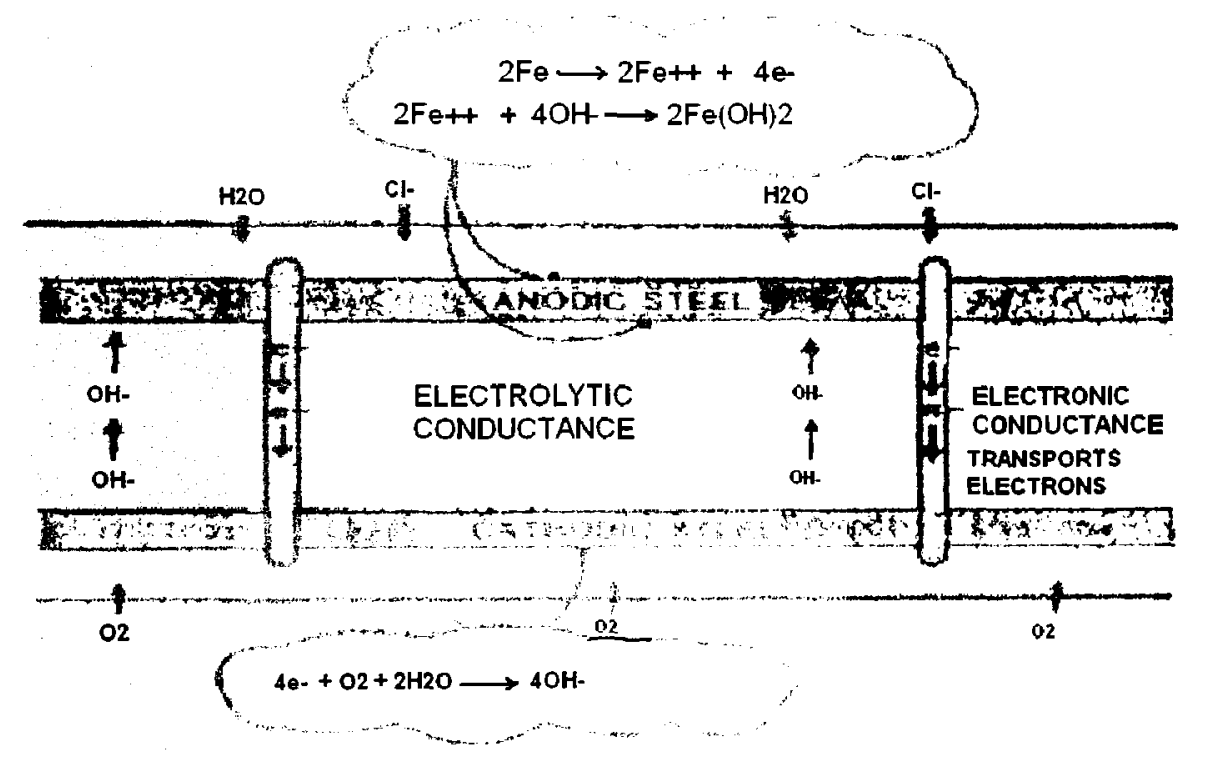

Figure 2.8: Electrolytic corrosion of reinforcement in concrete exposed to chloride and moisture [Smith et al, 2000].

The process by which steel reinforcing bars are depassivated is not fully understood. Several theories have been presented to explain the role of chloride ions. Chloride ions reach the reinforcing steel by penetrating the concrete via the porewater and through cracks in the concrete. In the oxide film theory, the chloride ions break down the passive oxide film [Smith et al, 2000]. At this point, the steel reinforcing bar becomes depassivated and corrosion may be initiated. In the adsorption theory, chloride ions are 
adsorbed into the surface of the steel reinforcing bar and attack the steel directly. In the transitory complex theory, chloride ions, act as a catalyst [Smith et al, 2000]. The chloride ions combine with the ferrous ions to form a soluble iron-chloride complex that diffuses away from the anode. Subsequent breakdown of the iron-chloride complex frees the chloride ions for reuse when ferrous hydroxide is formed. When carbon dioxide $\left(\mathrm{CO}_{2}\right)$ penetrates concrete and dissolves in the pore solution, carbonic acid is formed. This acid reacts with the alkali in the cement to form carbonates and to lower the $\mathrm{pH}$ of the concrete. When the alkalinity reaches a low enough level, the steel reinforcing bar becomes depassivated and in the presence of sufficient water and oxygen, corrosion is initiated and proceeds. Usually, carbonation advances very slowly in sound concrete and is generally not a factor.

The corrosion of steel in concrete in the presence of oxygen, but without chlorides, takes place in several steps [Smith et al, 2000]:

1. At the anode, iron is oxidized to the ferrous state and releases electrons.

$$
\mathrm{Fe} \rightarrow \mathrm{Fe}^{++}+2 \mathrm{e}^{-}
$$

2. These electrons migrate to the cathode where they combine with water and oxygen to form hydroxyl ions.

$$
2 \mathrm{e}^{-}+\mathrm{H}_{2} \mathrm{O}+1 / 2 \mathrm{O}_{2} \rightarrow 2 \mathrm{OH}^{-}
$$

3. The hydroxyl ions combine with the ferrous ions to form ferrous hydroxide.

$$
\mathrm{Fe}^{++}+2 \mathrm{OH}^{-} \rightarrow \mathrm{Fe}(\mathrm{OH})_{2}
$$

4. In the presence of water and oxygen, the ferrous hydroxide is further oxidized to form $\mathrm{Fe}_{2} \mathrm{O}_{3}$.

$$
\begin{aligned}
& 4 \mathrm{Fe}(\mathrm{OH})_{2}+\mathrm{O}_{2}+\mathrm{H}_{2} \mathrm{O} \rightarrow 4 \mathrm{Fe}(\mathrm{OH})_{3} \\
& 2 \mathrm{Fe}(\mathrm{OH})_{3} \rightarrow \mathrm{Fe}_{2} \mathrm{O}_{3} \cdot \mathrm{H}_{2} \mathrm{O}
\end{aligned}
$$


The corrosion of steel in concrete in the presence of chlorides, but with no oxygen (at the anode), takes place in several steps [Smith et al, 2000]:

1. At the anode, iron reacts with chloride ions from an intermediate soluble ironchloride complex.

$$
\mathrm{Fe}+2 \mathrm{Cl}^{-} \rightarrow\left(\mathrm{Fe}^{++}+2 \mathrm{Cl}^{-}\right)+2 \mathrm{e}^{-}
$$

2. When the iron-chloride complex diffuses away from the bar to an area with a higher $\mathrm{pH}$ and concentration of oxygen, it reacts with hydroxyl ions to form $\mathrm{Fe}(\mathrm{OH})_{2}$. This complex reacts with water to form ferrous hydroxide.

$$
\left(\mathrm{Fe}^{++}+2 \mathrm{Cl}^{-}\right)+2 \mathrm{H}_{2} \mathrm{O}+2 \mathrm{e}^{-} \rightarrow \mathrm{Fe}(\mathrm{OH})_{2}+2 \mathrm{H}^{+}+2 \mathrm{Cl}^{-}
$$

3. The hydrogen ions then combine with electrons to form hydrogen gas.

$$
2 \mathrm{H}^{+}+2 \mathrm{e}^{-} \rightarrow \mathrm{H}_{2}
$$

4. As in the case of the corrosion of steel without chlorides, the ferrous hydroxides, the ferrous hydroxide, in the presence of water and oxygen, is further oxidized to form $\mathrm{Fe}_{2} \mathrm{O}_{3}$.

$$
\begin{aligned}
& 4 \mathrm{Fe}(\mathrm{OH})_{2}+\mathrm{O}_{2}+\mathrm{H}_{2} \mathrm{O} \rightarrow 4 \mathrm{Fe}(\mathrm{OH})_{3} \\
& 2 \mathrm{Fe}(\mathrm{OH})_{3} \rightarrow \mathrm{Fe}_{2} \mathrm{O}_{3} . \mathrm{H}_{2} \mathrm{O}
\end{aligned}
$$

There are two main types of chloride contents that are tested for and reported: acidsoluble chlorides, sometimes referred to as total chlorides, and water-soluble chlorides [Smith et al, 2000]. Acid-soluble chlorides are the chlorides extracted from a concrete sample using an acid. Water-soluble chlorides are those chlorides present that can dissolve in water. The amount of water-soluble chlorides is less than the total or acidsoluble amount of chlorides present in a concrete sample. The minimum chloride ion concentration needed to initiate corrosion of steel reinforcing bars is also called the corrosion chloride threshold. Although the concept of a chloride threshold is generally 
accepted, there is little argument on what the threshold value is. Several factors influence the chloride threshold value [Smith et al, 2000]:

- The composition of the concrete (resistivity),

- The amount of moisture present and

- The atmospheric conditions (temperature and humidity).

The threshold concentration depends on the $\mathrm{pH}$ level and the concentration of oxygen. When chlorides are uniformly distributed, higher concentrations are needed to initiate corrosion. The amount of tricalcium aluminate $\left(\mathrm{C}_{3} \mathrm{~A}\right)$ present in the cement influences the threshold level. Regardless of what concentration of chloride ions is needed to initiate corrosion, an increase in the chloride ion concentration increases the probability that corrosion of the steel reinforcing bars will occur. The concentration of chloride ion needs to be more than $0.71 \mathrm{~kg} / \mathrm{m}^{3}$. The ratio of chloride ions to hydroxyl ions also needs to be greater than 0.6. However, the corrosion of steel reinforcing bars embedded in concrete is a complex process. The use of a single value or criteria for a chloride threshold may not be appropriate or accurate [Smith et al, 2000].

\subsection{Concrete Deterioration due to Corrosion}

The four stages of chloride-induced deterioration of reinforced concrete are:

1. Chloride contamination and corrosion initiation.

2. Cracking-Occurs when the corrosion-induced tensile stresses exceed the tensile strength of the concrete (can be inclined or parallel to the roadway surface).

3. Delamination-Occurs when the cracks are parallel to the roadway surface and results in a fracture plane (often at the rebar level).

4. Spalling-When inclined cracks reach the roadway surface, freeze-thaw cycles and traffic loading cause the cracked delaminated portions to break away (accelerates the corrosion process). 
A simple model for the corrosion of steel in concrete is shown in Figure 2.9. This servicelife model for reinforced concrete structures has two stages: initiation and propagation. This model describes the time to corrosion initiation and the subsequent deterioration rate. Some structures have been found to follow this model with reasonable accuracy. The initiation time is the length of time until depessivation of the steel reinforcing bars and the initiation of corrosion have occurred. The corrosion rate is controlled by corrosion-process kinetics and may increase or decrease. At some point, cracking and spalling occur and the structure is either rehabilitated or has reached the end of its service life and is replaced [Smith et al, 2000].

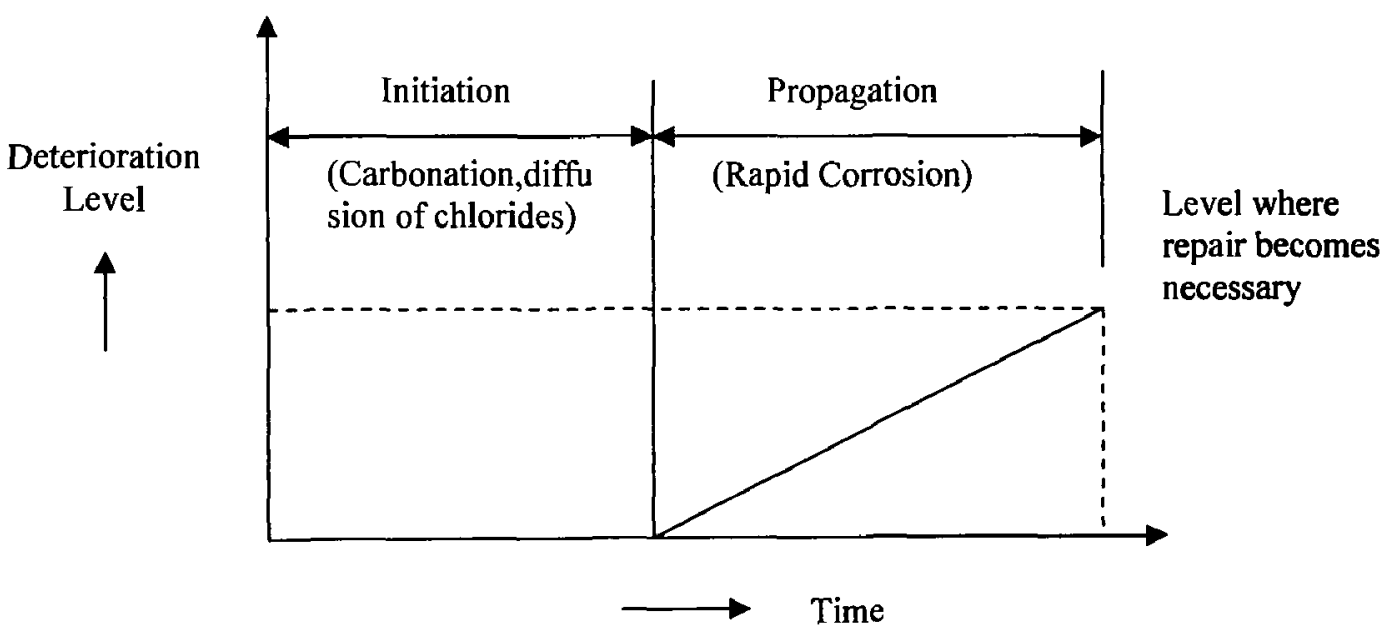

Figure 2.9: Simple deterioration model, corrosion of steel in concrete [Smith et al, 2000].

To quantify the deterioration rate, following important factors are needed to consider:

- chloride profile,

- cover depth,

- carbonation depth,

- corrosion rate,

- concrete resistivity and

- the environment. 
The amount of section loss after the initiation of corrosion can be estimated using Faraday's law (Law of electromotive force in a magnetic field). An electrochemical equivalent is obtained by converting the corrosion current density to metal loss. A corrosion current density of $1 \mu \mathrm{A} / \mathrm{cm}^{2}$ is equivalent to a metal loss of $12 \mu \mathrm{m} / \mathrm{year}$. This is generally considered to be a high rate and cause of cracking and spalling within 1 year. Laboratory tests have shown that a 15 to $40 \mu \mathrm{m}(0.6$ to $1.6 \mathrm{~mm})$ loss of metal has resulted in cracking in specimens containing rebars with a cover-to-diameter ratio between 2 and 4. This is equivalent to a current density of $0.5 \mu \mathrm{A} / \mathrm{cm}^{2}$. The three principal rate phenomena that control corrosion-induced deterioration of reinforced/prestressed concrete bridge components are [Smith et al, 2000]:

- chloride diffusion,

- corrosion and

- deterioration rates.

The chloride diffusion rate is the rate at which chloride ions diffuse through the concrete cover. The corrosion rate is the rate at which the corrosion process progresses after depassivation of the steel reinforcing bars has occurred. The deterioration rate is the rate at which concrete distress (cracking, delamination, and spalling) progresses. The deterioration rate will determine the length of time before repair or replacement of a deteriorated concrete bridge component is required [Smith et al, 2000].

\subsection{Factors influencing the chloride diffusion rate}

Concrete permeability is the main factor that controls the diffusion of chloride ions in concrete. It can be reduced by:

- Reducing the water-cement ratio of the concrete.

- Adding pozzolanic and pozzolonic/cementitious materials to the concrete.

- Adding polymer modifiers to the concrete.

- Aggregate gradation. 
Diffusion of chloride ions in the concrete influenced by the following factors:

- Surface charge on the hydrated cement paste.

- Formation of porous transition zones at the aggregate/cement paste interface

- Microcracking

An increase in microcracking can increase the rate of chloride ion permeability for structures subjected to cycle loadings. Static compressive stresses do not have any significant effect on chloride ion permeability. However, concrete exhibits a significant increase in permeability when loaded with cyclic compressive loads that are 60 to 80 percent of its ultimate strength. The rate of chloride ion permeability increases as residual strength decreases. The prediction/calculation of chloride penetration into concrete is generally done using Fick's Second Law (the concentration within the diffusion volume changes with respect to time). Results yields using Fick's Second Law are very conservative. This is mainly due to the description of concrete as a homogenous medium to model the transport of dissolved ions. In addition, the prediction of chloride ion penetration using diffusivity may be uncertain as the assumption of a constant chloride ion diffusivity is rare in real structures [Smith et al, 2000].

\subsection{Factors influencing corrosion rate}

If sufficient amount of chlorides has reached the reinforcing/prestressing steel to depassivate the steel and initiate corrosion, following factors influenc the corrosion rate:

1. Availability of water and oxygen.

2. Ratio of the steel surface area at the anode to that at the cathode.

3. Amount of chloride ions in the porewater.

4. Resistivity of the concrete.

5. Temperature.

6. Relative humidity (both internal and external).

7. Concrete microstructure [Smith et al, 2000]. 
The availability of oxygen is a function of its rate of diffusion through the concrete, which is affected by how saturated the concrete is with water. When totally submerged, the diffusion rate is slowed because the oxygen must diffuse through the porewater. When the concrete is dry the oxygen can freely move through the pores. Alternating wetdry cycles accelerates the corrosion process. Wet concrete has a lower resistivity than dry concrete due to the presence of water as an electrolyte. When the ratio of the area at the cathode to the area at the anode increases, the current density at the anode increases. The current density is the amount of electrical current passing through a unit area at the anode. An increase in current density results in an increase in the corrosion rate. The following are factors that influences the porewater chemistry parameters which may influence the corrosion rate and the nature of the resulting corrosion products:

1. Ionic strength.

2. $\mathrm{pH}$.

3. Redox potential.

4. Cation composition.

Ionic strength affects the ionic exchange between the pore solution and the cement hydrate phases. When the $\mathrm{pH}$ is between 12.4 and 13.5 , pore solutions have fairly high ionic strengths. The redox potential determines the oxidation state for those elements with multiple valances. Portland cement concrete pore solutions are generally oxidizing (positive redox potential), except when blast-furnace slag is added. The dominant cations in Portland cement porewater solutions are sodium and potassium. The calcium content is significantly lower. This includes cements with slag, silica fume, and fly ash added. The alkali concentration in porewater solutions is generally not affected by the aggregates. However, alkali-reactive aggregates can affect the alkali concentration as the reaction removes alkalis from the pore solution. The factors influencing the ionic conductivity/resistivity of concrete include [Smith et al, 2000]:

- Internal relative humidity.

- Amount of free water. 
- Amount of connected porosity in cement paste.

- Ionic strength of the porewater.

An internal relative humidity of 70 to 80 percent is essential to maintain corrosion activity. Below this level of relative humidity, active corrosion does not occur. The threshold varies with the concrete type and the ambient conditions. When free water evaporates, electrical conductivity decreases to a low level. A high porewater content and

the presence of electrolyte salts lead to lower resistivity. Lower resistivity generally increases the corrosion activity. The controlling factors in the amount of connected porosity are the water-cement ratio and the use of mineral admixtures. Dense concretes have higher resistivity and inhibit ionic transport (i.e., they have low corrosion currents). Less dense concretes have lower resistivity and do not inhibit ionic transport (i.e., they have higher corrosion currents). This is particularly important when corrosion currents are between two layers of steel reinforcing bars (i.e., macrocell corrosion). The heterogeneous nature of concrete, along with the non-uniform distribution of chlorides, results in localized depassivation and corrosion (both micro and macro) of the steel reinforcing bars. Corrosion is not uniform over the entire surface of steel reinforcing bars [Smith et al, 2000].

\subsection{Effect of concrete cracking on corrosion}

Concrete cracking and crack widths influence on the corrosion of steel reinforcement in concrete members has much debate. In the past, considerable research and discussion has been conducted. In general, two points of view exist:

- Cracks reduces the service life of the structure by promoting a more access for moisture, chloride ions and oxygen to reach the reinforcement, thus accelerating the corrosion i.e., cracking has a significant effect on corrosion.

- Cracks may accelerate the corrosion, but such corrosion will be localized to the region of the crack. It was found over time, chloride ions penetrate even uncracked concrete, initiating more widespread corrosion. Thus, after a long 
service life, the difference between the amount of corrosion in cracked and uncracked concrete will be minor i.e., cracking does not have a significant effect on corrosion [West et al, 1999].

The two points of view are illustrated in Figure 2.10 and Figure 2.11. Both points of view indicate that the presence of cracks will accelerate the attack of corrosion. The first point of view suggests that the accelerated attack of corrosion will lead to more corrosion damage in a shorter period, and thus reduce the service life of the structure. The second point of view suggests that the corrosion rate in uncracked concrete will reach almost the same corrosion rate at the crack locations. After some duration this point of view implies that the length of time between corrosion initiation at a crack, $t_{i}$, and corrosion initiation in uncracked concrete $t_{i c r}$, is not significant. This latter point of view means that the two curves in Figure 2.11 are close together when the entire service life is considered, and thus the early onset of corrosion at cracks has little effect on the service life in comparison to the case where the concrete was entirely uncracked [West et al, 1999].

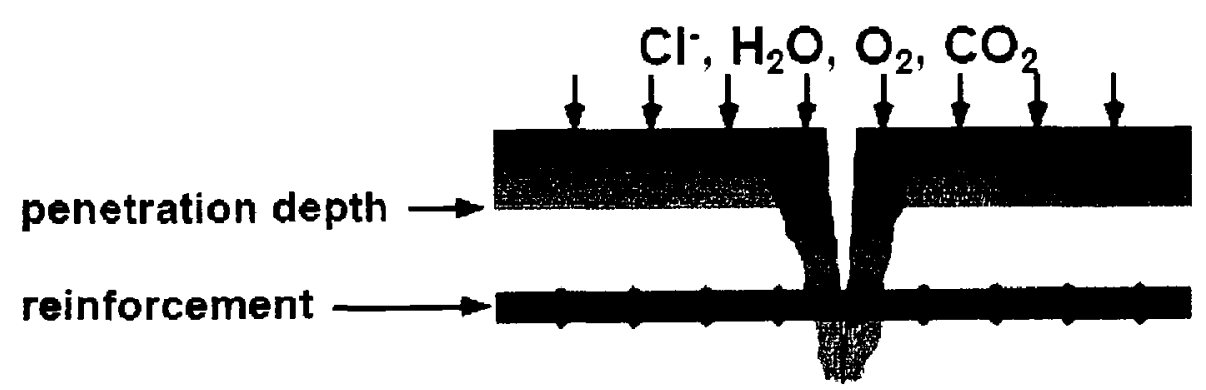

Figure 2.10: Increased Penetration of Moisture and Chlorides at Crack

Location Accelerates the Onset and Severity of Corrosion [West et al, 1999] 


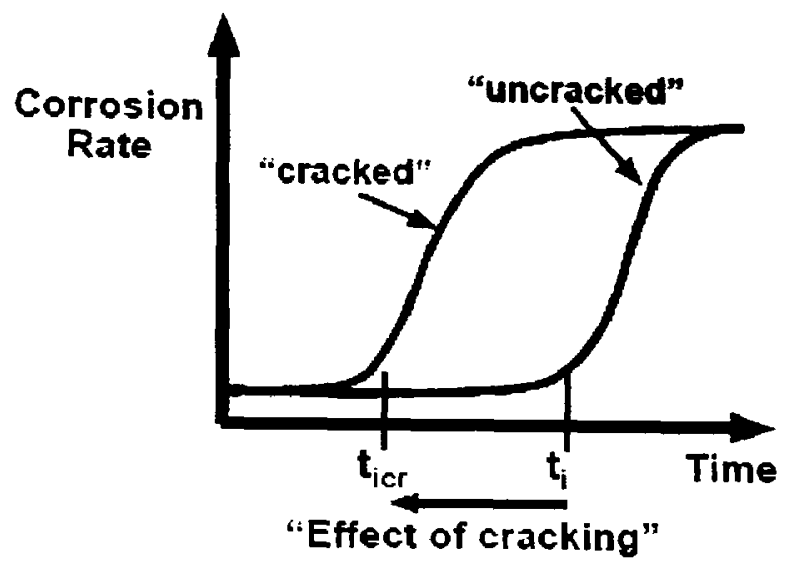

Figure 2.11: Cracking Accelerates Onset of Corrosion, But Over Time Corrosion is Similar in Cracked and Uncracked Concrete [West et al, 1999]

\subsection{Consequences of Corrosion}

Corrosion in prestressed concrete has greater consequences than conventionally reinforced concrete. While the corrosion of non-prestressed reinforcing is generally considered to be more of an issue of concrete durability and aesthetics than structural performance, the corrosion of prestressed steel and the subsequent loss of section have greater ramifications. Since the applied stress level is typically between $55-65 \%$ of ultimate, loss of cross section and an increase in stress on the remaining cross section could possibly lead to a point of yielding or fracture. Secondly, when compared to reinforcing bar, prestressed tendons are made up of smaller diameter wires that lose cross sectional area more rapidly at the same corrosion rate (ACI 222.2R-01).

In a recent Transportation Research Board Report on the costs of deicing (Transportation Research Board, 1991), the annual costs of bridge deck repairs was estimated to be $\$ 50$ to $\$ 200$ million, with substructures and other components requiring $\$ 100$ million a year and a further $\$ 50$ to $\$ 150$ million a year on multistory car parks. In the United Kingdom, the Highway Agency's estimate of salt induced corrosion damage is a total of 616.5 million on motorway and truck road bridges in England and Wales alone (Wallbank, 1989). These bridges represent about $10 \%$ of the total bridge inventory of the country. The 
eventual cost may therefore be ten times the Highways Agency's estimate. The statistics for Europe, the Asian Pacific countries and Australia are similar. In the Middle East the severe conditions of a warm marine climate with saline ground water increase all corrosion problems. This is made worse by the difficulty of curing concrete and has led to very short lifetimes for reinforced concrete structures. In many countries with rapidly developing infrastructures, economies in construction have led to poor quality concrete and low concrete cover to the steel resulting in carbonation problems.

Occasionally lives are lost when steel pipes, pressure vessels or structural elements on bridges fail. The corrosion of steel in concrete has previously caused only economic problems; recently there have been cases of large pieces of concrete falling from bridges in North America, with the loss of a motorist's life in New York City. The failure of posttensioning tendons in a bridge caused a collapse with the loss of a tanker driver's life in Europe [Bertolini et al, 2003]. 


\section{CHAPTER 3}

\section{CORROSION DETECTION}

\subsection{Introduction}

It is possible to greatly reduce the risk of corrosion by proper material selection and by implementing suitable design and maintenance principles. High quality concrete is more resistant to chloride penetration and carbonation. Low permeability is crucial in defining durable concrete. This property is affected by the following variables: water-cement ratio, concrete cover, curing process, compaction, and characteristics of the mix constituents. Concrete must be designed, compacted, and cured to minimize defects that will allow rapid ion penetration. Precise engineering drawings must include drainage provisions and angles of inclination to avoid water accumulation on the concrete surface. Supervision during the construction phase must ensure that concrete cover, steel spacing and placement, vibration techniques, and finishing are all done according to the specifications. It is important to protect the steel from rain and chemicals that might cause it to corrode before placement.

A harsh environment will cause corrosion even in the highest quality steel-reinforced concrete. Altemating wet-dry cycles are very detrimental to concrete structures. Marine exposure is one of the most severe environments in nature accelerating the corrosion process. Deicing salts and other chemicals facilitate the penetration of chlorides and increase corrosion. High temperatures, contaminated soils, industrial and polluted air are other factors that increase the rate of corrosion. Increasing the resistance of the concrete cover to the penetration of chlorides is the primary measure used in increasing the service life of marine structures. The basic repair principle is to create a protective barrier around either the concrete or the steel, thus decreasing permeability, and preventing the penetration of unwanted elements through the concrete to the steel surface. Some of the techniques incorporating these ideas are epoxy coatings, dense concrete, inhibitors, 
overlays, and sealers. FRP wrapping also work to eliminate water and oxygen from entering the concrete, thus creating an airtight barrier system around the structure. Electrochemical methods such as cathodic protection are also used to reduce corrosion damage.

The corrosion of steel is an electrochemical process that produces an electric current, measurable as an electric field on the surface of the concrete. Most detection techniques currently used rely on the electrochemical nature of corrosion for their data collection. A wide variety of instruments produced by different manufacturers exists for this purpose. They may vary in size, cost, application methods, underlying theories, and information given. The most used method is the half-cell potential procedure. In addition, visual inspections should complement any monitoring program, but they may not detect corrosion early enough to prevent serious damage. The acoustic emmision (AE) method detects acoustic waves generated by flaw growth, thus providing early and accurate data on corrosion activity [Verhulst et al, 2001].

\subsection{Non-Destructive Techniques for Corrosion Detection}

Highway bridges, among other structures, have extensively used pre-stressing and post-tensioning techniques. Although prestressing offers many competitive edges to it's traditional rival reinforced concrete, the consequence of damage to prestressing tendons could be catastrophic. Therefore early detection of damage to prestressing steel is important. Unfortunately, no reliable and practical non-destructive evaluation technique has been available for assessing the condition of prestressing steel within concrete. The traditional non-destructive techniques for reinforced concrete structures, such as visual inspection, half cell potential survey, chloride and carbonation testing provide only limited information on the degree of distress in prestress concrete structures specially when the tendons are ducted. Fortunately there are new emerging technologies that have the potential to provide far more information than the existing ones. However, most of these techniques are not widely used for detection of prestressing tendons condition [Ali et al, 2003]. 


\subsection{Inspection Methods}

The following inspection methods have been used as non-destructive inspection methods for prestressed concrete structures:

1 Radiography

2 Magnetic Field Disturbance Technique

3 Computed Tomography

4 Remnant Magnetism Method

5 Surface Penetrating Radar

6 Linear Polarisation Method

7 Impact Echo

8 Electrical Resistance

9 Acoustic Emission Monitoring

10 Surface Potential Survey

The review of these techniques are not provided in-detail, but to provide background information on their suitability as non-destructive techniques for assessing prestressing steel in concrete. A summary of the techniques ability to locate voids, assess ducted tendons, detect corrosion and tendon loss is given in Table 3.2. Visual inspection has not been discussed but it is recommended that a visual survey be conducted for all sites prior to performing any destructive or non-destructive assessment of the status of the prestressing tendons. Following record and comment on the visible status of the structure is expected:

- Cracking, following prestressing ducts and transverse or skew cracks.

- Crushing of concrete and failed joints.

- Discoloration and leaching deposits on faces, including rust staining.

- Spalling and surface erosion. 


\subsubsection{Radiography}

A powerful radiation source is used in radiographic examination to produce $\mathrm{x}$-rays of beta or gamma particles. A beam of radiation is passed through the concrete structure and detected on the other side. Access to both sides of the structure to be inspected must be possible for this technique. Differential absorption of the radioactive particles allows detection of changes in material characteristics. Visualization can be made by either radiographs or real time imaging. To produce radiographs, radiographic film is exposed for periods of up to 30 minutes. As the thickness of the material increases, so too does the exposure time, with practical thickness limits of around $600 \mathrm{~mm}$. The French developed Scorpion System provides real-time imaging capabilities. Radiography techniques are suitable in locating voids, ducts and prestressing steel. The quality of radiograph is sometimes poor for detecting loss of section, particularly for ducted tendons. Due to the resultant images being 2-dimensional, the orientation is important as corroded tendons may be hidden behind sound tendons. Radiographic systems are portable. However, restrictive access requirements are to be maintained during testing to ensure personnel health and safety [Ali et al, 2003].

\subsubsection{Computed Tomography}

Computed tomography methods use conventional $\mathrm{x}$ - or gamma ray to measure the attenuation of an incident beam that travels in a straight path through an object. The incident beam is partially absorbed and scattered in the object of interest, with the remaining transmitted radiation traveling in a straight line to the detector. The amount of attenuation is related to the atomic number of the phases distributed in the object, as well as their density distribution. As with radiography, access to both sides of the structure is required. Computed tomography is unable to detect cracks in prestressing wires and only able to detect significant loss of section due to corrosion. It is however capable of inspecting tendons in ducts. Surface temperature variations related to the surface properties and varying weather conditions complicate the interpretation of retrieved data. Spatial resolution due to equipment limitations must be increased from the present limit 
of $1 \mathrm{~mm}$ if determination of corrosion/metal loss is to be possible. Additionally, contrast resolution must be increased to aid detection in similar density materials. Data acquisition and processing is slow and an increase in speed without decrease in either contrast or spatial resolution is required for acceptance as a non-destructive test method. A 3D CT image is shown in Figure 3.1 [Ali et al, 2003].

\section{Neutron CT of a steel concrete cube \\ $(100 \times 100 \times 9 \mathrm{~mm})$ - partial image}

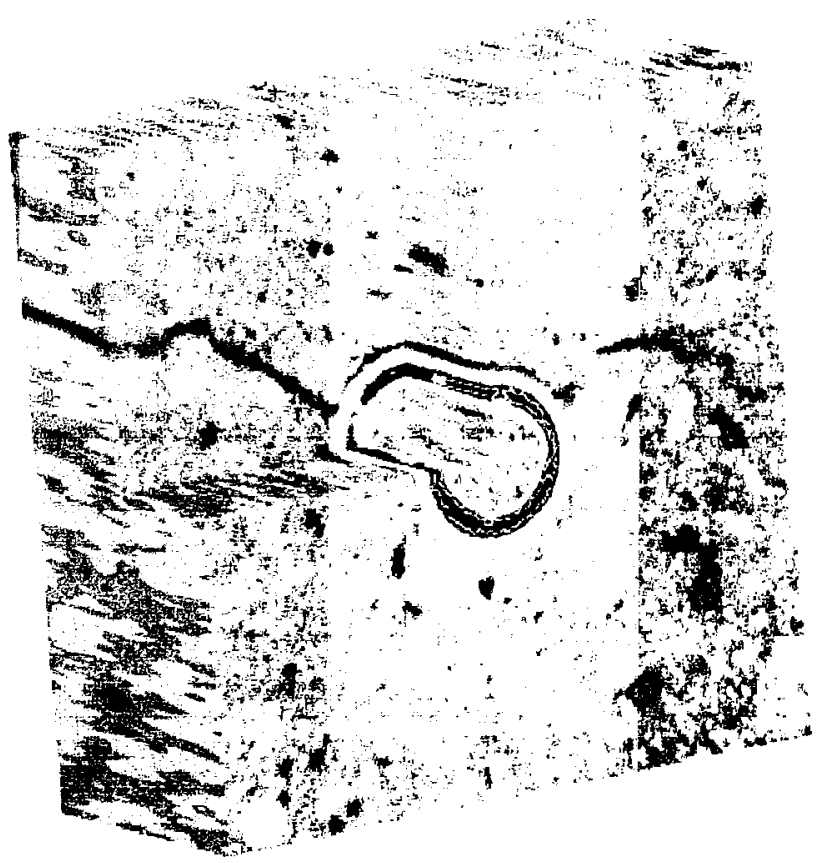

Figure 3.1: 3D-neutron CT-image of slice 6 to 14 of the concrete cube [Pfister, 1996]

\subsubsection{Surface Penetrating Radar}

Surface penetrating radar works on the principal of reflection of high frequency $(1 \mathrm{GHz})$ electromagnetic pulses from interfaces between materials with different dielectric constants, such as bars, voids and ducts. When the transmitted electromagnetic pulse reaches the interface between two materials with different electromagnetic properties, a portion of the pulse is reflected and the rest is transferred into the new material. The 
continuing pulse undergoes some refraction, depending on the material properties of the new material and the angle of incidence. An electromagnetic emitter/receiver is passed across the surface of the concrete in the expected position of the tendon. The scattered signals are analyzed to convert time domain data to the frequency domain using fast Fourier Transforms to aid in visualization and interpretation. The radar is capable of locating the position and depth of tendons, ducts and voids including the detection of prestressing below reinforcing. However, this technique is qualitative only. Intrusive techniques including concrete breakouts allow the tendon loss to be estimated. Limitations on thickness of specimens to be investigated have been reported as approximately one (1) meter. There is also a trade off between resolution and penetration with increased resolution resulting in a decrease in penetration. Additionally, the resolution is not high enough to determine if cracking or minor loss of section has occurred. For ducted tendon inspection, metallic ducts may absorb or reflect energy, making inspection difficult and possibly leading to erroneous results. Non-metallic ducts may make the detection of voids impossible. A GPR test system is shown in Figure 3.2 [Ali et al, 2003].

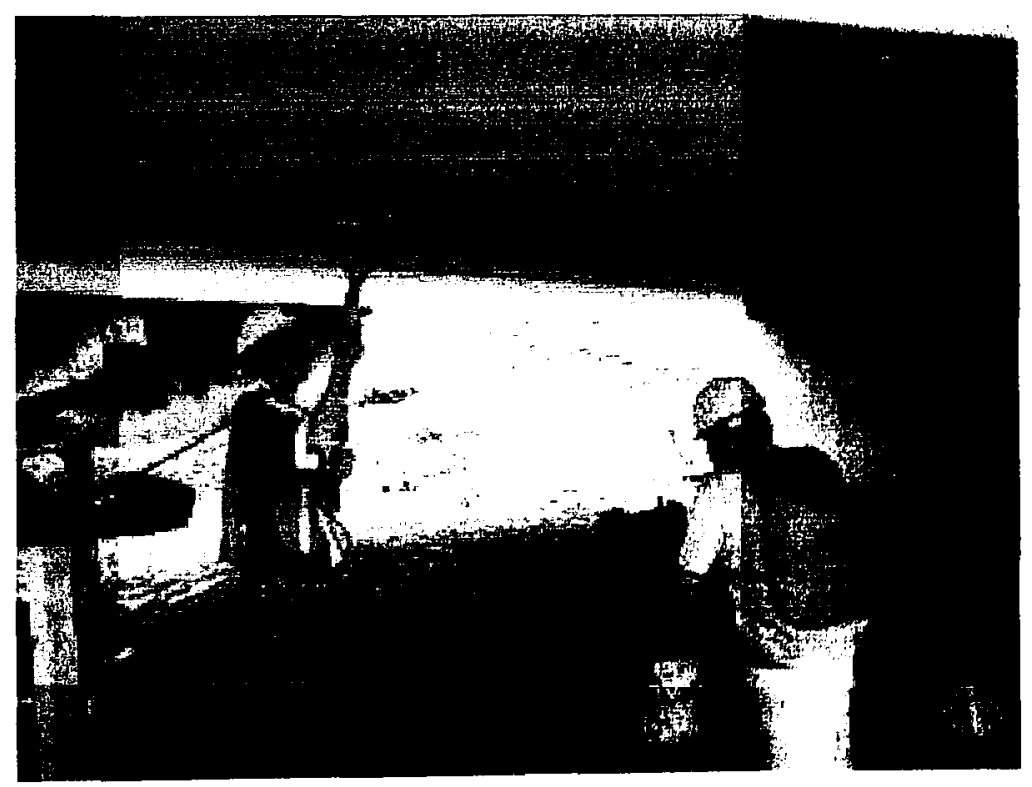

Figure 3.2: Ground Penetrating Rader (GPR) Test to Locate Steel Reinforcement [Olson Engineering, Inc., 2004] 


\subsubsection{Impact Echo}

In the impact echo method, a transient stress pulse is introduced to a structure by mechanical impact at a point on the surface. This pulse travels as three (3) wave types; Dilatational (P-) and Distortional (S-) waves travel into the concrete, Rayleigh (R-) waves propagate along the surface. The $\mathrm{P}$ - and $\mathrm{S}$ - waves propagate into the structure along spherical wavefronts. Internal voids, cracks or interfaces (such as reinforcing bars) act as boundaries, reflecting the waves. A displacement transducer located close to the impact point is used to monitor the arrival of the reflected waves. The reflected wave signals are then transferred into the frequency domain using the fast Fourier Transform technique. Peaks in the amplitude corresponding to characteristic frequencies allow the detection of voids, reinforcement and prestressing bars. Through relatively simple calculations, defect depths may be calculated. Impact echo has been widely used to detect voids and defects in reinforced concrete beams and columns. It appears however that the technique cannot give an accurate analysis of corrosion or cracking of prestressing tendons. Also, this method cannot inspect internals of ducts or post-tensioned structures. Concrete/air interfaces are different to concrete/reinforcing interfaces and may lead to erroneous results. Shadowing of voids below reinforcement may also lead to false results [Ali et al, 2003].

\subsubsection{Acoustic Emission Monitoring}

This technique is based on the principle that waves are emitted when damage occurs to materials. Damage may be the cracking of the concrete or fracture of the strands. The waves created in response to a wire rupture or fracture, propagate at a given velocity in a given medium. Monitoring is carried out continuously with appropriate sensors. Each sensor consists of an accelerometer and circuitry to transmit the data to a central logger for data processing. Analysis of received signals may allow pinpointing of the source of the emission. Monitoring can determine new cracks and/or damage, but will not give results for existing damage or damage whilst monitoring is not being conducted. Failures 
of internal or external wires, stressing wires and strands can be detected. A AE Monitoring system and technique is shown in Figure 3.3 and 3.4 [Ali et al, 2003].

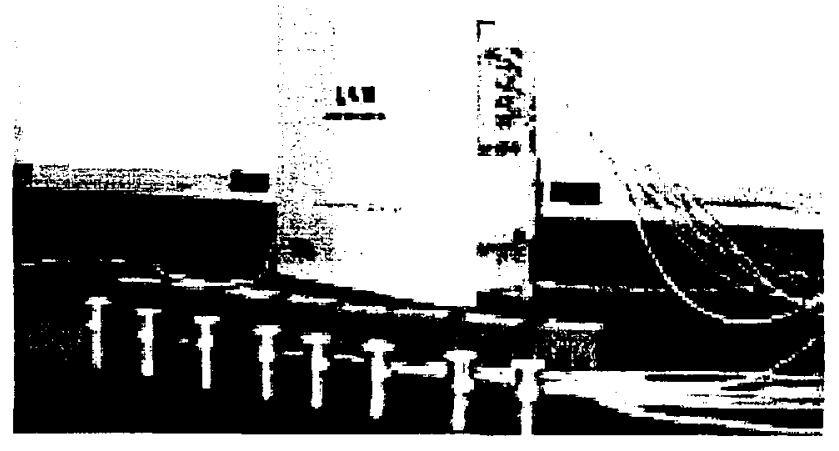

Figure 3.3: Local Area Monitoring (LAM) System with 8 sensors and holding magnets [NDE Validation Center, FHWA]

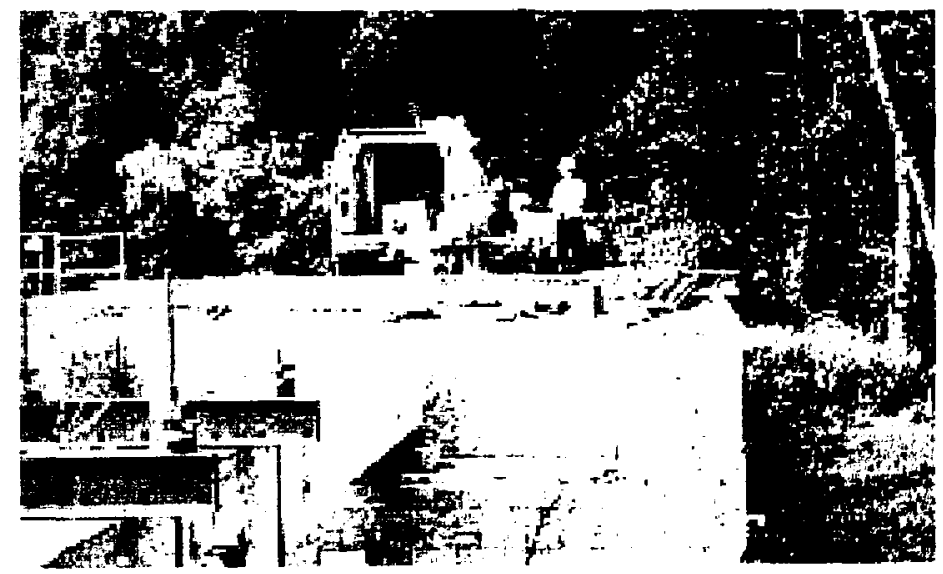

Figure 3.4: AE Monitoring of NYSDOT boxbeam test [NDE Validation Center, FHWA]

\subsubsection{Magnetic Field Disturbance}

The Magnetic Field Disturbance (MFD) method consists of applying a steady magnetic field to the member under inspection and concurrently scanning the side and bottom 
surfaces to search for perturbations in the field caused by the presence of flaws in the tendons. The magnitude of the perturbation will depend on several factors, most importantly, the strength of the applied and induced magnetic field, the size of the flaw, and the distance between the magnet-sensor assembly and the flawed bar. MFD is able to resolve corrosion and breaks in pre-stressing steel. Defect signatures are unique to each type of defect e.g. pitting, notches, loss of section with the orientation of the defect having no influence on the results. The minimum defect size ranges from $5 \%$ loss of section (no local stirrups) to $40 \%$ loss of section when stirrups placed $400 \mathrm{~mm}$ apart. Size of the defect is directly proportional to the signal and therefore cracks within the steel may miss detection. A knowledge of the structure is required, e.g. location of reinforcement, to overcome limitations in direct interpretation of results. This technique is not able to detect corrosion of prestressing steels in metallic ducts. Nor does it allow detection of voids in grouting. A MFD method of schematic measurements is shown in Figure 3.5 [Ali et al, 2003].

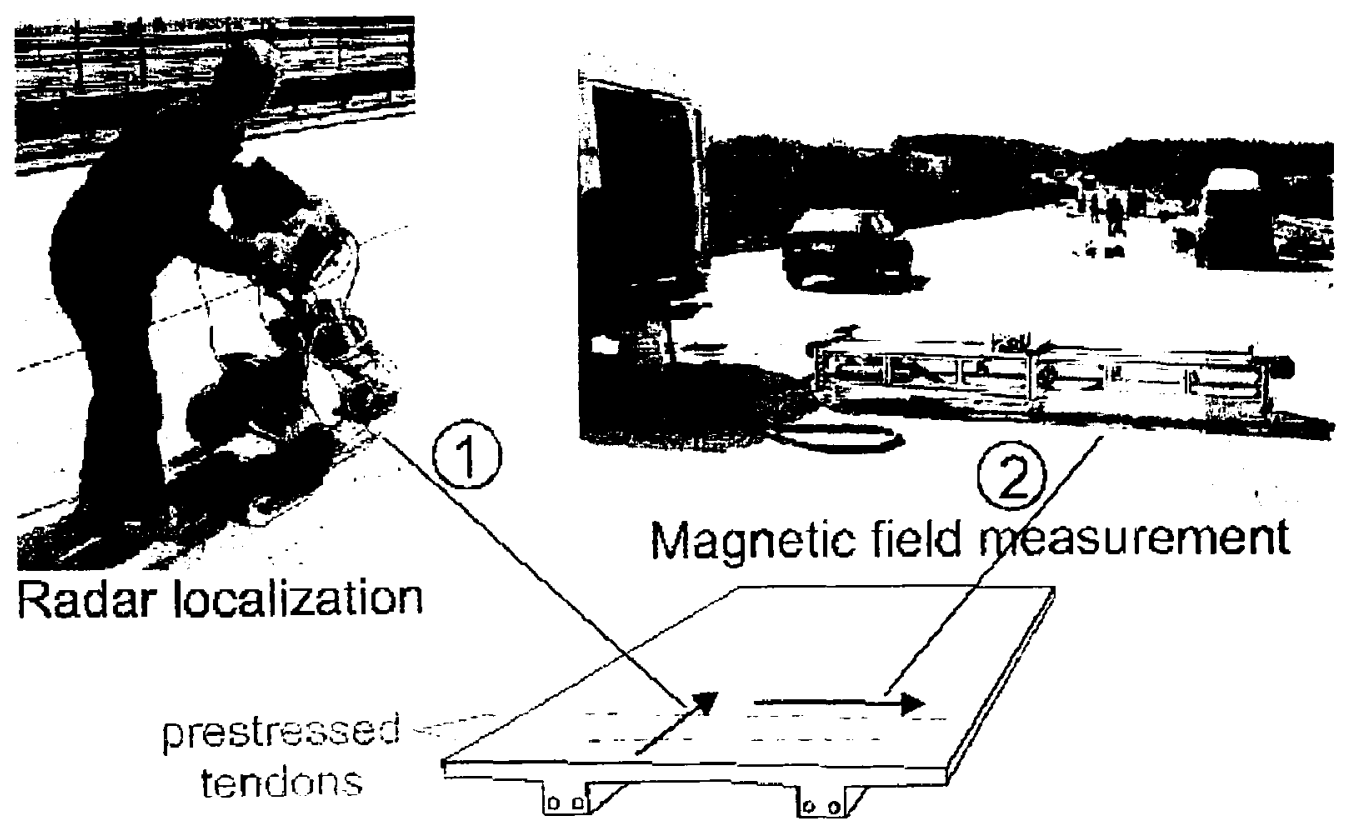

Figure 3.5: Schematic of the measurements conducted on the valley bridge Michelsrombach. (1) the tendons were localized using Ground Penetrating Radar. (2) the prestressed steel rebars were inspected by scanning the yoke with the SQUID system along the member [ Krause et al, 2000]. 


\subsubsection{Remnant Magnetism Method}

Prestressing steel is magnetised up to saturation to remove the magnetic history of the steel. The magnetisation is performed from the concrete surface with an electromagnet led along the projection of the tendon. A yoke-shaped electromagnet is used for this purpose. Magnetisation to saturation of tendons has been possible on tendons with 250 $\mathrm{mm}$ of concrete cover. Remnant magnetism is able to resolve fractures and breaks in prestressing tendons including that in ducts. Signals for reinforcement and prestressing tendons can be distinguished from each other. However, the size of defect or loss of section cannot be determined. A magnetic technique of measurements is shown in Figure 3.6 [Ali et al, 2003].
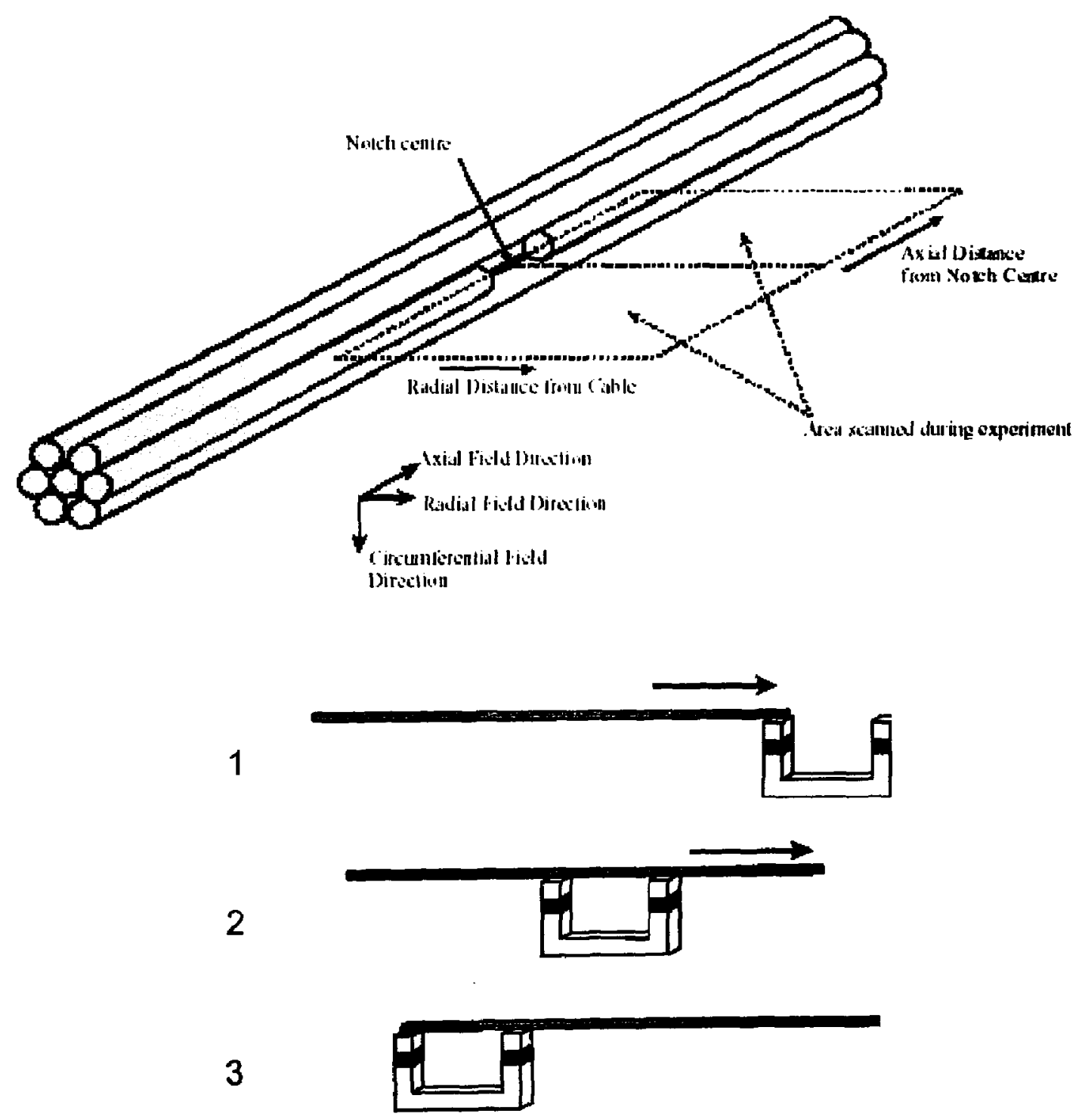


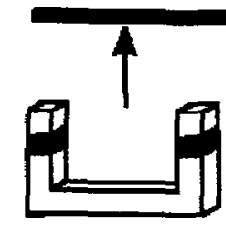

$4 b$

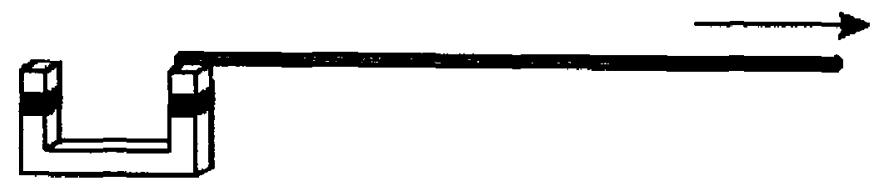

Figure 3.6: Magnetizing techniques used for residual field experiments. In each case the magnetization procedure started by drawing the cable on to the yoke (Stage 1). The cable was then pulled along the yoke (Stage 2) until the end was reached (Stage 3). Two different procedures were then followed. The cable was either pulled directly away from the yoke (Stage 4a) or the cable was pulled off the magnet by continuing the movement in the same direction as the previous stages (Stage 4b) [Maker et al, 2001].

\subsubsection{Linear Polarization Method}

Within $10 \mathrm{mV}$ more noble or more active than the corrosion potential, it is observed that the applied current is a linear function of the electrode potential. By measuring applied current and potential shift, a corrosion current can be calculated. This method, also termed Polarization Resistance, has been shown to be most accurate when dealing with small specimens. By determination of the true value of the polarization resistance per unit area of the metallic surface, the instantaneous corrosion intensity can be calculated through the Stern-Geary equation. The linear polarization method permits rapid corrosion rate measurement and is useful in measuring very low corrosion rates (less than 2.5 microns per year). Measurements of the corrosion rate provide a rate in $\mathrm{mm}$ per year and data acquisition and processing is carried out using a laptop computer and a small control/command box. The technique is based on the assumption that individual wires all undergo uniform corrosion at the same rate. Localized corrosion, in the form of pitting, is averaged over the total surface area. Corrosion rate measurement does not reflect the actual loss of section. Prediction and measurement of the polarization 
resistance in large concrete structures requires further investigation, especially the application of a guard ring device to limit current spread. The surface probes cannot distinguish between reinforcement and prestressing steel. Also, this technique is not suitable for corrosion detection of tendons in ducts unless embedded probes are installed within the metallic ducts. A 3LP test device with measurement system is shown in Figure 3.7 and a data interpretation of 3LP device is shown in Table 3.1 [Ali et al, 2003].

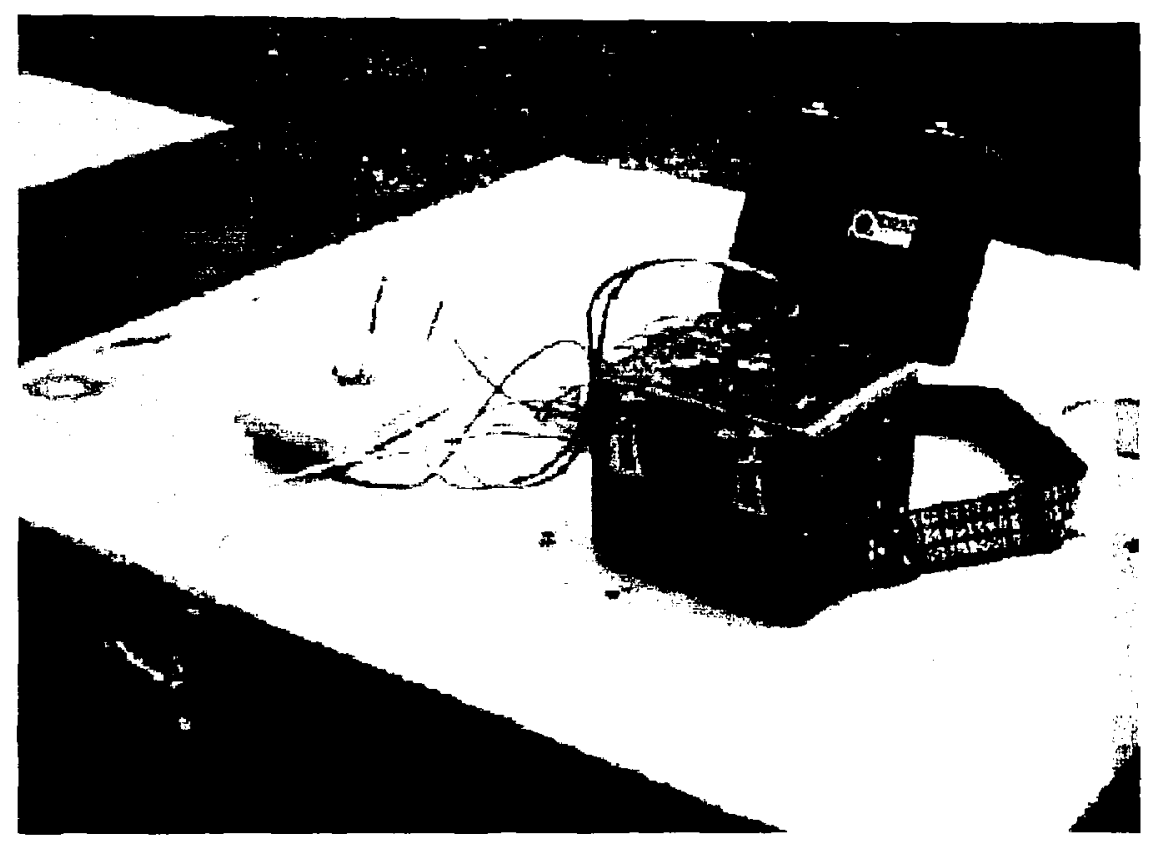

Figure 3.7: Three Electrode Linear Polarization (3LP) device [Óemajtis, 1998]

Table 3.1: Data interpretation for the 3LP Device [Ôemajtis, 1998]

\begin{tabular}{|l|l|}
\hline $\mathbf{I}_{\text {corr }}$ & Interpretation \\
\hline$<0.21 \mathrm{~mA} / \mathrm{cm}^{2}$ & No damage expected \\
$0.21-1.07 \mathrm{~mA} / \mathrm{cm}^{2}$ & Damage possible in 10-15 years \\
$1.07-10.7 \mathrm{~mA} / \mathrm{cm}^{2}$ & Damage possible in 2-10 years \\
$>10.7 \mathrm{~mA} / \mathrm{cm}^{2}$ & Damage possible in less than 2 years \\
\hline
\end{tabular}




\subsubsection{Electrical Resistance}

Electrical resistance is an important property of any metallic material. Since resistivity is constant for a given material, electrical resistance therefore depends on the crosssectional area. As the cross-section decreases (due to say corrosion), electrical resistance increases. A four (4) probe technique (in two probe mode) is used to measure the resistance. The technique is based on the assumption that all individual wires undergo uniform corrosion at the same rate. Short circuits at anchorage ends and within ducts may affect results [Ali et al, 2003].

\subsubsection{Surface Potential Survey}

Half-Cell or electrode potential mapping is widely accepted as a method of detecting the corrosion of steel reinforcement embedded in concrete. Potential maps are made by recording concrete surface potentials with respect to a standard reference electrode. Passive steels embedded in concrete have potentials, which is usually more positive than. $200 \mathrm{mV}$ w.r.t. a saturated calomel electrode (SCE). Active, or corroding steel potentials may be more negative than $.200 \mathrm{mV}$ w.r.t SCE. Based on this fact, a relationship between surface potential and corrosion activity is assumed. However, correlation between surface potential and actual corrosion has not been reported in all cases. Surface potentials are greatly influenced by surface conditions. Potential mapping cannot distinguish between reinforcement and prestressing tendons. Potentials of prestressing cables in duct is not possible, at best the potential of the duct is the only possible measurement [Ali et al, 2003]. 
Table 3.2: Summary of Non-Destructive Techniques

\begin{tabular}{|l|c|c|c|c|}
\hline \multicolumn{1}{|c|}{ NDT's } & $\begin{array}{l}\text { Locates } \\
\text { voids }\end{array}$ & $\begin{array}{l}\text { Suitable for } \\
\text { ducted } \\
\text { tendons }\end{array}$ & $\begin{array}{l}\text { Detects } \\
\text { corrosion }\end{array}$ & $\begin{array}{l}\text { Quantifies } \\
\text { tendon loss }\end{array}$ \\
\hline Radiography & $\mathrm{Y}$ & $\mathrm{Y}$ & $\mathrm{Y}$ & Y (if large) \\
\hline Computed Tomography & $\mathrm{Y}$ & $\mathrm{Y}$ & $\mathrm{Y}$ & $\mathrm{Y}$ (if large) \\
\hline Surface Penetrating Radar & $\mathrm{Y}$ & Unclear & $\mathrm{Y}$ & Y (if large) \\
\hline Impact Echo Emission & $\mathrm{N}$ & $\mathrm{Y}$ & Unclear & $\mathrm{N}$ \\
\hline Acoustic & & & $\mathrm{N}$ & $\mathrm{N}$ \\
Monitoring & $\mathrm{N}$ & $\mathrm{N}$ & $\mathrm{Y}$ & $\mathrm{Y}$ \\
\hline Magnetic Field disturbance & $\mathrm{N}$ & $\mathrm{Y}$ & $\mathrm{N}$ & $\mathrm{N}$ \\
\hline Remnant Magnetism & $\mathrm{N}$ & $\mathrm{N}$ & $\mathrm{Y}$ & $\mathrm{N}$ \\
\hline Linear Polarization & $\mathrm{N}$ & Unclear & $\mathrm{N}$ & $\mathrm{Y}$ \\
\hline Electrical Resistance & $\mathrm{N}$ & $\mathrm{N}$ & $\mathrm{Y}$ & $\mathrm{N}$ \\
\hline Surface Potential Survey & $\mathrm{Y}=\mathrm{Yes}, \mathrm{N}=$ No & & \\
\hline
\end{tabular}

From the limited literature search conducted it appears that there does not exist a single technique that will provide all the information required for a total assessment of the tendons. A combination of a few techniques should be used. Use destructive techniques (where practical) for calibration of NDT results. Among the NDT techniques, linear polarization, potential mapping and electrical resistance are relatively simple techniques. It appears that the techniques reviewed are more suitable when tendons are not in ducts. For ducted tendons, the techniques more suitable include electrical resistance (when not short-circuited), radiography, surface penetrating radar, remnant magnetism and acoustic emission. NDT's should be used only following a visual inspection of the structure. A visual inspection will aid in directing inspection activities, minimizing manpower and equipment usage [Ali et al, 2003]. 


\section{CHAPTER 4}

\section{CORROSION PROTECTION}

\subsection{Introduction}

Corrosion-induced deterioration of reinforced/Prestressed concrete structures occurs when the environmental loading on the structure is greater than the ability of the structure to resist the environmental loading (environmental resistance). One can either decrease the loading or increase the resistance or do a combination of both. The main deterioration mechanisms (chloride-induced corrosion of rebar) focus on the reinforcement and its protection. Corrosion can also occur as a result of other deterioration process:

- freeze-thaw cycles,

- expansive reactions,

- excessive deflections,

- fatigue, etc.

These processes cause the concrete to crack, which allows water and chlorides easy access to the interior of the concrete and the steel reinforcing bars. These other deterioration mechanisms create more conducive to the corrosion of the embedded steel reinforcing bars. which leads to further deterioration of the concrete.

The factors that influence the corrosion of steel reinforcing bars embedded in concrete are ISmith et al. 20001:

- the amount of chloride ions at the steel level.

- the resistivitv of the concrete.

- temperature,

- relative humidity (both internal and external) and

- the concrete microstructure. 
In general, by controlling these factors to an acceptable level, the corrosion of the steel reinforcing bars and resulting concrete deterioration can be minimized. This is the first step in most corrosion control strategies in addition to other suitable corrosion-protection systems. Corrosion-control methods or systems are classified as mechanical or electrochemical.

The mechanical methods are physical barriers that prevent or delay the ingress of chlorides, oxygen, and moisture through the concrete cover to the reinforcing steel. They include admixtures, sealers and membranes, overlays, and coatings on steel reinforcing bars. Sealers and membranes made with materials such as resins, epoxies, emulsions, etc. are used to reduce the ingress of deleterious species. Their effectiveness and durability on the bridge decks due to the abrasion of applied sealers or the cracking of installed membranes are of concern. Portland cement concrete, low-slump dense concrete, latexmodified concrete, silica fume-modified concrete, and polymer concrete overlays are commonly used. Coatings used on steel reinforcing bars are either organic or metallic. Organic coatings include the non-metallic fusion-bonded epoxy coatings. Metallic coatings include materials such as nickel, stainless steel, and zinc. The nickel and stainless steel coatings protect steel by being a barrier system and more noble, i.e., have a lower potential than iron to corrode. The zinc coating protects steel by being sacrificial or more active i.e., it has a greater potential than iron to corrode. Corrosion-resistant materials include austenitic stainless steels and fiber-reinforced polymer (FRP) rebars [Smith et al, 2000].

The electrochemical methods force the steel reinforcing bars to be cathodic. They include chloride extraction and cathodic protection. Chloride ion extraction and cathodic protection are typically used in the rehabilitation of reinforced concrete structures and not as a corrosion-control measure for new construction. There are three categories of variables that influence the corrosion process and the extent of the corrosion-induced deterioration of reinforced and prestressed concrete members: materials, design, and environmental variables. Material variables for making durable concrete include cement type, admixtures, aggregate type and gradation, and the water-cement ratio. Design 
variables include the depth of concrete cover, physical properties of the hardened concrete, the size and spacing of the steel reinforcing bars, and the efficiency of drainage from the structure. Environmental variables include the source of chloride ions; temperature extremes; wet-dry cycles; relative humidity; and to a certain extent, applied live loading [Thompson et al, FHWA, Smith et al, 2000].

\subsection{Selection of protection systems}

Corrosion-protection strategy may vary from structure to structure. Following factors has to be considered during the design of a structure:

1. Intended design life of the structure.

2. Effects of corrosion and corrosion-induced deterioration which includes the costs due to closure (entire permanent or temporary) for repair.

3. Quality of workmanship in construction - The quality of construction entails good consolidation, proper rebar placement, sufficient concrete cover over the reinforcing/prestressing steel bars, and other measures.

4. Possible rehabilitation methods - The design of structures should include provisions for the possible future rehabilitation of corrosion-induced deterioration.

5. Initial costs - May need to consider more than just initial costs (i.e., life-cycle costs). As the rehabilitation and replacement cost increase, corrosion-control measures become more cost effective.

For long-term corrosion protection, multiple protection strategies may be cost-effective. One such strategy is the use of epoxy-coated rebar in combination with a durable concrete containing corrosion inhibitors, having a low permeability, and adequate concrete cover. Silica fume and fly ash can be added to the concrete to reduce permeability and provide additional corrosion control. However, additional costs of control measures against additional service life can be expected. The additional costs can usually be justified based on a life-cycle cost analysis. 
When choosing a corrosion-control measure, following factors has to be considered [Smith et al, 2000]:
a. Reliability and effectiveness of the measure.
b. Risk of unintended side effects.
c. Possibility of future installation of other control measures.
d. Life expectancy of the measure.
e. Any incremental costs over the "do nothing" option.
f. Any impacts on the cost of other elements in the structure.
g. How aggressive the environment is where the structure will be located.

For reinforcing/Prestressed steel bars embedded in concrete, corrosion-protection strategies can be grouped into four general categories: design, concrete, corrosion inhibitors, and reinforcement type.

\subsubsection{Design Provisions for Protection}

Design details influence the overall performance and durability of reinforced/Prestressed concrete components. Following design factors that affect the durability of concrete structure are:

1 Construction type.

2 Expansion joints.

3 Construction joints.

4 Tendency of concrete to crack.

5 Duct and anchorage layout in post-tensioned concrete.

6 Drainage details.

7 Access for inspection and maintenance.

8 Proximity to seawater.

9 Exposure to deicing chemicals. 
Expansion joints lifespan and effectiveness depend on how well they are installed. If possible, construct integral abutments and continuous structures to eliminate expansion joints. Provide adequate and proper drainage so that water does not reach the anchorages or bearings. Consider inspection provisions for the inspection of the joints and structural components under the joint. Sometimes well-constructed joints also leak. If possible, locate deck construction joints away from critical areas particularly in prestressed anchorages. Cracks may be thermal or shrinkage. Cracking may also be due to creep or to the high modulus of elasticity of the hardened concrete. For post-tensioned structures, provide an adequate amount and distribution of reinforcement in the anchorage areas. The ease of grouting will influence the quality of the completed grouting operation in post-tensioned concrete structures. Both tendon profiles and duct size affect the ease of grouting. The location of anchorages affects the ease of stressing and inspection, as well as susceptibility to the ingress of water. Anchorages located in the top surfaces of decks are easy to construct, stress, and grout. However, due to their location, it is easier for chloride-contaminated water to penetrate and reach tendons. Several design parameters can be adjusted as cost-effective corrosion-control measures. These include the use of adequate concrete cover, reinforcement distribution, the size and spacing of reinforcing steel for crack control, the use of rigid overlays, and provisions for good roadway drainage. The use of well-consolidated, low-permeability adequate concrete cover is a cost-effective corrosion-control measure. Since the diffusion of chloride ions in concrete is non-linear with increasing cover thickness, there is a significant increase in the time required for the chloride ions to reach the steel reinforcing bars [Smith et al, 2000, FIP, 1996].

\subsubsection{Construction as Protection Provisions}

Several construction variables that influence the durability of concrete structures. These include concrete placing, consolidating, and curing; rebar placement; duct and tendon placement; and grouting procedures and materials. Good consolidation practices help to avoid segregation and honeycombing, and a uniform concrete with low permeability. A 
well-consolidated concrete can be achieved through the use of proper construction techniques and equipment. Poor consolidation results in concrete with higher permeability and voids, cavities, and poor bonding. Voids, cavities, and areas of poor bonding aid in the corrosion process. Poor procedures for grouting post-tensioning ducts can leave voids where moisture can accumulate and initiate corrosion of the prestressing tendons. In post-tensioned structures, certain grout can cause severe corrosion if the excess mix water bleeds into the voided areas and is not absorbed into the grout during hardening. A recent example is the severe corrosion of all 19 seven-wire strands in the external post-tensioning ducts of the Niles Channel Bridge in Florida. The proper consolidation of the concrete ensures that concrete is in close contact with the steel reinforcing bars. Concrete curing procedures are an important part of workmanship. Proper and adequate curing provides durable concrete through increased cement hydration. A minimum of 7 days of uninterrupted moist cure is recommended. Whatever the curing method used, the surface of the concrete must be kept wet. Alternating wet-dry cycles promotes cracking in the concrete. There are three general categories of curing methods are a continuous water cure is done by a continuous spray, ponded water, or saturated surface coverings (barlap). Curing compounds seal the surface of the concrete. Moisture barrier materials, such as plastic sheets or waterproof paper, cover the surface of the concrete. A continuous water cure supplies sufficient water to prevent the surface

of the concrete from drying. Both membranes and moisture barriers work by preventing evaporation of the mix water from the surface of the concrete [Smith et al, 2000, FIP, 1996].

\subsubsection{Concrete as Protection Provisions}

Good-quality concrete in new structures can protect the steel reinforcing bars from corrosion for the service life of the structure. Any corrosion-induced concrete deterioration may not reach a point where repair or rehabilitation will be required during the expected service life of the structure. However, the concrete quality may be changed by either chemical or mechanical means. Chemical means are chloride diffusion and carbonation, and the primary mechanical means is cracking. Cracks in concrete allow 
water, oxygen, and chlorides to enter the concrete at a faster rate and reach the reinforcing steel sooner than by the diffusion process alone.

A good-quality concrete with low permeability is a primary corrosion-control measure for both pretensioned and post-tensioned concrete. Low permeability can be achieved in a well consolidated concrete with a low water-cement ratio. Admixtures such as silica fume and fly ash may also be used. The use of corrosion inhibitor is also possible. In very corrosive environments, it may be necessary to use very high-quality concretes with an extremely low permeability. High-quality concrete with a low water-cement ratio and low permeability are typical characteristics of precast pretensioned concrete that is produced in a controlled environment [Smith et al, 2000, FIP, 1996].

\subsubsection{Reinforcement as Protection}

There are some corrosion-protection measures that can be applied to the tendons themselves. Epoxy-coated strands are coated with an extra-thick coating of epoxy to allow for elongation, and often have a coarse grit embedded in the epoxy to aid in bonding. The epoxy coating provides a mechanical moisture barrier. The coating thickness is considerably more than that on epoxy-coated steel reinforcing bars. The performance of epoxy-coated strands in both pretensioned and post-tensioned specimens under severe exposure conditions has been excellent. However, there are a number of issues besides cost-effectiveness that need to be resolved before epoxy coated strands are commonly used in either pretensioned or post-tensioned construction. An "intelligent strand" is a strand where a fiber-optic sensor is placed through the center wire. It can be used to monitor strains and for any breaks in the strands. Precautions can be taken during the design of prestressed concrete beam structures that will enhance the corrosion performance. The exposure of the ends of prestressed concrete beams to deicing chemicals can be minimized by using continuous prestressed concrete beams or encasing the prestressed concrete beam ends in concrete diaphragms or abutments [Smith et al, 2000, FIP, 1996]. 


\subsection{Corrosion Protection for Post-Tensioned Concrete Structures}

Corrosion protection for post-tensioned concrete structures are similar to many aspects of protection for conventional reinforced concrete structures. The basics of corrosion protection for reinforced concrete structures are provided by many sources. Posttensioned concrete introduces several extra variables in corrosion protection, including additional hardware and grouting of the tendon ducts. Some general aspects of corrosion protection are briefly reviewed first. Corrosion of steel reinforcement or prestressing steel in concrete is a complex phenomenon influenced by many factors. For this reason, it is best to approach corrosion protection by providing several measures to guard against different influences and breakdowns or limitations in any single protective measure. This strategy is often referred to as providing multilevel corrosion protection. Corrosion protection in Prestressed concrete can take many forms. Four general categories of protection mechanisms are listed in Table 4.2 [West et al, 1999].

Table 4.1: Corrosion Protection Mechanisms and Methods

\begin{tabular}{|l|c|}
\hline \multicolumn{1}{|c|}{ Mechanism of Protection } & Protection Method \\
\hline Prevent chlorides from entering concrete & 1. Reduce permeability \\
& - Low w/c ratio \\
& - Use fly ash/silica fume/slag \\
& Eliminate voids (through \\
& compaction, reinforcement \\
& 2. Waterproof membranes \\
& 3. Surface polymer impregnation \\
& 4. Structural form \\
& 5. Structural detailing (drainage, anchorage \\
& 6. Crack width limitations \\
\hline
\end{tabular}




\begin{tabular}{|c|c|}
\hline Mechanism of Protection & Protection Method \\
\hline $\begin{array}{l}\text { Prevent chlorides from reaching steel (in the } \\
\text { event chlorides penetrate the concrete) }\end{array}$ & $\begin{array}{l}\text { 1. Increases cover } \\
\text { 2. Coated reinforcement \& tendons (epoxy } \\
\text { coated, copper clad, etc.) } \\
\text { 3. Encapsulated post-tensioning systems } \\
\text { 4. Plastic post-tensioning ducts } \\
\text { 5. Cement grout (bonded post-tensioning) } \\
\text { 6. Greases and waxes (unbonded post- } \\
\text { tensioning) }\end{array}$ \\
\hline Control corrosion reactions & $\begin{array}{l}\text { 1. Galvanized reinforcement/tendons } \\
\text { 2. Electrical isolation } \\
\text { 3. Corrosion inhibitors } \\
\text { 4. Cathodic protection }\end{array}$ \\
\hline Remove reactive substances (steel) & $\begin{array}{l}\text { 1. FRP reinforcement } \& \text { tendons } \\
\text { 2. Stainless steel reinforcement/tendons }\end{array}$ \\
\hline
\end{tabular}

During design and construction of the structure and through the life of the structure with proper maintenance attention requires for corrosion protection. Primary concern of design aspects of corrosion protection for Prestressed concrete structures are described here. Following are the durability design aspects of corrosion protection:

- Overall structural form

- Structural design details

- Corrosion protection provided by concrete

- Post-tensioning systems details

The concepts are similar to measures for conventional reinforced concrete structures though the first three categories are not unique to post-tensioned structures. The final category of corrosion protection measures involves aspects unique to post-tensioned concrete. A brief discussion of the first three categories is followed by a more in-depth look at corrosion related aspects of the post-tensioning system. Both bonded and unbonded post-tensioning systems are considered, although emphasis is placed on bonded post-tensioning [West et al, 1999]. 


\subsubsection{Structural Form}

Selection of the structural form may influence the corrosion and must be considered at the conceptual design stage. The layout and geometry of the structure determines which portions of the structure will be exposed to aggressive environmental conditions. In some cases, such as marine substructures, exposure to an aggressive environment is unavoidable. However, in other cases the structural form can have a large impact on durability. Because the most common cause of reinforcement corrosion is moisture-borne chlorides, whether as seawater or deicing chemicals, adequate drainage is a critical factor in the selection of structural form. Many design aspects that may influence corrosion and durability find out by examining the field performance of structures.

\subsubsection{Drainage}

In bridge superstructure and substructure component design, drainage should be considered. Adequate superstructure drainage must be provided and must ensure chloride-laden water does not come in contact with the substructure. If drains are provided, they must be located such that they can readily be inspected, maintained and repaired. Horizontal surfaces in the substructure should be avoided by sloping whether possible, as shown in Figure 4.1. Typical examples would include the top surface of bent caps and pile caps, and flanges of girders and inverted T-beams. Drainage and ventilation are important for box girders and hollow columns. Although the interior of these elements are not intended to be exposed to moisture, water accumulation can occur and lead to corrosion damage.

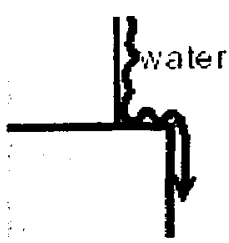

Poor

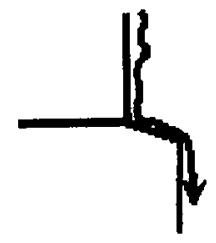

Better

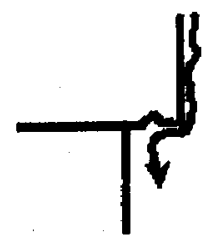

Better

Figure 4.1: Avoiding Horizontal Surfaces for drainage [West et al, 1999] 


\subsubsection{Joints}

Substructure corrosion problems in moisture and chlorides dripping onto substructure components through leaking deck joints are very common and shown in Figure 4.2. Corrosion damage can occur on bent caps and columns or piers. Sloping of the top surface of the bent cap, as shown in Figure 4.3 could reduce the severity of corrosion damage. Proper joint design and maintenance are better solutions when the severe conditions shown in Figure 4.2 are encountered. Another option is to reduce the number of expansion joints by making the bridge deck continuous for several spans.

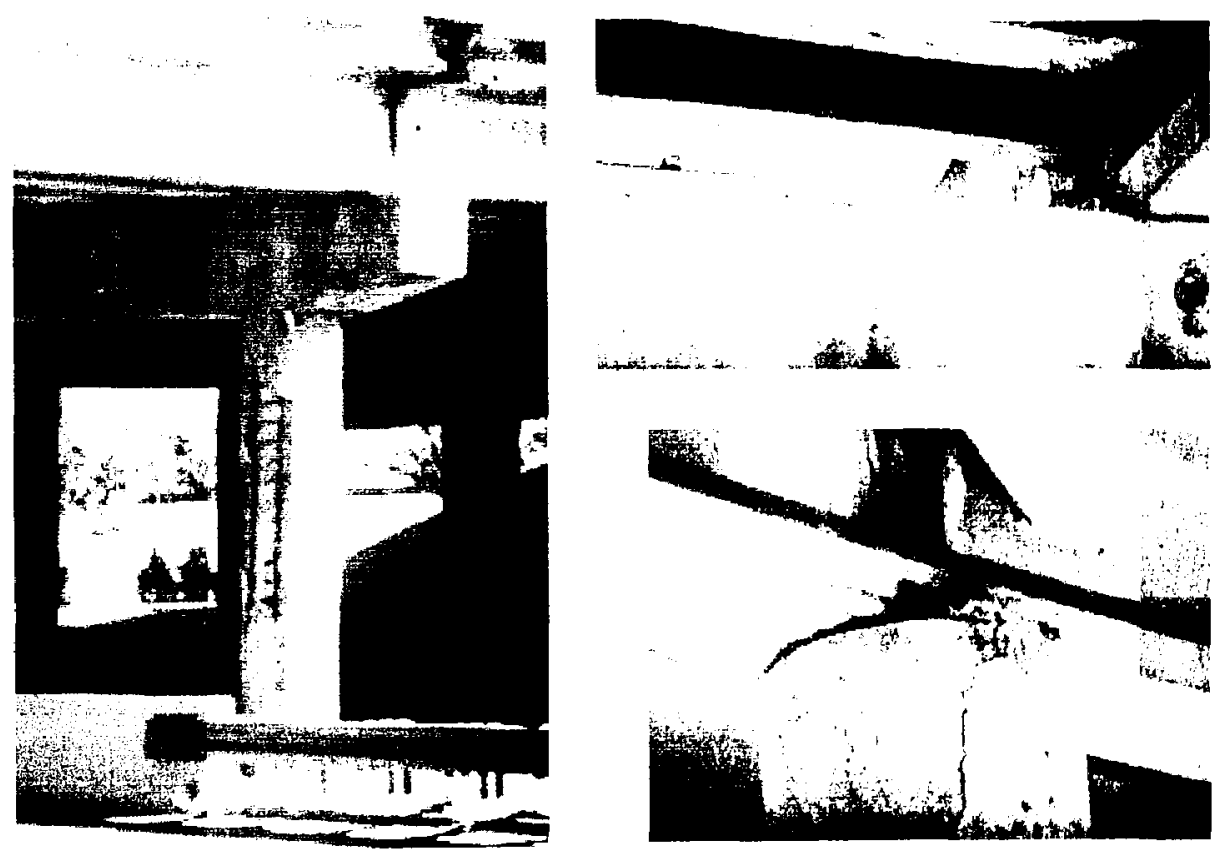

Figure 4.2: Severe Substructure Corrosion Damage Due to Defective Expansion Joint

[West et al, 1999]

\subsubsection{Splashing}

Due to splashing, substructure components adjacent to roadways where deicing chemicals are used can be prone to corrosion damage. Figure 4.4 shows a close-up of the bases of a column located very close to traffic. Splashing of chloride-laden moisture has caused extensive corrosion damage. Increasing the distance between the roadway and 
substructure may increase initial construction costs, but may reduce long-term costs by avoiding this type of corrosion damage.

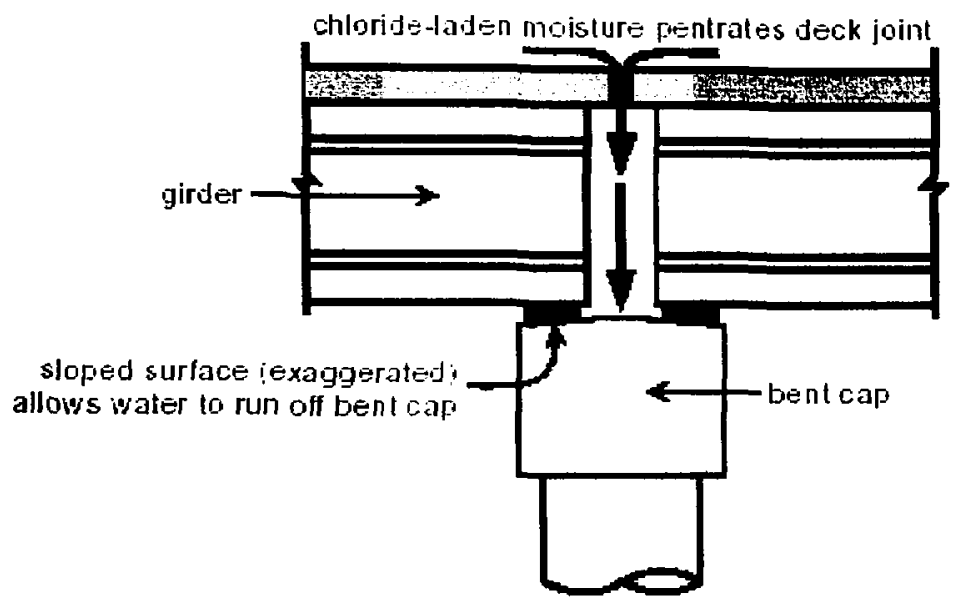

Figure 4.3: Sloped Bent Cap to Promote Run-Off [West et al, 1999]

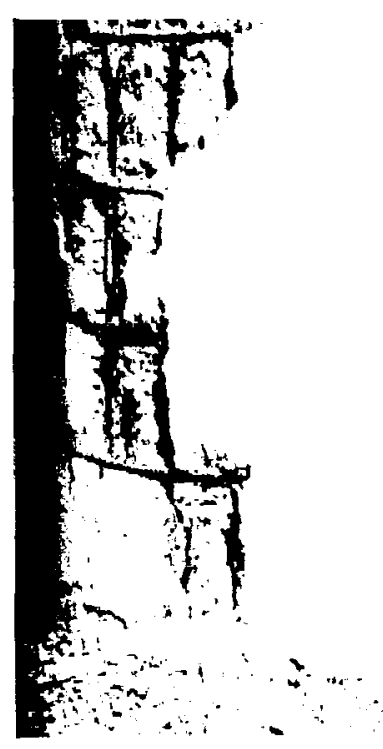

Figure 4.4: Column Corrosion Resulting for Splashing Adjacent to Roadway [West et al, 1999]

\subsubsection{Geometry}

Durability aspects can be influenced by the geometry of the structure. For example, consider the two substructures shows in Figure 4.5. Assuming the substructures are located in a marine saltwater environment, the single column/ pier substructure (A) offers 
a more durable alternative than the multi-column substructure (B). The surface area to volume ratio is decreased in the large single column. In addition, increased concrete cover is more easily accommodated and the potential for spalling is reduced.
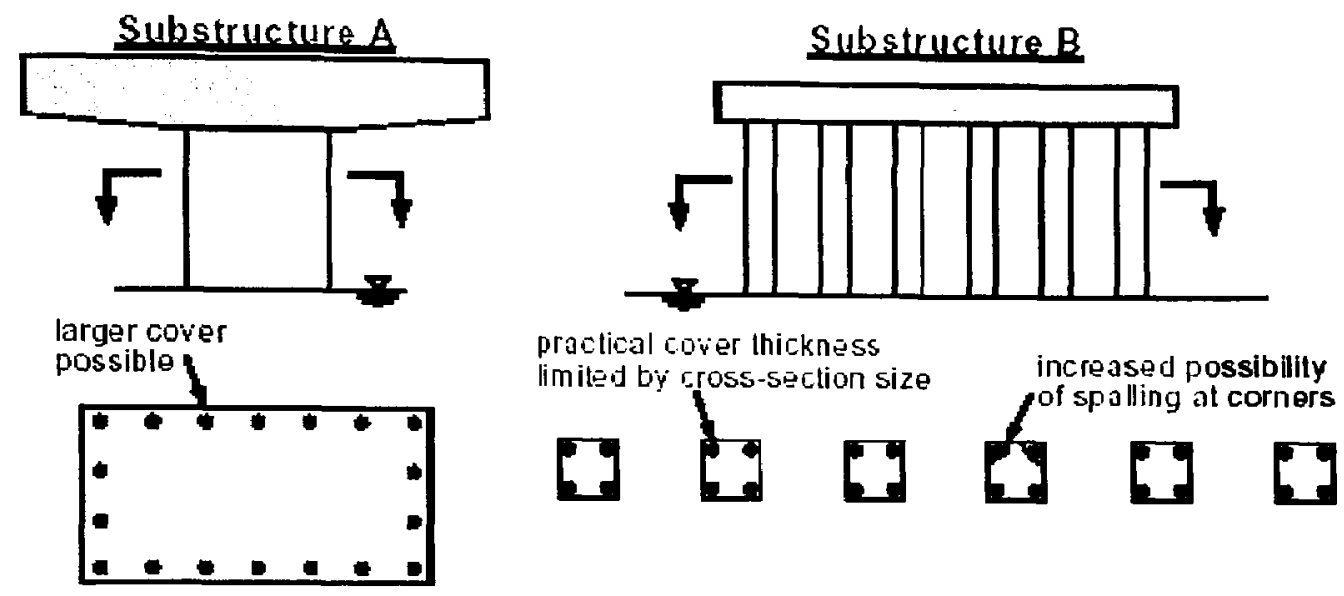

Figure 4.5: Geometry Effects on Durability for Alternate Substructure Designs [West et al, 1999]

\subsection{Structural Design Details}

The durability of the element and structure can also influence by the structural design details. These design aspects do not necessarily influence the structural behavior of the member, and therefore should not have a negative effect on the design. Most design details that affect durability are related to the constructibility of the structure. In general, the quality of construction and durability will increase if the structure is easier to build.

\subsubsection{Cracking}

Cracking in the concrete provides easy access for moisture and chlorides to reach the reinforcement. The significance of cracking on corrosion is often debated. Cracking should be avoided or minimized where possible. Attention must be paid to both intended cracking due to loading, and unintended cracking due to plastic shrinkage and settlement, drying shrinkage, thermal effects and differential settlement. Crack control under design 
loading is covered by most design codes. Guidance on control of other forms of cracking is provided in many references.

\subsubsection{Reinforcement Detailing}

Cracking and construction both are influenced by the reinforcement detailing. Congested reinforcement details make concrete placement difficult and can lead to poor compaction and voids. Complicated details also can lead to construction errors in the reinforcement and insufficient cover.

\subsection{Post-Tensioning Details}

Anchorage location of post-tensioning plays an important role in corrosion protection for the anchorages. The common location at member ends or ages often exposes the anchorage region to moisture and chlorides lead to severe anchorage corrosion damage. The location of post-tensioning anchorages is often dictated by the method of construction. In instances where the anchorage can not be located away from a possible source of aggressive agents, the anchorage must be detailed to provide multiple layers of corrosion protection.

Detail of the post-tensioning tendon profile must facilitate proper grouting. Provision must be made for appropriate vent locations. An optimum grout for post-tensioning combines desirable fresh properties with good corrosion protection. The fresh properties of the grout influence how well the grout fills the duct. The corrosion protection provided by the grout is rendered ineffective if the duct is only partially or intermittently filled with grout. These situations can lead to severe conditions for corrosion. The corrosion protection provided by the grout is also heavily dependent on the construction practices. Many corrosion problems have resulted from poor construction practices and inexperienced contractors. An optimized grout design is of no use if it is not placed properly and the ducts are not completely filled with grout. Attention must be given to 
batching and grouting/injection equipment, location of vents along the duct and grouting properties [West et al, 1999].

\subsubsection{Bonded Post-Tensioning System Details}

Multiple strand tendons and bonded prestressing bars are mostly used in bonded posttensioned concrete construction. Corrosion protection for the bonded post-tensioning system itself consists of several components including the duct, grout and anchorage protection. Coatings for the prestressing steel can also provide an additional layer of corrosion protection. Epoxy-coated and galvanized prestressing steels are both options in bonded post-tensioned systems. Aspects of the corrosion protection system for bonded post-tensioning are described herein.

\subsection{Post-Tensioning Tendon Materials Selection}

Material for prestressing tendons can be directed by both structural and durability concerns. This section describes some of the choices for prestressing tendon materials when corrosion is a concern.

The common forms of prestressing steel used in North America are high strength prestressing wire, seven-wire prestressing strand and high strength prestressing bars. The selection of prestressing wire, strand or bar for a particular application is dependent primarily on structural requirements and construction considerations rather than durability. The permissible materials and manufacturing process for prestressing steels used in North American structures are directed by standard specifications and code requirements such as AASHTO LRED Design and Construction Specifications, ACI 301 and $\mathrm{ACI} 318$. These specifications require prestressing strand, wire and bars to conform to ASTM standards A416, A421 and A722 respectively. In some countries, quenched and tempered steels have been used for prestressing. This manufacturing process can leave the steel more susceptible to stress corrosion cracking than cold drawn prestressing steels. The material requirements of AASHTO and ACI preclude the use of quenched and tempered steel for prestressing, and thus only cold drawn prestressing wire or hot-rolled 
bar are used in North America. Metallic and non-metallic coatings have been investigated as protection methods for mild steel reinforcement. The most common and widely used are epoxy coating and zinc galvanizing. Other coatings that have shown good results in laboratory testing include stainless steel-clad bars, copper-clad bars and zinc alloy-clad bars. Some coatings have been considered for prestressing steels. Suitable coatings for prestressing steel must possess several important properties that often make technology applied to mild steel reinforcement unusable. For example, the coating must not have an adverse effect on the strength or durability of the steel, must have sufficient flexibility and duclity to withstand stranding during manufacture and elongation during stressing without cracking or spalling. Coatings also should not have a detrimental effect on bond between the steel and concrete and should be able to withstand handling and placement without damage. Finally, the improvement in corrosion protection provided by the coating should not be at a prohibitive cost. At present, only epoxy coatings and zinc galvanizing have been successfully applied to prestressing steels. The development of advanced composite materials or fiber reinforced plastics has produced an additional choice in the selection of prestressing tendons. These materials are non-corroding but require special design considerations [West et al, 1999].

\subsubsection{Epoxy Coatings for Prestressing Steel}

Epoxy coating is an organic coating for corrosion protection that isolates the steel from contact with oxygen, moisture and chloride. Epoxy-coated seven-wire prestressing strand and threaded prestressing bars are widely available in the U.S.

\subsubsection{Epoxy-Coated Strand}

Available epoxy-coated strands are in two configurations: coated and filled. The two configurations are shown in Figure 4.6. In the coated configuration, a thick epoxy coating is provided around the exterior circumference of the seven-wire strand. In the coated and filled version, the interstices between the individual wires are filled with epoxy in addition to the external coating. By filling the interstices with epoxy, migration of 
moisture and chlorides along the strand interstices is prevented. Both configurations of epoxy-coated strand are available either with a smooth surface or with grit particles embedded on the surface to improve bond transfer characteristics. The smooth surface epoxy-coated strand is intended for use in applications where bond is not critical, such as unbonded post-tensioning system, external post-tensioning systems and stay cables. When used in unbonded systems, the strand must still be encased in a duct as the smooth epoxy coating is not a replacement for the sheathing used in monostrand post-tensioning systems. The grit impregnated epoxy-coated strand is intended for used in bonded posttensioning systems and in pretensioned applications. Epoxy-coated strand is available in conventional sizes of 10 to $16 \mathrm{~mm}$ diameter at Grade $1860(270 \mathrm{ksi})$. Details of installation and stressing procedures are provided in a PCI report on the use of epoxycoated strand.

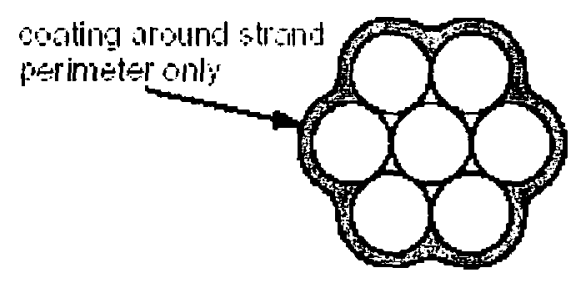

Coated Strand

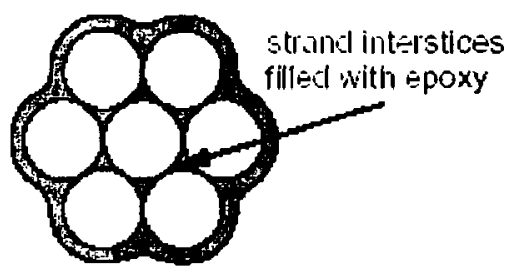

Caated and Filled Strand

Figure 4.6: Epoxy-Coated Strand for Pre and Post-tensioning System [West et al, 1999]

Epoxy-coated strand is manufactured to meet the requirements of ASTM A882-92. "Standard Specification for Epoxy-coated Seven-Wire Prestressing Steel Strand" and ASTM A416, "Standard Specification for Seven-Wire Prestressing Steel Strand". The physical properties of the epoxy coating used for prestressing strand are significantly different from those used to coat mild steel reinforcement. The epoxy coating developed for prestressing strand is very tough and ductile with good bond to the steel to withstand the elongation during stressing. The coating is also durable and abrasion resistant to minimize damage during handling, placement and stressing. The design final coating thickness for the strand is usually $0.76 \mathrm{~mm}$, although the thickness can range from 0.63 to $1.14 \mathrm{~mm}$ according to ASTM A882. This strand coating thickness is considerably thicker 
than the coating thickness for mild steel reinforcement. The coating is a thermo-setting, fusion-bonded epoxy applied in a continuous process to the bare strand. The manufacturing process starts with strand that meets ASTM A416. The strand is mechanically cleaned and then preheated to $300{ }^{\circ} \mathrm{C}$ prior to application of the coating. The strand is then run continuously through a fluidized bed of electrostatically charged epoxy particles. As the electrically grouted strand passes through the bed the charged particles are attracted to the surface of the strand. To manufacture the coated and filled strand the outer six wires are separated from the inner wire just prior to entering the fluidized bed. When the wires are re-stranded with the epoxy still in a plastic state the interstitial space between the wires is completely filled with epoxy.

The use of epoxy-coated strand in post-tensioning applications and stay cables requires the use of special wedges that bite through the epoxy coating and into the underlying strand. Concerns have been raised since the protective barrier of the epoxy is broken by the wedges at a very critical location. Experimental work has confirmed the occurrence of corrosion at locations where the wedge teeth were embedded in the steel. Corrosion was also found under the epoxy coating between the wedge teeth marks. The significance of corrosion at the wedge locations may vary. In bonded post-tensioned construction, corrosion at the wedge locations should not have a significant effect on the integrity of the structure, particularly if coated and filled strands are used. However, in unbonded post-tensioned applications or stay cables, anchorage failure due to corrosion at the wedge could lead to failure of the tendon or cable. In these situations, additional protection must be provided for the strand at the wedge locations [West et al, 1999].

\subsubsection{Epoxy-Coated Prestressing Bars}

Commonly used high strength threaded bars for post-tensioning may be specified with epoxy coating. Epoxy-coated threadbars are coated according to ASTM A775-97, "Standard Specification for Epoxy-coated Reinforcing Steel Bars. This standard is the same one used for epoxy-coated mild steel reinforcement. Anchorage hardware, including bearing plates, nuts and couplers are also epoxy-coated. Nuts and couplers are 
proportioned to allow free movement over threads without damaging the epoxy coating. The fusion-bonded epoxy coating process is similar to that for prestressing strand. The bars are first cleaned and preheated, then the epoxy powder is applied on the bars electrostatically. The final thickness of the epoxy coating ranges from 0.18 to $0.30 \mathrm{~mm}$. Epoxy-coated prestressing bars face similar issues in quality control as epoxy-coated mild steel reinforcement. The effectiveness of the corrosion protection provided by the epoxy coating is dependent on the quality of the coating and the amount of damage to the coating. Transportation and handling are common sources of coating damage. Padded building bands, frequent supports, and nonmetallic slings are required to prevent damage during transportation. Care must also be taken during placement and stressing of bars to minimize coating damage. Damaged coating can be repaired on-site using a two-part liquid epoxy. However, it is more desirable to adopt practices that prevent damage to the coating [West et al, 1999].

\subsubsection{Galvanized Prestressing Steel}

Most effective metallic coating for corrosion protection is zinc galvanizing. Zinc provides protection by sacrificially corroding in place of steel when exposed to a corrosive environment. Zinc is anodic to steel in the electromotive force (EMF) series and will corrode sacrificially to steel when there is electrical contact and a sufficiently conductive electolyte is present. The advantage of a sacrificial protection system is that it theoretically does not have to completely cover the protected part, and nicks and abrasions in the zinc should not permit corrosion of the underlying steel. Zinc is widely used to protect exposed steel from atmospheric corrosion. The effectiveness of zinccoated mild steel reinforcing bars in concrete has been uncertain. Galvanized bars were found to increase time to concrete cracking in some cases, while reducing time to cracking in others. A detailed discussion is provided I ACI 222-96. There are additional concerns when using zinc-coated steel, especially high strength steel, in contact with cement paste. In the high-alkaline environment of concrete or cement grout the corrosion rate of zinc can be very high. One product of zinc corrosion in this environment is 
hydrogen gas, raising concerns of hydrogen embrittlement of the high strength steel [West et al, 1999].

\subsubsection{Galvanized Prestressing Strand}

Galvanized prestressing strand is not commonly used in North America and is currently prohibited by the Federal Highway Administration for use in bridges. The use of galvanizing in prestressing applications and stay cables is very popular in Europe as well as Japan. In addition to concerns for increased risk of hydrogen embrittlement in galvanized strand, the galvanizing process may also affect the mechanical properties of the strand. Galvanizing of cold drawn wire for prestressing strand may reduce the tensile strength of the wire and degrade relaxation properties. The ultimate elongation of the wire may increase, and the elastic modulus of the seven-wire strand is normally decreased. Galvanized seven-wire strand suitable for prestressing applications is commercially available in standard size from 10 to $16 \mathrm{~mm}$ diameter and in standard grades. The strand is stress relieved and conforms to all the requirements of ASTM A416 except that the wires are galvanized. During the production process, the wires are zinc coated individually and then stranded. The minimum weight of zinc coating for the strand ranges from 275 to $305 \mathrm{~g} / \mathrm{m}^{2}$. The single wires before galvanizing meet the requirements of Grade 270 strand when fabricated to the corresponding finished strand size [West et al, 1999].

\subsubsection{Galvanized Prestressing Bars}

Galvanized prestressing bars are threaded and are commercially available in standard sizes and strengths of threadber for prestressing. Although prestressing bars are not cold drawn like prestressing wire, the process of zinc galvanizing still raises concerns for hydrogen embrittlement. A specification for galvanizing prestressing bars to minimize the effects of galvanizing on the potential for hydrogen embrittlement and on mechanical properties has been developed. The highest potential for damage due to hydrogen embrittlement occurs during acid pickling of the bars prior to hot-dip galvanizing. Flash 
pickling of the bars should be carefully controlled in terms of pickling time and acid temperature, and hydrogen inhibitors should be used in the acid bath. The bars should be galvanized immediately after pickling. The maximum weight of zinc coating is $250 \mathrm{~g} / \mathrm{m}^{2}$. Provisions for maintaining the threadability of the bars after coating should also be considered [West et al, 1999].

\subsubsection{Non-Metallic Prestressing Materials}

Fiber reinforced plastic (FRP) products have been used for pretensioning and posttensioning in bridges, buildings, marine structures, pavements and rock anchors. The use of fiber reinforced plastic reinforcement in concrete structures can have many benefits. In most application, the main benefit of using fiber reinforced plastics is that they do not corrode and therefore eliminate structural deterioration related to corrosion of steel reinforcement. Fiber reinforced products normally consist of continuous fibers of glass, aramid or carbon embedded in a polymer matrix. The matrix transfers stresses between the fibers and allows them to work as a single element. The matrix also provides stress transfer between the fibers and concrete and protects the fibers. Common matrix materials are polyesters and epoxies. The material properties of fiber reinforced plastic tendons for prestressing can be significantly different from prestressing steel, and thus their use requires special design considerations. An excellent source of information on this subject is ACI 440R-96, State-of-the Art report on Fiber Reinforced Plastic reinforcement for Concrete Structures [West et al, 1999].

\subsection{Ducts for Post-Tensioning}

In post-tesioned concrete, ducts have several functions. The duct provides the void to allow placement and stressing of the tendons after concrete has been cast, and transfers stresses between the grouted tendon and the concrete. As corrosion protection, the duct works as a barrier to moisture and chlorides. In order for the duct to work effectively as a barrier, it must be impervious to moisture and must itself be corrosion resistant. Duct splices and connections to anchor hardware must also be watertight. 


\subsubsection{Galvanized Steel Duct}

Widely used duct material is corrugated galvanized steel. The steel is sufficiently strong to prevent crushing and damage during concrete placement, and can withstand the fractional forces associated with post-tensioning. Galvanizing provides some resistance to duct corrosion. However, research studies and field performance have found that the corrosion protection provided by galvanizing is limited and severe corrosion damage, including corrosion through the duct, can occur in marine or deicing salt exposures. Some galvanized steel ducts are manufactured with a longitudinal crimped seam. The crimped seam may not be watertight, allowing moisture ingress even if the steel duct is undamaged. Grout bleed water observed leaking from ducts with longitudinal seams has confirmed the potential moisture pathway in ducts manufactured in this manner. Splices for galvanized steel ducts are performed in many different ways. Common practice is to wrap the joint between ducts with ordinary duct tape. Sometimes a short length of oversized duct is used to span the joint between duct segments to maintain alignment. Heat shrink tubing developed for sealing electrical connections has also been used for duct splicing [West et al, 1999].

\subsubsection{Epoxy-Coated Duct}

Several problems associated with galvanized steel duct are not with epoxy-coated steel duct. The epoxy coating protects the duct from corrosion and seals the longitudinal duct seams. A laboratory study showed excellent performance of epoxy-coated ducts in comparison to galvanized steel ducts. Performance was evaluated in terms of grout chloride levels and extent of duct and strand corrosion damage. Epoxy-coated ducts are not widely used and may be faced with some shortcomings similar to epoxy-coated reinforcement, the quality of the epoxy coating and level of coating damage will influence the effectiveness of the coating as corrosion protection [West et al, 1999]. 


\subsubsection{Plastic Duct}

The highest level of corrosion protection can provide the use of plastic duct systems for post-tensioning tendons since they are non-corroding and provide an impermeable barrier to aggressive agents. Plastic ducts have been developed with sufficient strength, rigidity, abrasion resistance and bond properties to satisfy structural requirements. Testing has also shown lower friction losses and reduced fretting fatigue for plastic duct systems in comparison to steel ducts. Commercially available plastic ducts for post-tensioning are normally provided with fitted watertight couples for duct splices and connection to anchorage hardware. Plastic ducts made from polypropylene are available in a two-strand system for slabs, and in multistrand systems for tendon configurations of up to fifty-five $12.7 \mathrm{~mm}(0.5 \mathrm{in}$.) diameter strands or up to thirty-seven $16 \mathrm{~mm}(0.6 \mathrm{in}$.) diameter strands [West et al, 1999].

\subsection{Temporary Corrosion Protection}

The time between stressing and grouting of internal tendons should be as short as possible to minimize the opportunity for corrosion while the tendons are unprotected. Many specifications limit the length of time between stressing and grouting. The AASHTO LRED Construction Specifications provides time limits for grouting ranging between seven days and twenty days, dependent on the ambient humidity. The PTI Guide Specification for Grouting has a similar requirement, with time limits for grouting ranging between seven days and forty days. If the permissible time limits between stressing and grouting are exceeded, temporary corrosion protection measures are required by both specifications. A range of temporary protection measures are available. The most common form of temporary corrosion protection is to coat the prestressing steel with water soluble oils or vapor phase inhibitors. Other materials, including sodium silicate and biodegradable soap have been used for temporary corrosion protection. The duct must be thoroughly flushed with water immediately prior to grouting to remove all traces of the temporary corrosion protection materials that may inhibit bond between the steel and grout. With the exception of the vapor phase inhibitor, these materials can have 
the added benefit of reducing friction losses during post-tensioning if they are applied on the strands before stressing. Other options for temporary corrosion protection include sealing the ducts to prevent moisture entry, continuous pumping of dry air through the ducts and purging with compressed air or dry gas. A comprehensive study of materials for temporary corrosion protection and lubrication of post-tensioning tendons found that water soluble oils could not be flushed from the strands completely and adversely affected bond between the strand and grout. Adhesion tests found that bond was reduced by $90 \%$ if the ducts were not flushed. When the ducts were thoroughly flushed with water, bond was still reduced by $75 \%$ in comparison to untreated strands. The effect of sodium silicate on bond was not as significant as the water soluble oils, reducing bond by $50 \%$ before flushing and $10 \%$ after flushing. Stearate soap did not affect bond. These findings illustrate the potential negative side effect of many agents used for temporary corrosion protection. The use of water soluble oils for temporary corrosion protection should be avoided if the tendons are to be bonded [Smith et al, 2000].

\subsection{Cement Grout for Post-Tensioning}

Cement grout bonds the post-tensioning tendon to the surrounding concrete and provides corrosion protection for the tendon. Corrosion protection is in the form of a barrier to moisture and chloride penetration and in the presence of an alkaline environment for the tendon. An optimum grout for post-tensioning combines desirable fresh properties with good corrosion protection. The fresh properties of the grout influence how well the grout fills the duct. The corrosion protection provided by the grout is rendered ineffective if the duct is only partially or intermittently filled with grout. These situations can lead to severe conditions for corrosion. The presence of voids or discontinuous grouting may also permit movement of moisture and chlorides along the length of the tendon. Important grout fresh properties are listed below:

1. Fluidity: Fluidity is a measure of how well the grout flows or pumps. Insufficient fluidity may lead to difficulties in placement, blockages and incomplete grouting. Excessive fluidity may lead to avoid formation near 
crests in draped tendon profiles and incomplete grouting. Grout fluidity also influences the ability of the grout to fill the space between strands in a multistrand tendon.

2. Bleed Resistance: Resistance to bleed is very important in grouts for posttensioning. Unlike concrete where bleed water can evaporate, bleed water in grouted ducts tends to migrate to high points in the duct, forming bleed lenses. Eventually, the bleed water will be re-absorbed into the grout, leaving a void. Bleed lenses are particularly a problem where large vertical differences are encountered along the tendon profile.

3. Volume Change: reduction in volume or shrinkage in the plastic state can lead to voids and must be avoided. In some cases, it may be desirable for the grout to possess expansive properties while in the plastic state to offset shrinkage and possibly fill voids resulting from entrapped air or bleed water collection.

4. Set Time: Rapid setting grouts lead to insufficient fluidity, hindering placement and leading to incomplete grouting.

The fresh properties of grout can be controlled through water-cement ratio, by the use of chemical and mineral admixtures, and by the type of cement. Without the use of admixtures, fluidity is primarily a function of the water-cement ratio. In most cases, it will be desirable to reduce the water content to lower permeability and minimize bleed water. In this situation, sufficient fluidity can be provided through the use of superplasticizer. Partial cement replacement with fly ash will tend to increase fluidity for the same ratio of water to total cementitious material. The addition of silica fume or partial cement replacement with silica fume tends to decrease fluidity due to its small particle size. Bleed can be minimized by reducing the water-cement ratio and by using fly ash or silica fume. Antibleed admixtures may also be used, particularly in situations where the tendon profile has large variations in vertical distance and bleed water accumulation may be severe. Antibleed admixtures are sometimes referred to as thixotropic admixtures. This class of admixture gives the grout gel-like properties to minimize bleeding, while permitting the grout to become fluid when agitated (mixed, pumped, etc.). Expansive properties may be provided through the use of chemical 
admixtures. Expanding or non-shrink admixtures are generally categorized as gasliberating, metal oxidizing, gypsum forming or expansive cement based. Set time is normally controlled through the use of set retarding admixtures. Some control may also be available through the selection of cement type [Smith et al, 2000].

The corrosion protection provided by the grout is primarily related to its permeability. Low permeability will reduce or slow the ingress of moisture and chlorides. Similar to concrete, the permeability of grouts may be lowered by reducing the water-cement ratio and by the use of mineral admixtures. 'Schokker' performed an extensive research study to develop two optimized grouts for post-tensioning. The study was part of this overall research project. The first grout was developed for use in applications where the tendon profile was primarily horizontal. The grout contained $30 \%$ fly ash, superplasticizer and had a water-cement ratio of 0.35 . This grout had excellent fluidity, good bleed resistance and provided excellent corrosion protection. The second grout was recommended for vertical tendons where resistance to bleed is critical. This grout had a water-cement ratio of 0.33 and contained a combined superplasticizer and antibleed admixture. Additional information on mix proportioning and guide specifications for grouts for post-tensioning is provided by the PTI "Guide Specification for Grouting of Post-Tensioned Structures" and by the U.K. Concrete Society Report "Durable Bonded Post-Tensioned Bridges" [Smith et al, 2000].

\subsection{Anchorage Protection}

Anchorages and end stubs of the post-tensioning strands must be carefully protected. Although anchorage corrosion may lead to failure of the anchorage, bond between the tendon and concrete will prevent a complete loss of prestress. However, corrosion of the anchorage hardware may lead to cracking and spalling of the concrete in the vicinity of the anchorage and increased corrosion action. Corrosion of the anchorage and strand stubs may also allow moisture entry into the duct and subsequent tendon corrosion. Multistrand anchorage systems may be fitted with a sealed end cap to protect strand ends. The cap is grouted or filled with corrosion inhibiting grease. Not all multistrand post- 
tensioning systems include an end cap. Anchorages are commonly recessed in a pocket at the end or edge of the concrete element. Corrosion protection for the anchorage normally consists of filling the anchorage recess or pocket with mortar or concrete. Common practice is to coat the anchorage and pocket surfaces with an epoxy-bonding agent prior to filling the anchorage pocket with a non-shrink mortar.

Anchorage location within the structure can also play a role in corrosion protection and corrosion damage. In many structures, the anchorages are located at the ends of structural elements below expansion joints, or at exterior member ends or slab edges. These locations are prone to concentrated exposure with moisture and chlorides, and often lead to severe anchorage corrosion damage. The location of post-tensioning anchorages is often dictated by the method of construction. In instances where the anchorage cannot be located away from a possible source of aggressive agents, the anchorage must be detailed to provide multiple layers of corrosion protection. The Concrete Society (U.K.) Technical Report No. 47 on bonded post-tensioned bridges provides suggestions for anchorage protection details. The report discusses two approaches for anchorage protection. The first is to provide an anchorage that is not encased in mortar or concrete after stressing. Exposed anchorage hardware is protected by end caps and waterproof membrane, and has the advantage that the anchorage can be readily inspected for corrosion damage. The second approach provides a higher level of corrosion protection at the expense of inspectability by recessing the anchorage in a filled pocket. Details of multilevel corrosion protection for this form of buried anchorage are shown in Figure 4.7. The details of the member end can also be designed to minimize contact with moisture and chlorides draining through expansion joints as shown in Figure 4.8. The member end is detailed to prevent water from dripping onto the anchorage region. An abutment gallery is provided to allow inspectors to gain access to the anchorage [West et al, 1999, Smith et al, 2000]. 


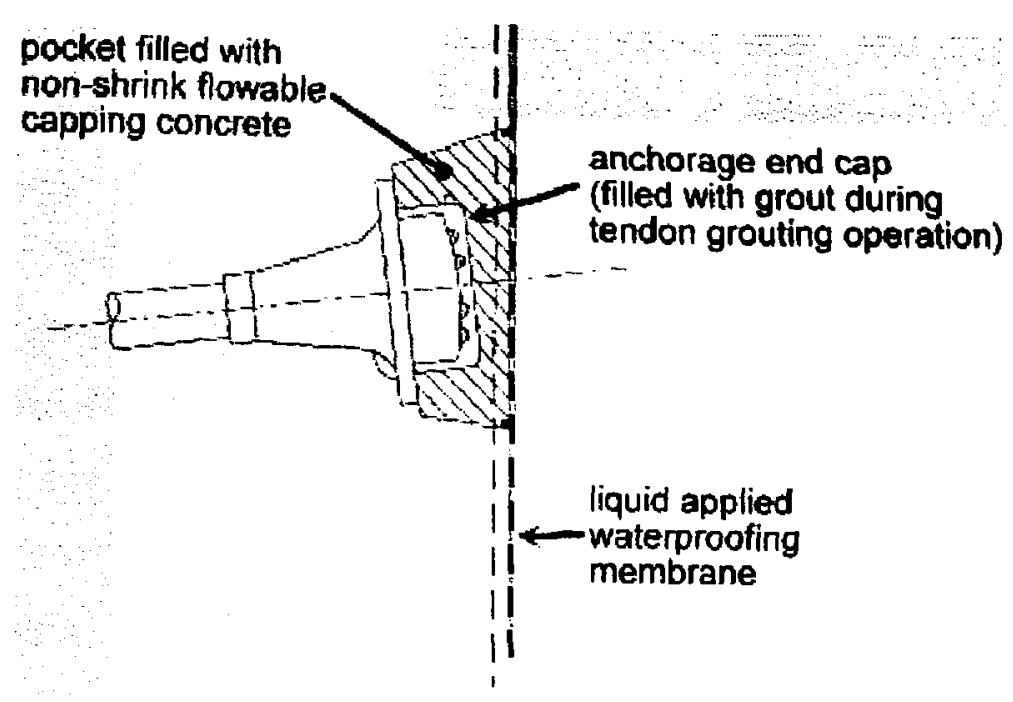

Figure 4.7: Multi-Layer Corrosion Protection for Buried Post-Tensioning Anchorages [West et al, 1999]

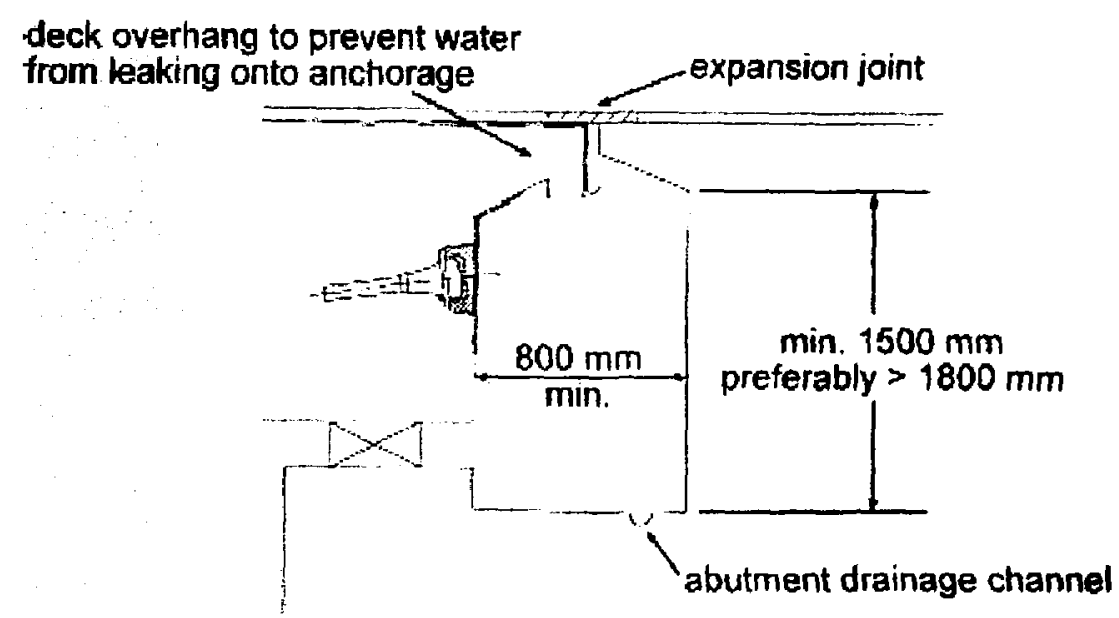

Figure 4.8: Member End Details for Anchorage Corrosion Protection [West et al, 1999]

\subsection{Encapsulated and Electrically Isolated Systems}

Highest level of corrosion protection can be provided by the encapsulated and electrically isolated multistrand post-tensioning systems. Encapsulation and electrical isolation are terms that are sometimes used interchangeably. However, it is important to note that encapsulated systems are not necessarily electrically isolated. Normally, encapsulation 
refers to encapsulation if the post-tensioning tendon only, and not necessarily the anchorage. Encapsulation of the tendon is provided by an impermeable duct, full grouting and sealed end cap over the strand or bar stubs. Complete encapsulation and electrical isolation includes coating of the anchorage or use of non-metallic anchorage components. Ideally, this approach provides an impermeable barrier around the entire post-tensioning system, protecting the system from aggressive agents and corrosion induced by stray currents or coupling with uncoated mild steel reinforcement. The use of encapsulated, watertight post-tensioning systems also allows the system to be testes for leaks. Pressure testing is performed immediately prior to grouting with all vents closed and end caps sealed. The duct is pressurized with air and the leakage rate is monitored using a flowmeter. Sources of leaks can be identified using soapy water or other means. Significant sources of leaks should be repaired as applicable, including re-sealing of end caps, grouting or patching and crack sealing. The use of a watertight and airtight duct system also permits vacuum grouting. Vacuum grouting applies a negative pressure at one end of the duct while the grout is pumped under pressure from the opposite end. Vacuum grouting is particularly useful for long tendons or where large vertical distances are involved. An encapsulated multistrand post-tensioning system is available in three configurations, each providing an increased level of corrosion protection. All ducts, connections and trumpets are plastic. The bearing plate is a composite of metal and high performance mortar, and a sealed end cap is provided. The highest level of protection is provided by a configuration that provides electrical isolation for the tendon, and the ability to electrically monitor the tendon throughout the life of the structure [West et al, 1999].

\subsection{Unbonded Post-Tensioning System Details}

Unbonded multiple strand or bar systems that may be used for corrosion protection for post-tensioning systems in bridge substructures. Unbonded single strand or monostrand systems are not discussed here. Guide specifications for monostrand systems are provided by the Post-tensioning Institute (PTI). These comprehensive guide specifications include requirements for sheathing materials and corrosion preventive coating (grease). ACI 
Committee 423 (Prestressed Concrete) is currently in the process of producing a detailed specification for monostrand tendons that will supercede the PTI specifications for monostrand tendons [West et al, 1999].

\subsection{Embedded Post-Tensioning}

Unbonded multistrand post-tensioning systems and unbonded post-tensioned bar systems are available although these are not widely used in bonded post-tensioned construction. Unbonded post-tensioning may be selected for various applications and structural design criteria. Common applications include flat slabs and foundations, joining precast concrete elements, precompression of bearings and structures that are to be later disassembled. Multilevel corrosion protection in unbonded multistrand and post-tensioned bar systems is similar to bonded systems with the exception of the cement grout. Corrosion protection options include plastic or non-corroding ducts and epoxy-coated or galvanized strands or bars. Some multistrand systems may be fitted with greased and sheathed strands normally used in monostrand systems. Amchorage protection for unbonded systems is the same as for bonded post-tensioning.

\subsection{External Post-Tensioning}

To strengthening of structures including precast segmental bridge construction, external post-tensioning are widely used. Stay cables (the prestressed cables in the bridges are spaced closely which transfer the loads to the foundation via the pylon) may also be considered in this category. External post-tensioning tendons are not embedded in the concrete, but rather are bonded to the structure at discrete locations including anchorages and deviators. Several options are available to provide multilevel corrosion protection for external tendons. Most external multistrand tendons are encased in a sheath, as shown in Figure 4.9. The steel or plastic sheath provides an exterior protective barrier around the tendon. Similar to considerations for post-tensioning ducts, the use of a plastic or other non-corroding material for sheathing provides the highest level of corrosion protection. Strands or bars used for external tendons may be epoxy-coated or galvanized. Greased 
and sheathed strands (as used in monostrand systems) are also commonly used for external multistrand tendons. The space between the strands or bars inside the outer sheathing can be filled with cement grout, grease or wax to provide additional corrosion protection. Grout properties should meet similar requirements as grouts used in bonded post-tensioned construction. Greased or waxes should be similar to those used for greased and sheathed monostrand tendons [J. S. West, et al. 1999].

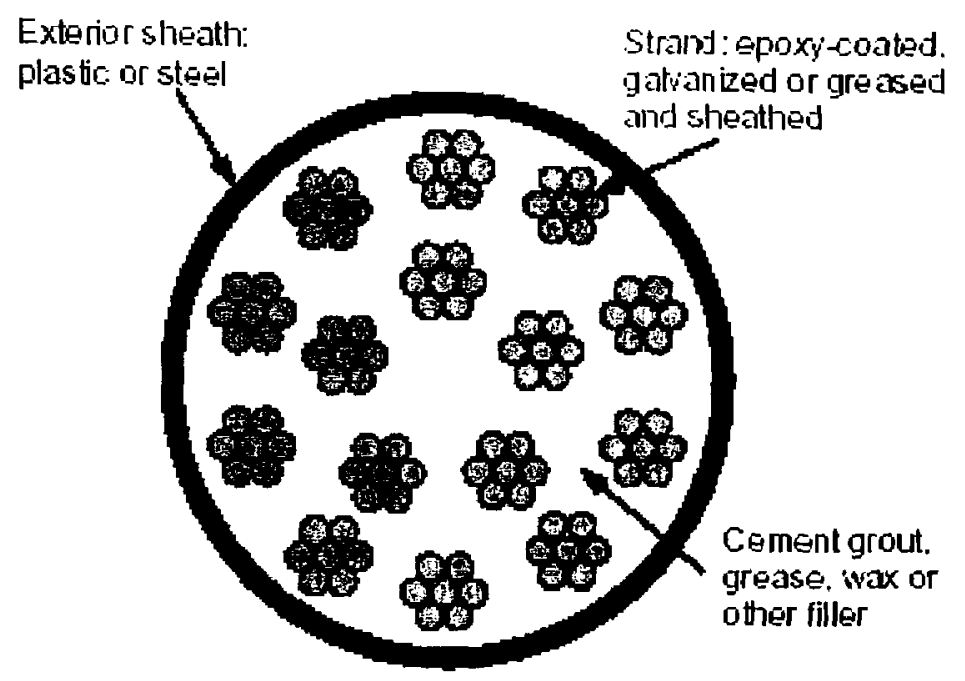

Figure 4.9: External Post-Tensioning Tendon Corrosion Protection [West, et al. 1999]

\subsection{Corrosion Inhibitors as Corrosion Protection}

Chemical admixtures as corrosion inhibitors are added to Portland cement concrete mixes during batching usually in very small concentrations as a corrosion protection measure. Corrosion inhibitors are a variable corrosion protection measure for the long-term durability of both conventionally reinforced and prestressed concrete bridge structures. When used as part of a multiple strategy corrosion protection system, they delay the corrosion reaction of reinforcing and prestressing steel corrosion. Inhibitors are often used in combination with low-permeability concrete and usually they have the effect of increasing the threshold chloride concentration needed to initiate corrosion. Inhibitors play an important role in protecting uncoated high-strength steel strands used in prestressed concrete bridge members and stays used in cable-stayed bridges. They are 
also used in cementitious grouts for filling the ducts of bonded post-tensioned bridges. Inhibitors may also reduce the subsequent corrosion rate after the initiation of corrosion, which ultimately leads to less corrosion-induced concrete deterioration. There are three major concerns regarding the use of corrosion inhibitors. The first one is the long-term stability and performance of the inhibitor. The second is the inhibitor's effect on corrosion propagation after corrosion initiation. The third is the inhibitor's effect on the concrete's physical properties over the service life of the structure.

In order for a corrosion inhibitor to be an effective long-term corrosion-protection measure, it needs to be able to maintain long-term stability. It should be chemically intact and physically present (not leaching or evaporating) to retain its effectiveness. Inhibitors may have an effect on the corrosion process after corrosion initiation. An insufficient dosage will have a negative impact on corrosion progression. Some inhibitors will have an effect on chloride transport and can reduce the rate of chloride ion migration. Inhibitors should not have any negative effects on the concrete properties. The use of an inhibitor should not cause an undue increase in the amount of any concrete cracking. Some inhibitors decrease the concrete resistivity, which has a tendency to increase the corrosion rate. This effect is offset due to the inhibition provided by a suitable corrosion inhibitor. Corrosion inhibitors are either inorganic or organic and, in general are classified based on their protection mechanism. They can protect by affecting the anodic reaction, the cathodic reaction, or both reactions (mixed). An active type of inhibitor (anodic) facilitates the formation of an oxide film on the surface of the steel reinforcing bars. Passive systems protect by reducing the rate of chloride ion migration. Calcium nitrate is an inorganic inhibitor. It protects the steel reinforcing bars through oxidationreduction reactions at the steel surface. Organic inhibitor consists primarily of amines and esters. They form a protective film on the surface of steel reinforcing bars and sometimes delay the arrival of chloride ions at the steel reinforcing bars [Smith et al, 2000].

There are four major commercially available corrosion inhibitors:

- DCI (Darex Corrosion Inhibitor) and DCI-S. 
- Rheocrete 222 and Rheocrete $222^{+}$.

- Armatec 2000, Ferrogard 901, and MCI 2000.

- Catexol $1000 \mathrm{Cl}$.

\subsubsection{DCI (Darex Corrosion Inhibitor) and DCI-S}

DCI (Calcium nitrite) is an organic corrosion inhibiting concrete admixture. It has been commercially available since 1978 and up to now it was only marketed by W. R. Grace and Company. Recently, master Builders, Inc. also started marketing a calcium nitrite inhibitor similar to DCI. DCI has approximately a 30-percent concentration of calcium nitrite. DCI-S is the same as DCI, but also includes a set retarder. When silica fume is used in combination with calcium nitrite, the silica fume reduces the rate of chloride ion penetration (migration) and the calcium nitrite increases the threshold for corrosion inhibition. Calcium nitrite reduces the resistivity values of concrete, but the addition of silica fume offsets this reduction and, in fact, there is a net gain in resistivity. DCI is an anodic type of inhibitor (active) and functions by passivating the anode. The oxidationreduction protection mechanism is electro-chemical in nature and, as a result, its effectiveness is understandable and quantitatively measurable. The chloride and nitrite ions are involved in simultaneous, complicated, competing reactions at the surface of the steel reinforcing bars: corrosion vs. passivation. Chloride ions accelerate corrosion through the formation of $\mathrm{Fe}^{++}$ions. Nitrite ions inhibit corrosion through the formation of passive iron oxide $\left(\mathrm{Fe}_{2} \mathrm{O}_{3}\right)$.

Calcium nitrite inhibits or interferes with the removal of $\mathrm{Fe}^{++}$ions through the following reactions:

$$
2 \mathrm{Fe}^{++}+2 \mathrm{OH}^{-}+2 \mathrm{NO}_{2}^{-} \rightarrow 2 \mathrm{ON}+\mathrm{Fe}_{2} \mathrm{O}_{3}+\mathrm{H}_{2} \mathrm{O}
$$

The relative rates of the two processes (corrosion and passivation) are known. This prevents further corrosion. However, nitrite ions are reduced to nitric oxide gas. This reduces the nitrite concentration in the concrete in the immediate vicinity of the 
reinforcing steel. As the chloride ion content increases, the ability to maintain passivity is reduced (with a constant amount of nitrite). DCI appears to be primarily effective because it does not allow the development of large electrical potentials betweens areas that otherwise would be anodic and cathodic adjacent steel areas in the top mat of reinforcing steel bars and between top and bottom mats of reinforcing steel bars in a bridge deck. Electrical potentials are maintained at similar values that are also at or near the passive range. Large electrical potential between otherwise anodic and cathodic areas allows the flow of a corrosion current and subsequent dissolution of iron in the top mat. The relative concentrations of nitrite and chloride ions are important. For a low $\mathrm{Cl}^{-} / \mathrm{NO}_{2}^{-}$ratio (less than 1), the potentially anodic rebar is passivated. For a high $\mathrm{Cl}^{-} / \mathrm{NO}_{2}^{-}$ratio, the eventual corrosion of the steel reinforcing bar is certain.

The amount of calcium nitrite that should be added to the concrete during mixing depends on expected chloride ion concentration at the rebar for the desired corrosion-free service life. There is no significant benefit in using calcium nitrite as an inhibitor for $\mathrm{Cl}^{-}$ $\mathrm{NO}_{2}{ }^{-}$ratios grater than 1 . Therefore, the recommended dosages is that which will yield a $\mathrm{Cl}^{-} / \mathrm{NO}_{2}{ }^{-}$ratio at the rebar level that is less than or equal to 1 during the service life of the structure. This conclusion is based on research where the chloride ions were mixed into the fresh concrete along with $\mathrm{DCl}$, which is not the normal practice in the field. Therefore, the inhibitor has a better chance of performing when chloride ions diffuse through the concrete. With time, the chloride ion level is the expected accumulative content at the surface of the reinforcing steel bars due to deicer applications or marine exposure. Long-term stability is an issue as the inhibitor is not needed until a sufficient amount of chloride ions reach the steel and corrosion is initiated. Recommended dosage rates for different expected chloride ion contents for a corrosion-free service life are shown in table 2 [Smith et al, 2000]. 
Table 4.2: Calcium nitrite dosage rates [Smith et al, 2000].

\begin{tabular}{|c|c|}
\hline $\begin{array}{c}\text { Calcium Nitrite } \\
\left(\mathbf{L} / \mathbf{m}^{\mathbf{3}}\right)\end{array}$ & $\begin{array}{c}\text { Chloride Ion Content } \\
\left(\mathbf{K g} / \mathbf{m}^{\mathbf{3}}\right)\end{array}$ \\
\hline 10 & 3.6 \\
\hline 15 & 5.9 \\
\hline 20 & 7.7 \\
\hline 25 & 8.9 \\
\hline 30 & 9.5 \\
\hline
\end{tabular}

\subsubsection{Rheocrete 222 and Rheocrete $222^{+}$}

An organic corrosion-inhibiting concrete admixture is Rheocrete $222^{+}$. It is manufactured and marketed by Master Builders, Inc. It is an improved formulation of Rheocrete 222 and contains amines and esters in a water medium. Rheocrete 222 is a combination inhibitor, both anodic and cathodic passive-active mixed type). It protects the steel reinforcing bars in two ways: First, it forms a corrosion-resistant organic film that is adsorbed on the steel surface. Secondly, it also coats the pores of the concrete matrix, which slows the migration of chloride ions. Both Rheocrete 222 and Rheocrete $222^{+}$have not been available for a very long time, compared to calcium nitrite. As a result, there is less published data on their performance. Rheocrete 222 has been used in a number of parking garages, and in a few bridges and marine structures. The recommended dosage rate is $5 \mathrm{~L} / \mathrm{m}^{3}$. It is typically added to the concrete batch water. The dosage rate is not adjusted for the anticipated corrosiveness of the expected service environment [Smith et al, 2000].

\subsubsection{Armatec 2000, Ferrogard 901, and MCI 2000}

These inhibitors are a blend of surfactants and amine salts [specifically dimethylethanolamine (DMEA), also referred to as alkanolamines or amino-alcohols (AMA)] in a water medium. Armatec 2000 and MCI 2000 are manufactured and 
marketed by Cortec Corporation. Armatec is reported to have a slightly different formulation from MCI. Ferrogard 901 is manufactured and marketed by Sika Corporation. According to the manufacturers, they protect the steel reinforcing bars by forming a continuous mono-molecular film on the steel surface and they cover both the anodic and cathodic sites (mixed type). This film consists of an adsorbed layer of aminoalcohol that leads to the formation of insoluble iron oxide complexes. These stabilize the oxide surface and inhibit further corrosion. The film is typically $10^{-8} \mathrm{~m}$ thick and also acts as a barrier to aggressive ions migrating through the concrete. It has been reported that incoming chloride ions on the steel surface can be displaced by amino alcohols. The recommended dosage rate for Ferrogard 901 is $10 \mathrm{~L} / \mathrm{m}^{3}$. The dosage is not adjusted for the corrosiveness of the anticipated service environment [Smith et al, 2000].

\subsubsection{Catexol $1000 \mathrm{Cl}$}

This inhibitor is a water-based formulation of amine derivatives. Catexol $1000 \mathrm{Cl}$ is manufactured and marketed by the Axim Concrete Technologies, Inc. the manufacture claims that protection is provided by formation of a protective barrier. This barrier reportedly stabilizes the passive iron oxide layer. This inhibitor appears to exhibit the characteristics of an organic film-forming inhibitor, as well as those of a nitrite-based inhibitor [Smith et al, 2000]. 


\section{CHAPTER 5}

\section{CORROSION PREVENTION AND REPAIR}

\subsection{Common Methods for Corrosion Prevention and Repair}

Repair or prevention techniques will be needed to mitigate the effects of corrosion when the corrosion in a structure is or is expected to be substantial. There are many techniques both physical and electrochemical to delay initial or to slow existing corrosion activity. Similarly, there are various approaches to repair corrosion damage.

\subsection{Repair Measures}

Application of surface coating or sealer is one of the repair methods that is intended to create a barrier to the incoming contaminated water, which might be protects corrosion of its reactants. Though sealers are used, still there is some question about the reliability of waterproofing using these treatments. On the other way, the use of corrosion inhibitors has gained interest as a means of corrosion protection. Use of epoxy coated reinforcement and galvanized reinforcement are widely used techniques for corrosion prevention. Fusion-bonded epoxy is intended to prevent corrosive elements from reaching the steel surface provided there is no damage of epoxy layer during transport or installation. If so, epoxy coatings are effective for corrosion prevention. There are two ways of corrosion protection by galvanized reinforcement. Zinc galvanized layer on the steel surface acts as a barrier to chlorides. The zinc coating keep remains $\mathrm{pH}$ values around 9.5 , which is much lower than the threshold for unprotected steel. Galvanized reinforcement is most effective for low or moderate chloride exposure. Some practical corrosion prevention methods are reduction of concrete permeability and pore water through the addition of chemical admixture and changing structural drainage characteristics to prevent chloride contamination at critical sections. Adequate concrete cover is the most important factor for long-term durability for a given exposure environment. 


\subsection{Preventive Measures}

To reduce or prevent further corrosion, electrochemical repair methods take advantage of electrochemistry of the corrosion process. Cathodic protection and chloride extraction are most popular electrochemical techniques used for corrosion repair process. Cathodic protection is the polarization of a metal to reduce the corrosion rate. An electrode is connected electrically with the reinforcement. This electrode becomes an anode forcing the steel to become a cathode thus halting the corrosion process. Chloride removal process also involves polarization of the reinforcement. In this process an electrode applies current to the steel, driving it to a more negative potential. The negatively charged chloride ions are repelled from the steel surface and are attracted to the positive anode. Out of these electrochemical repair process cathodic protection is often a permanent or long-term technique, while chloride removal is temporary and uses higher impressed current densities. Because of this concern, the repair of precast/prestressed concrete members in practice may only include the removal of the delaminated concrete cover to keep the steel partially bonded in an attempt to prevent the loss of additional prestress force. Following these repair procedures, patch accelerated corrosion can be more severe since new corrosion activity can take place throughout the base of the repair (where the steel is in contact with both chloride contaminated and fresh concrete) instead of just around the patch edges. Figure 5.1 shows a Prestressed concrete delaminated beam repair.

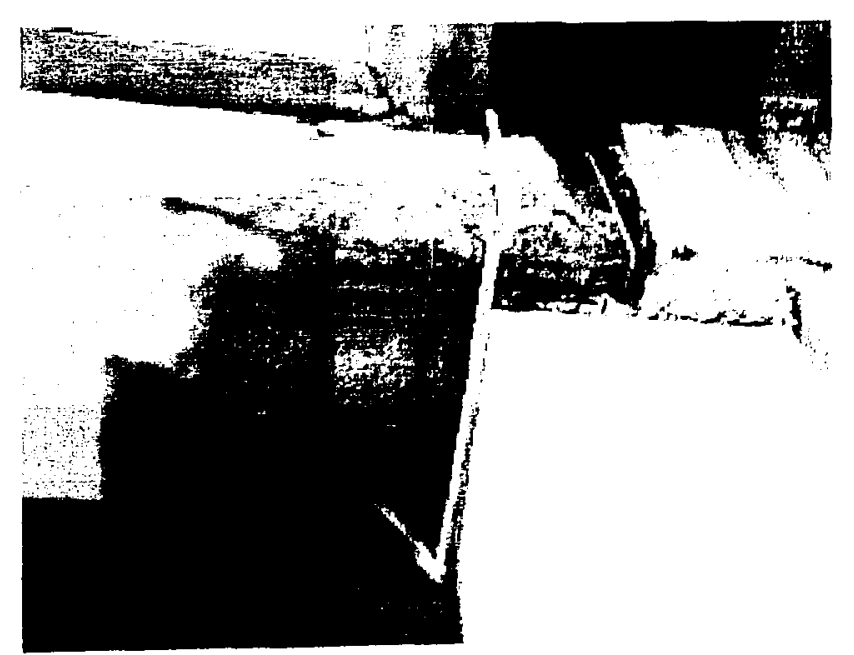

Figure 5.1: Precast/prestressed beam repair. Delaminated concrete cover removed but strands remain partially embedded in chloride contaminated concrete. 


\subsection{Galvanic Protection}

Galvanic protection is a long-term corrosion protection system. Galvanic protection can be used alone or in combination with barrier systems for multilevel protection. Galvanic protection is achieved when two dissimilar metals are connected. The metal with the higher potential for corrosion generally a zinc-based system in concrete applications will corrode in preference to the more noble metal. As the sacrificial metal corrodes, it generates electrical current to protect the reinforcing steel. Unlike impressed current cathodic protection systems, the galvanic system voltage is fixed and the amount of current generated is a function of the surrounding environment. Galvanic anodes will generate higher current output when the environment is more corrosive or conductive. For example, current output will likely exhibit a daily and seasonal variation based on moisture and temperature changes. As above, when placed on prestressed steel, the polarized potentials of cathodic protection systems should remain less negative than -977 $\mathrm{mV}$ cse to prevent the generation of hydrogen. The potential for actively corroding zinc is $-1,100 \mathrm{mV} c s e$ compared to passive steel in concrete at $-200 \mathrm{mVcse}$ and actively corroding steel at $-350 \mathrm{mVcse}$. Connecting actively corroding zinc to steel inside the concrete will provide a source of electrons to the steel and will shift the potential of the steel in a negative direction. Since the maximum driving potential of the zinc is limited to $-1,100 \mathrm{mVcse}$ and there will be voltage drops due to the resistance of the concrete and polarization of the zinc itself, it is very unlikely that the potential of the steel will be driven to be more negative than $-977 \mathrm{mVcse}$. As a result, it is unlikely a zinc based galvanic system will be responsible for the generation of atomic hydrogen and will not increase the hydrogen embrittlement.

\subsection{Cathodic Protection Fundamentals}

To slow down the corrosion process, cathodic protection (CP) is the only technology that has proven to stop corrosion in existing reinforced/prestressed concrete structures, regardless of the chloride content in the concrete. Quite simply CP is a widely used and effective method of corrosion control. It is defined as the reduction or elimination of 
corrosion by making the metal a cathode via an impressed direct current (DC), or by connecting it to a sacrificial or galvanic anode. Cathodic areas in an electrochemical cell do not corrode. If all the anode sites were forced to function as current-receiving cathodes, then the entire metallic structure would be a cathode and corrosion would be eliminated [Steven, 2001].

\subsection{FRP Wraps for Corrosion Protection}

Over 1500 reinforced structures throughout the world have been reinforced with FRP laminates. Although many of these are seismic applications, the use of composite wraps for corrosion repair and prevention is rapidly increasing. A list of some composite wrap manufacturers is presented in Table 5.1. FRP laminates have been used for encapsulation in seismic regions where wrapping a member increases its load capacity and durability, thus reducing the damage suffered from earthquakes. In non-seismic regions, these systems have strengthened utility poles and rehabilitated piers and bent caps. Composites are useful in strengthening reinforced concrete because they increase the structure's capacity without adding weight. In earthquake retrofitting, the goal is to make the column more ductile. A composite jacket prevents the concrete spalling and steel buckling. The California Department of Transportation (Caltrans) has permitted the wrapping of bridge columns with FRP in addition to the better known technique of steel jacketing of existing columns constructed for resisting earthquake loads. Caltrans strengthened columns in San Diego using XXsys Technologies' Robowrapper equipment, an automated wrapping machine. The Kansas DOT has encased two bridge columns for esthetic repairs of moderate spalling due to road salt corrosion. The Wisconsin DOT has wrapped about twelve bridges to rehabilitate spalled surfaces subjected to corrosive environments. The Texas DOT has wrapped several bridges in Lubbock with composite laminates to protect them from corrosion. The bridges had shown damage in the form of severe cracking and spalling, as shown in Figure 5.2, due to water penetration. Many of these bridge bents were wrapped by Delta Structural Technology, Inc. after concrete in the most damaged areas was removed to the level of the reinforcement and the members were patched [Verhulst et al, 2001]. 
Table 5.1- FRP Wrap Manufacturers [Verhulst et al, 2001]

\begin{tabular}{|c|c|c|}
\hline Company & Product & Project \\
\hline $\begin{array}{l}\text { Delta Structural } \\
\text { Technology, Inc. } \\
\text { Amarillo, Texas }\end{array}$ & $\begin{array}{l}\text { Applies Tyfo's Fibrwrap system. } \\
\text { Glass fiber impregnated at site with } \\
\text { saturating machine. Hand lay-up. }\end{array}$ & $\begin{array}{l}\text { UT/TxDOT corrosion } \\
\text { protection study (project } \\
\text { 1774) TxDOT bridge } \\
\text { rehabilitation project in } \\
\text { Lubbock, TX. }\end{array}$ \\
\hline $\begin{array}{l}\text { XXSys } \\
\text { Technologies San } \\
\text { Diego, California }\end{array}$ & $\begin{array}{l}\text { Robowrapper Equipment, } \\
\text { automated filament winding } \\
\text { machine. Applies } 350 \mathrm{lbs} \text { of } \\
\text { composite in } 7 \text { hours. Resin cured } \\
\text { with an oven. Hand lay-up also } \\
\text { possible }\end{array}$ & $\begin{array}{l}\text { Seismic and Corrosion } \\
\text { repair with CALTRANS }\end{array}$ \\
\hline $\begin{array}{l}\text { Fyfe Co. L.L.C. } \\
\text { (Hexcel Fyfe until } \\
\text { 1997) Pleasanton, } \\
\text { california }\end{array}$ & $\begin{array}{l}\text { Fibrwrap system. } 2 \text {-in-wide carbon } \\
\text { fabric strips impregnated at site } \\
\text { with a saturating machine (bath and } \\
\text { rollers). Hand lay-up. }\end{array}$ & $\begin{array}{l}\text { Slab strengthening with } \\
\text { south Carolina DOT. }\end{array}$ \\
\hline $\begin{array}{l}\text { C.C.Myers, Inc. } \\
\text { Ranch Cardova, } \\
\text { California }\end{array}$ & $\begin{array}{l}\text { Snap Tite composite jacketing } \\
\text { system. Procured epoxy shells } \\
\text { adhere to column. }\end{array}$ & $\begin{array}{l}\text { Seismic retrofit and } \\
\text { rehabilitation of } \\
\text { damaged columns }\end{array}$ \\
\hline $\begin{array}{l}\text { Hardcore Dupont } \\
\text { Composites LLC } \\
\text { New Castle, } \\
\text { Delaware }\end{array}$ & $\begin{array}{l}\text { Precured jackets made from glass } \\
\text { reinforced/epoxy vinyl ester } \\
\text { composites }\end{array}$ & $\begin{array}{l}\text { UT/TxDOT corrosion } \\
\text { protection study }\end{array}$ \\
\hline $\begin{array}{l}\text { Tonen Corporation } \\
\text { Tokyo, Japan }\end{array}$ & $\begin{array}{l}\text { Forca Tow Sheet material, dry } \\
\text { sheet with unidirectional carbon } \\
\text { fibers. Proprietary epoxy pressed in } \\
\text { with squeegees. }\end{array}$ & $\begin{array}{l}\text { Crack propagation } \\
\text { prevention study with } \\
\text { DelDOT and the } \\
\text { University of Delaware. }\end{array}$ \\
\hline $\begin{array}{l}\text { Mitsubishi } \\
\text { Chemical Canada }\end{array}$ & $\begin{array}{l}\text { Unidirectional carbon fiber tape } \\
\text { with low epoxy resin content, and }\end{array}$ & $\begin{array}{l}\text { Girder shear strength } \\
\text { Reinforcement with }\end{array}$ \\
\hline
\end{tabular}




\begin{tabular}{|l|l|l|}
\hline $\begin{array}{l}\text { Ltd. Vancouver, } \\
\text { Canada }\end{array}$ & $\begin{array}{l}\text { backed by fiberglass scrim cloth } \\
\text { for easy handling. Hand lay-up. }\end{array}$ & $\begin{array}{l}\text { Alberta Transportation } \\
\text { and Utilities } \\
\text { Depeartment. }\end{array}$ \\
\hline
\end{tabular}

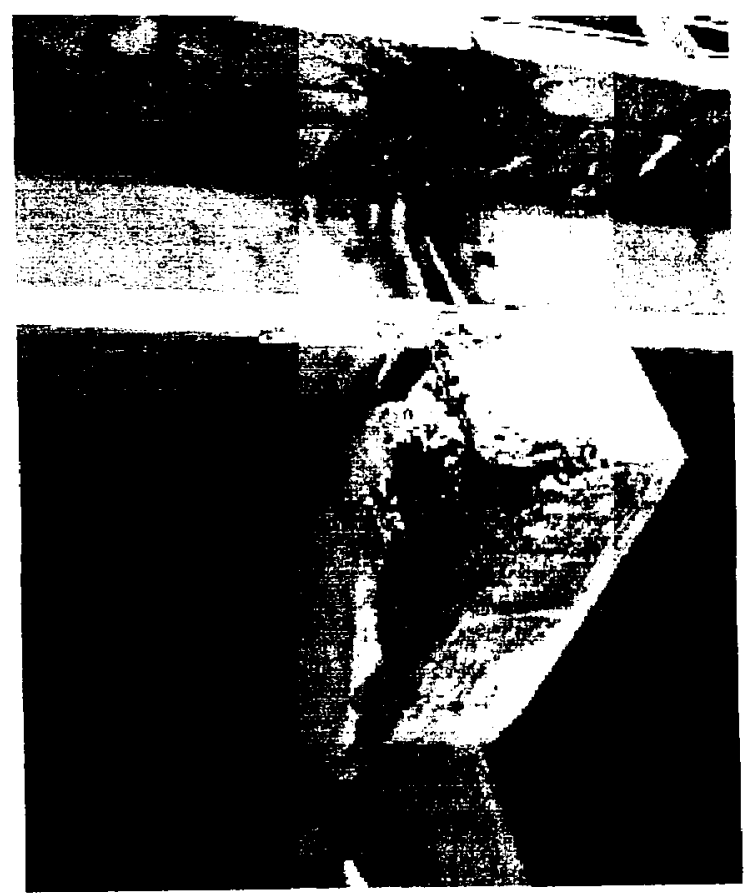

Figure 5.2: Endcap delamination [Verhulst et al, 2001] 


\section{CHAPTER 6}

\section{CONCLUSION AND FUTURE RECOMMENDATIONS}

- Corrosion is an inescapable and naturally occurred problem. Since all processed construction materials eventually made of natural resources like gravels, sands and other minerals resources that contain some chemical/mineral compounds might be initial sources of corrosion, then it aggravates from external sources. Therefore, it can be concluded that the corrosion in prestressed concrete has no remedy only the prevention by using any protection measure.

- Most corrosion problems encountered in recent times result from poor design details and construction practices that took place well in the past. New developments and improvements in prestressing systems and specifications will prevent a repetition of such past deficiencies that are now resulting in corrosion problems. There is a great benefit of learning from past problems. Awareness needed from possible corrosion problems such as for post tensioned concrete where the design guidelines and recommendations must address durability and corrosion protection throughout the design process, since durability is affected by decision at all design stages. Attention must be given beyond the design stage because many corrosion problems resulted from construction problems and inferior materials. Construction specifications must include provisions for the necessary procedures and materials to ensure durability and construction inspection and quality control must ensure these requirements are met. After construction phase attention must be given for proper maintenance which is required throughout the service life of the structure. At the final design stage where possible, designer should specify maintenance requirements and techniques.

- Early detection of corrosion in prestressing steel is also important. Otherwise it may be a catastrophic failure of the structure. Practical non-destructive evaluation 
technique has been available for assessing the condition of prestressing steel within concrete. The non-destructive techniques for prestressed concrete structures, such as visual inspection, half cell potential survey, chloride and carbonation testing provide limited information on the degree of distress in prestressed concrete structures especially when the tendons are ducted.

- Based on the latest research, epoxy coated prestressing strands, ducts, anchorages still appears to be a viable corrosion protection measures when they are used with minimize coating damage during shipment and placement. Plastic (polyethylene) ducts are virtually impermeable and can significantly improve corrosion protection. Low permeability grouts for post-tensioning improved corrosion protection.

- Corrosion inhibitors are a viable corrosion protection measure for the long-term durability of prestressed concrete structures. When used as part of a multiple strategy corrosion protection system, they delay the corrosion reaction of prestressing steel corrosion. In order for a corrosion inhibitor to be an effective long-term corrosion-protection measure, it needs to be able to maintain long-term stability. It should be chemically intact and physically present (not leaching or evaporating) to retain its effectiveness.

- Based on electrochemical cathodic protection (CP) field trials on marine and nonmarine bridge structures, it can be concluded that $\mathrm{CP}$ can be effectively used to control the corrosion of prestressing steel in pretensioned bridge members with careful monitoring of applied current and voltage.

- The repair of corroded reinforced/Prestressed piles and the endcaps of bridge substructures by FRP composites is the best procedure because of their ease application. As FRP is a barrier element it can only slow down but not stop corrosion from continuing. FRP offers the benefits of light weight, high strength and corrosion resistance that are particularly important in repair. As with 
traditional repairs, external FRP bonding cannot stop corrosion unless it also incorporates a sacrificial cathodic protection system. Such systems have yet to be proven. It is for this reason that ACI 440 does not recommended the use of FRP for conducting corrosion repair. FRP composite wrapping has been mostly used to prevent seismic overloading. To evaluate the performance of FRP wrapping systems in corrosive environments, further laboratory and field research programs are needed. 


\section{References}

- Ali M. G. and Maddocks A. R., "Evaluation of Corrosion of prestressing steel in Concrete Using Non-destructive Techniques," GHD Pty Ltd, Sydney, September 2003.

- American Society for Testing and Materials, "standard Specification for Epoxy-Coated Reinforcing Steel Bars," ASTM A775-97, Pheladelphia, PA, 1997.

- Bardal E., "Corrosion and Protection," July 2003.

- Bennett J.E., Schue T.J., "Cathodic Protection Field Trials on Prestressed Concrete Components, Final Report", EL TECH Research Corporation, 625 East Street, Fairport Harbour, OH 44077, January 1998.

- Bertolini Luca, Elsener Bernhard, Pedeferri Pietro, Polder Rob, "Corrosion of Steel in Concrete," November 2003.

- Broomfield John P., "Corrosion of Steel in Concrete," 1997.

- Ellis, W. E., Jr., Riggs, E. H. and Butler, W. B., "Comparative Results of Fly ash, Silica Fume and GGBFS in Reducing the Chloride Permeability of Concrete," durability of Concrete, second International Conference, ACI SP126, American Concrete Institute, Detroit, Michigan, 1991 pp, 443-447.

- Etienne, C.F., Binnekamp, D.C., Copier, W.J., Hendrickx, R., and Smit, C.L., "Corrosion Protection of Unbonded Tendons," Heron, Vol. 26, No. 3, 1981.

- FIP, "Corrosion Protection of Prestressing Steels," September 1996.

- Fogarasi G., "Prestressed Concrete Technology," 1986.

- Hussam A. Ali, "Masters Thesis", McGill University, January 2004.

- Krause H. J., Wolf, W. W. Zimmermann Glaas, E., Jülich M.I. Faley Forschungszentrum, D-52425 Jülich, Germany, G. Sawade Forschungs- und Materialprüfanstalt Baden-Württemberg, D-70569 Stuttgart, Germany, G. Neudert, U. Gampe Siempelkamp Prüf- und Gutachtergesellschaft mbH, D01099 Dresden, Germany, J. Krieger Bundesanstalt für StraBenwesen, D51427 Bergisch-Gladbach, Germany, "SQUID System for Magnetic Inspection of Prestressed Tendons on Concrete Bridges" October 2000. 
- Maker, J. M.; Desnoyers, R., "Magnetic field techniques for the inspection of steel under concrete cover", Institute for Research in Construction National Research Council Canada, 1500 Montreal Road, Ottawa, Ontario, K1A 0R6, Canada, October 2001.

- Monfore G. E. and Verbeck G. J., "Corrosion of Prestressing Wires in Concrete," December, 1960.

- Moore M., "Use of Epoxy-coated Prestressing Strand in Concrete Bridge Structures," FIP - 12th International Congress, Washington, DC., June 02, 1994.

- Ôemajtis Jerzy, “ Modeling the Time to Corrosion Initiation for Concretes with Mineral Admixtures and/or Corrosion Inhibitors in Chloride-Laden Environments", Dissertation submitted to the Faculty of the Virginia Polytechnic Institute and State University in partial fulfillment of the requirements for the degree of Doctor of Philosophy in Civil Engineering, Blacksburg, Virginia, January, 1998.

- Perenchio, W.F., Fraczek, J., and Pfiefer, D.W., "Corrosion Protection of Prestressing Systems in Concrete Bridges," NCHRP Report 313, February 1989.

- Poston, R. W., "Improving Durability of Bridge Decks by transverse Prestressing,' Doctor of Philosophy Dissertation, The University of Texas at Austin, December 1984.

- Sen Rajan and Mullins Gary, "Issues Related to FRP Wrap of Corroded Piling", Department of Civil and Environmental Engineering, USF , Tampa, Florida 33620, USA, October 2004.

- Smith J. L., Vimani Y. P., "Materials and Methods for Corrosion Control of Reinforced and Prestressed Concrete Structures in new Construction," Office of the Infrastructure R\&D, Federal Highway Administration, 6300 Georgetown Pike, McLean, Virginia 22101-2296, August 2000.

- Steinour Harold H., "Influence of the Cement on the Corrosion Behavior of Steel in Concrete," May 1964. 
- Steven F. Daily, "Understanding Corrosion and Cathodic Protection of Reinforced Concrete Structures", Corrpro Companies, Inc., 1055 West Smith Road, Medina, Ohio 44256, September, 2001.

- Tanaka Y., Kurauchi, M., and Masuda, Y., Ten Year Marine Atmosphere Exposure Test of Unbonded Prestressed Concrete Prisms, Post-Tensioning Institute, Phoenix, AZ, 1988.

- Thompson, N. G. and Lankard, D.R. (1997), "Improved Concrete Corrosion Resistance," (Report No. FHWA-RD-96-207), federal Highway Administration, Washington, DC, 176pp.

- Tuutti K., "Corrosion of Steel in Concrete," Report 4-82, Swedish Cement and Concrete Research Institute, Stockholm, Sweden, 1982, 469pp.

- Verhulst S. M., Fuentes L. A., Jirsa J. O., Flower D. W., Wheat H. G., and Moon T., "Evaluation and Performance Monitoring of Corrosion Protection by Fiber-Reinforced Composite Wrapping", Center for Transportation Research, The University of Texas at Austin, 3208 Red River, Suite 200, Austin, TX 78705-2650, January 2001.

- Virmani Y. P., and Clemena G. G., 'Corrosion Protection - Concrete Bridges," (Report No. FHWA-RD-98-088), Federal Highway Administration, Washington, DC, 72pp.

- West J. S., Larosche C. J., Koester B. D., Breen J. E., and Kreger M. E., "State-Of-The-Art Report about durability of Post-tensioned Bridge Substructures," Research Report 1405-01, Texas Department of Transportation, October 1999.

- Whitmore David W., P. Eng. a, Christopher Ball J ${ }^{\mathrm{b}}$, “Application for Galvanic Anodes in Prestressrd Concrete", Vector Corrosion Technologies, Winnipeg, Manitoba, Canada ${ }^{a}$, Vector Corrosion Technologies Tampa, Florida ${ }^{b}$, August 2003. 
. 